UNIVERSIDADE DE BRASÍLIA

FACULDADE DE EDUCAÇÃO FÍSICA

PROGRAMA DE PÓS-GRADUAÇÃO STRICTO SENSU EM EDUCAÇÃO FÍSICA

\title{
ESTUDO DE ASSOCIAÇÃO ENTRE ADIPOSIDADE CORPORAL, FORÇA MUSCULAR, DISTRIBUIÇÃO DE PRESSÃO PLANTAR, ESTABILIDADE POSTURAL E RISCO DE QUEDAS EM MULHERES IDOSAS
}

Silvia Gonçalves Ricci Neri

BRASÍLIA

2016 
ESTUDO DE ASSOCIAÇÃO ENTRE ADIPOSIDADE CORPORAL, FORÇA MUSCULAR, DISTRIBUIÇÃO DE PRESSÃO PLANTAR, ESTABILIDADE POSTURAL E RISCO DE QUEDAS EM MULHERES IDOSAS

SILVIA GONÇALVES RICCI NERI

Dissertação apresentada à Faculdade de Educação Física da Universidade de Brasília, como requisito parcial para obtenção do grau de Mestre em Educação Física.

ORIENTADOR: Dr. RICARDO MORENO LIMA 
Ficha catalográfica elaborada automaticamente, com os dados fornecidos pelo(a) autor(a)

Neri, Silvia Gonçalves Ricci

Estudo de associação entre adiposidade corporal,

NN 445 e força muscular, distribuição de pressão plantar, estabilidade postural e risco de quedas em mulheres idosas / Silvia Gonçalves Ricci Neri; orientador Ricardo Moreno Lima. -- Brasilia, 2016. $142 \mathrm{p}$.

Dissertação (Mestrado - Mestrado em Educação Física) -- Universidade de Brasilia, 2016.

1. Idoso. 2. adiposidade. 3. acidentes por quedas. 4. equilíbrio postural. I. Lima, Ricardo Moreno, orient. II. Título. 


\section{ESTUDO DE ASSOCIAÇÃO ENTRE ADIPOSIDADE CORPORAL, FORÇA MUSCULAR, DISTRIBUIÇÃO DE PRESSÃO PLANTAR, ESTABILIDADE POSTURAL E RISCO DE QUEDAS EM MULHERES IDOSAS}

Dissertação aprovada como requisito parcial para obtenção do título de Mestre em Educação Física pelo Programa de Pós-Graduação da Faculdade de Educação Física da Universidade de Brasília.

Brasília-DF, 07 de julho de 2016

\section{BANCA EXAMINADORA}

Prof. Dr. Ricardo Moreno Lima

(Presidente - PPGEF/UnB)

Prof. Dr. Aparecido Pimentel Ferreira

(Examinador externo - UNIP)

Profa. Dra. Ana Cristina de David

(Examinador interno - PPGEF/UnB)

Profa. Dra. Marisete Peralta Safons

(Examinador suplente - PPGEF/UnB) 


\section{AGRADECIMENTOS}

A Deus, pela vida e pela oportunidade de trilhar mais alguns passos em direção ao meu ideal. Aos ensinamentos da Seicho-No-le, por me proporcionarem a força necessária para o sucesso nessa jornada.

Aos meus pais Luiz e Memé, por todo o amor e incentivo. Obrigada por serem pais exemplares e se dedicarem ao máximo para a realização dos meus sonhos! Aos demais familiares, pela assistência durante a minha estadia em Brasília.

Ao professor e amigo Marcio Massao Kawano, por me fazer acreditar que chegar até aqui seria possível.

Ao meu orientador Prof. Dr. Ricardo Moreno Lima, por toda a confiança depositada em mim. Sou grata pela oportunidade de integrar o Grupo de Estudos em Fisiologia do Exercício e Saúde - GEFS, e poder me espelhar em você, um verdadeiro exemplo de profissional e de ser humano.

À Profa. Dra. Ana Cristina de David, pela brilhante contribuição com a minha pesquisa; e à Profa. Dra. Marisete Peralta Safons, pela constante disponibilidade em ajudar.

Aos meus colegas do GEFS, por todo o companheirismo e trabalho duro. Vocês são a minha família em Brasília, e sem vocês este projeto não seria viável!

Às voluntárias do estudo, pelo carinho indescritível.

Ao Programa de Pós-graduação em Educação Física da Universidade de Brasília, por possibilitar esta formação. A todos os professores, funcionários e colegas, minha profunda gratidão!

À Coordenação de Aperfeiçoamento de Pessoal de Nível Superior, pela bolsa de estudos.

E a todos aqueles que contribuíram, direta ou indiretamente, para que eu chegasse ao fim de mais uma etapa da minha formação. Muito obrigada! 
SUMÁRIO

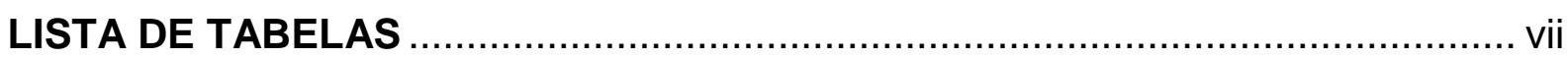

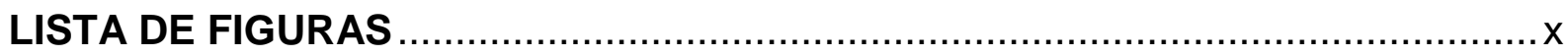

LISTA DE SIGLAS E ABREVIAÇÕES ...................................................... xii

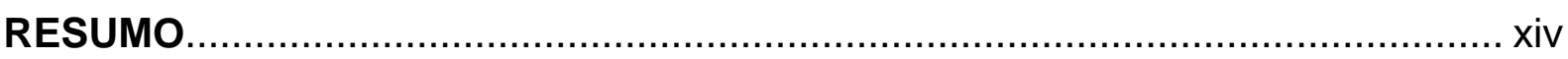

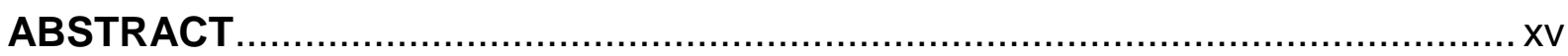

1 INTRODUÇÃO

2 OBJETIVOS

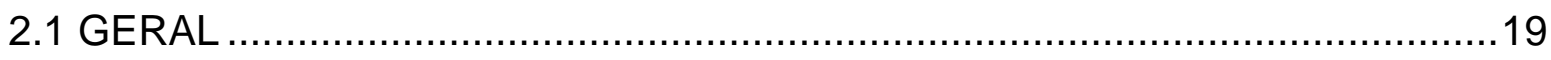

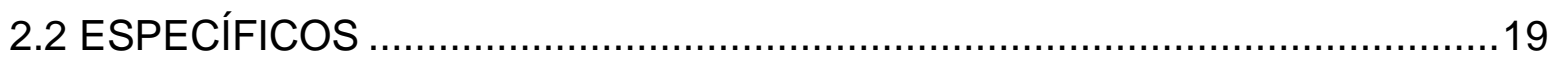

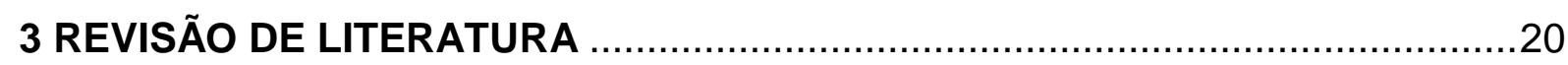

3.1 DADOS EPIDEMIOLÓGICOS DO ENVELHECIMENTO …...........................20

3.2 ENVELHECIMENTO E ALTERAÇÕES DA COMPOSIÇÃO CORPORAL ........23

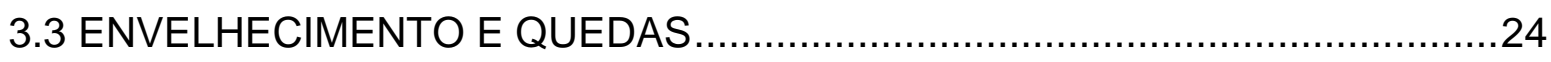

3.4 EXCESSO DE ADIPOSIDADE CORPORAL E QUEDAS EM IDOSOS ............26

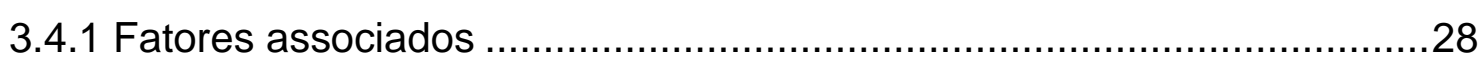

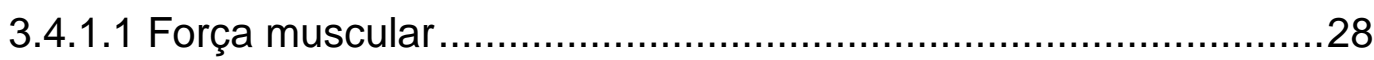

3.4.1.2 Distribuição de pressão plantar ...............................................31

3.4.1.3 Estabilidade postural .............................................................. 34

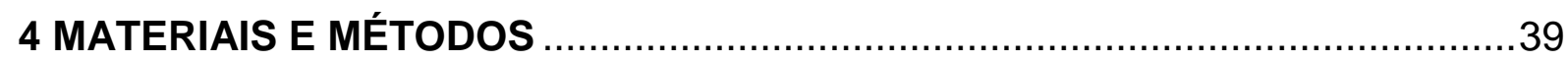

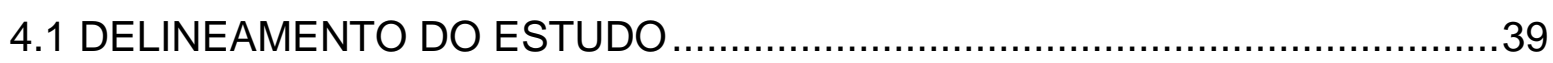

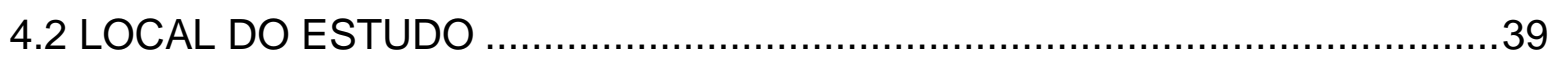

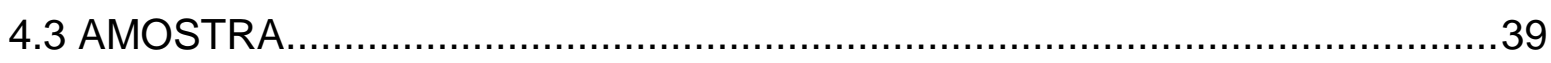

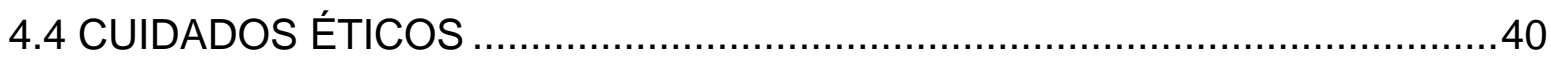

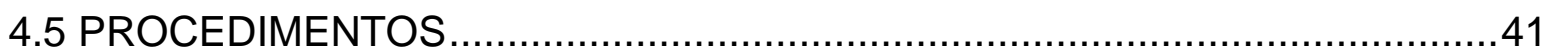

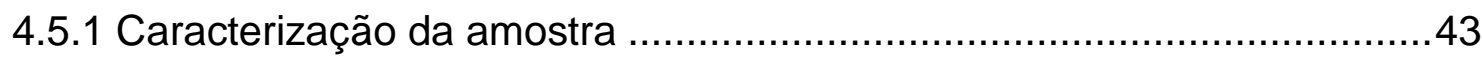

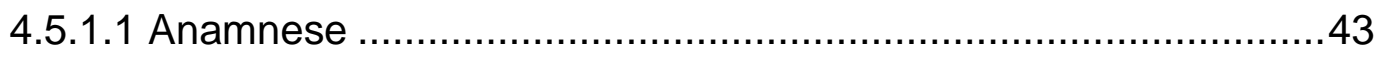

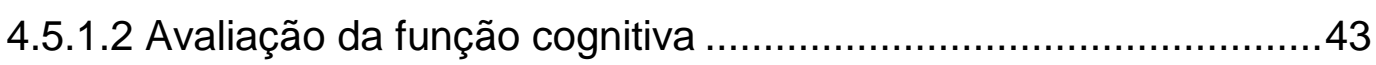


4.5.1.3 Avaliação da funcionalidade .44

4.5.1.4 Avaliação do nível de atividade física ...................................44

4.5.2 Avaliação da adiposidade corporal.......................................... 45

4.5.2.1 Antropometria .......................................................... 45

4.5.2.2 Absortometria de raio-x de dupla energia..............................47

4.5.3 Avaliação da força muscular .......................................................... 48

4.5.3.1 Força de preensão manual .................................................48

4.5.3.2 Força dos extensores do joelho.........................................50

4.5.4 Avaliação da distribuição de pressão plantar ...................................51

4.5.5 Avaliação da estabilidade postural ............................................... 54

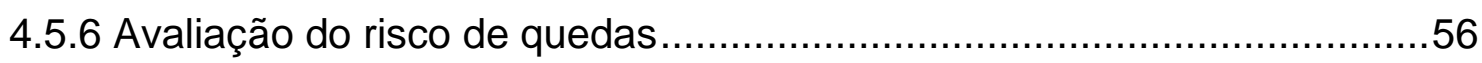

4.5.6.1 QuickScreen Clinical Falls Risk Assessment...........................56

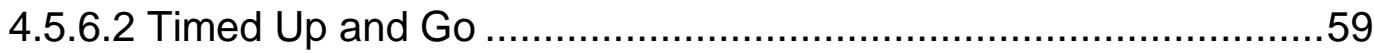

4.5.6.3 Escala de Eficácia de Quedas - Internacional .........................60

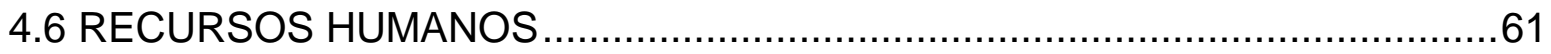

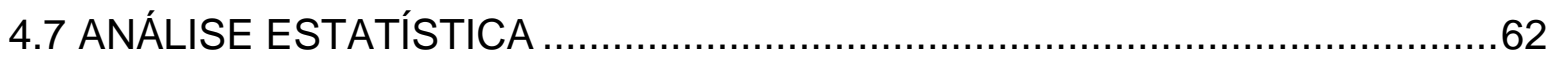

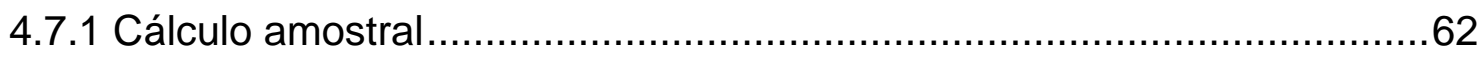

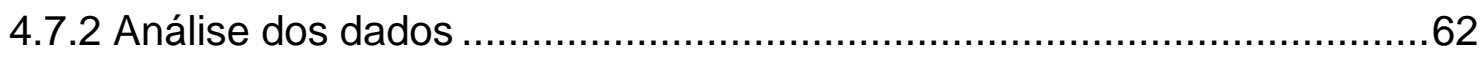

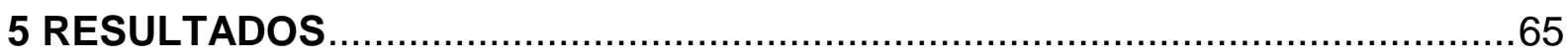

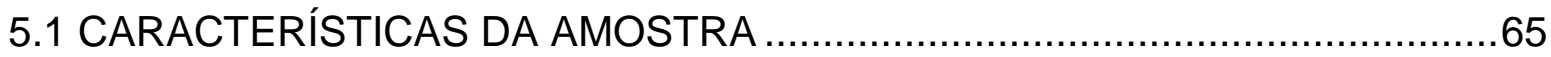

5.2 ADIPOSIDADE CORPORAL E FORÇA MUSCULAR .................................66

5.3 ADIPOSIDADE CORPORAL E DISTRIBUIÇÃO DE PRESSÃO PLANTAR ....72

5.4 ADIPOSIDADE CORPORAL E ESTABILIDADE POSTURAL ...................... 80

5.5 ADIPOSIDADE CORPORAL E RISCO DE QUEDAS ................................85

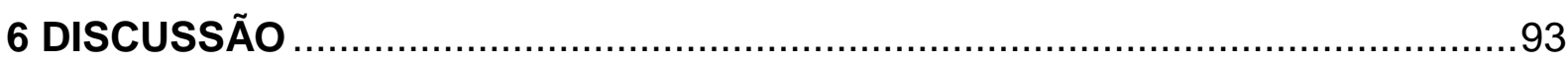

6.1 ADIPOSIDADE CORPORAL E FORÇA MUSCULAR …............................93

6.2 ADIPOSIDADE CORPORAL E DISTRIBUIÇÃO DE PRESSÃO PLANTAR ....95

6.3 ADIPOSIDADE CORPORAL E ESTABILIDADE POSTURAL.......................98

6.4 ADIPOSIDADE CORPORAL E RISCO DE QUEDAS ..............................101

6.5 APLICAÇÕES PRÁTICAS E PERSPECTIVAS ...................................... 103

5.6 PONTOS FORTES E LIMITAÇÕES ..................................................... 104 
7 CONCLUSÃO 107

8 REFERÊNCIAS 108

LISTA DE ANEXOS. 121 


\section{LISTA DE TABELAS}

Tabela 1. Características da amostra $(n=73)$. Dados expressos em média \pm desvio padrão. .65

Tabela 2. Características da amostra $(n=73)$. Dados expressos em frequência absoluta e relativa. 66

Tabela 3. Força muscular de mulheres idosas estratificadas de acordo com o IMC (eutróficas, sobrepesadas e obesas). Dados expressos em média \pm desvio padrão. .68

Tabela 4. Força muscular de mulheres idosas estratificadas de acordo com os tercis da CC (tercil inferior, intermédio e superior). Dados expressos em média \pm desvio padrão. 69

Tabela 5. Força muscular de mulheres idosas estratificadas de acordo com os tercis do \%G (tercil inferior, intermédio e superior). Dados expressos em média \pm desvio padrão. .70

Tabela 6. Correlação entre os índices de adiposidade corporal (IMC, CC e \%G) e a força muscular de mulheres idosas $(n=70)$. 71

Tabela 7. Distribuição de pressão plantar de mulheres idosas estratificadas de acordo com o IMC (eutróficas, sobrepesadas e obesas). Dados expressos em média \pm desvio padrão.

Tabela 8. Distribuição de pressão plantar de mulheres idosas estratificadas de acordo com os tercis da CC (tercil inferior, intermédio e superior). Dados expressos em média \pm desvio padrão. .75

Tabela 9. Distribuição de pressão plantar de mulheres idosas estratificadas de acordo com os tercis do \%G (tercil inferior, intermédio e superior). Dados expressos em média \pm desvio padrão. 
Tabela 10. Correlação entre os índices de adiposidade corporal (IMC, CC e \%G) e a distribuição de pressão plantar de mulheres idosas $(n=62)$.

Tabela 11. Estabilidade postural de mulheres idosas estratificadas de acordo com o IMC (eutróficas, sobrepesadas e obesas). Dados expressos em média \pm desvio padrão

Tabela 12. Estabilidade postural de mulheres idosas estratificadas de acordo com os tercis da CC (tercil inferior, intermédio e superior). Dados expressos em média \pm desvio padrão.

Tabela 13. Estabilidade postural de mulheres idosas estratificadas de acordo com os tercis do \%G (tercil inferior, intermédio e superior). Dados expressos em média \pm desvio padrão.

Tabela 14. Correlação entre os índices de adiposidade corporal (IMC, CC e \%G) e a estabilidade postural de mulheres idosas $(n=73)$.

Tabela 15. Risco de quedas de mulheres idosas estratificadas de acordo com o IMC (eutróficas, sobrepesadas e obesas). Dados expressos em frequência absoluta e relativa

Tabela 16. Risco de quedas de mulheres idosas estratificadas de acordo com os tercis da CC (tercil inferior, intermédio e superior). Dados expressos em frequência absoluta e relativa

Tabela 17. Risco de quedas de mulheres idosas estratificadas de acordo com os tercis do \%G (tercil inferior, intermédio e superior). Dados expressos em frequência absoluta e relativa

Tabela 18. Risco de quedas de mulheres idosas estratificadas de acordo com o IMC (eutróficas, sobrepesadas e obesas). Dados expressos em média \pm desvio padrão 
Tabela 19. Risco de quedas de mulheres idosas estratificadas de acordo com os tercis da CC (tercil inferior, intermédio e superior). Dados expressos em média \pm desvio padrão.

Tabela 20. Risco de quedas de mulheres idosas estratificadas de acordo com os tercis do \%G (tercil inferior, intermédio e superior). Dados expressos em média \pm desvio padrão. .90

Tabela 21. Correlação entre os índices de adiposidade corporal (IMC, CC e \%G) e o risco de quedas de mulheres idosas $(n=73)$. .91

Tabela 22. Odds Ratio (Intervalo de Confiança $=95 \%$ ) dos estratos superiores dos índices de adiposidade corporal (IMC, CC e \%G) para os desfechos de ocorrência de quedas no ano anterior e risco de quedas aumentado (QuickScreen $\geq 27 \%$ ), adotando como referência os estratos inferiores de adiposidade. .92 


\section{LISTA DE FIGURAS}

Figura 1. Percentual de idosos em diferentes regiões do mundo. Acima, percentual referente ao ano de 2012. Abaixo, projeção para 2050. Fonte: OMS, 2012. 20

Figura 2. Pirâmide populacional do Brasil em 2010. Fonte: IBGE, 2013. 21

Figura 3. Projeção da pirâmide populacional do Brasil para 2060. Fonte: IBGE, 2013. .22

Figura 4. Percentual de idosos obesos nas capitais dos estados brasileiros e Distrito Federal, por gênero. Fonte: VIGITEL Brasil 2014. .24

Figura 5. Taxa de atendimento em emergência médica por lesões relacionadas a quedas, por gênero e faixa etária, Estados Unidos, 2006. Fonte: Owens et al., 2009

Figura 6. Representação hipotética da influência do excesso de adiposidade corporal sobre o mecanismo de controle postural.

Figura 7. Fluxograma do recrutamento e seleção amostral .40

Figura 8. Fluxograma dos procedimentos do estudo 41

Figura 9. Representação esquemática da logística de coleta de dados. .42

Figura 10. Registro fotográfico de uma voluntária durante a avaliação antropométrica. A) Mensuração da massa corporal. B) Mensuração da estatura. C) Perimetria. 46

Figura 11. Registro fotográfico de uma voluntária durante a avaliação do DEXA. Abaixo, saída gráfica da composição corporal da voluntária avaliada. .48 
Figura 12. Registro fotográfico de uma voluntária durante a avaliação da força de preensão manual..

Figura 13. Registro fotográfico de uma voluntária durante a avaliação da força dos extensores do joelho do membro inferior dominante.

Figura 14. Registro fotográfico de uma voluntária durante a avaliação da distribuição de pressão plantar.

Figura 15. Localização das regiões anatômicas na impressão plantar do pé direito de uma voluntária (software EMED/R). .53

Figura 16. Registro fotográfico de uma voluntária durante a avaliação da estabilidade postural. À direita, representação esquemática das condições experimentais testadas. .55

Figura 17. Saída gráfica da oscilação do COP no software AMTI Balance Clinic. O painel ilustra a oscilação do COP de uma voluntária durante a execução da condição experimental BFOF. .56

Figura 18. Registro fotográfico de uma voluntária durante a execução do QuickScreen. A) Avaliação da ocorrência de quedas no ano anterior, quantidade de medicamentos em uso e utilização de psicotrópicos. B) Avaliação da acuidade visual. C) Teste da sensibilidade periférica. D) Avaliação do equilíbrio. E) Avaliação do tempo de reação. F) Avaliação da força.

Figura 19. Registro fotográfico de uma voluntária durante a execução do teste Timed Up and Go. 60

Figura 20. Registro fotográfico da aplicação da Escala de Eficácia de Quedas Internacional.

Figura 21. Estratificação da amostra de acordo com o índice de massa corporal....63 
Figura 22. Estratificação da amostra de acordo com a circunferência de cintura.....63 Figura 23. Estratificação da amostra de acordo com o percentual de gordura

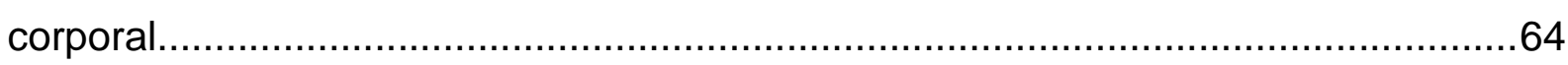




\section{LISTA DE SIGLAS E ABREVIAÇÕES}

$\%$ G: Percentual de gordura corporal

ABVDs: Atividades básicas de vida diária

AIVDs: Atividades instrumentais de vida diária

AMTI: Advanced Medical Technology Inc

AP: Anteroposterior

BAOA: Base aberta com olhos abertos

BAOF: Base aberta com olhos fechados

BFOA: Base fechada com olhos abertos

BFOF: Base fechada com olhos fechados

CC: Circunferência de cintura

COP: Centro de pressão

$C Q$ : Circunferência de quadril

DEXA: Absortometria de raio-x de dupla energia

FEF: Faculdade de Educação Física

FES-I: Escala de Eficácia de Quedas - Internacional

FPM: Força de preensão manual

GEFS: Grupo de Estudos em Fisiologia do Exercício e Saúde

IBGE: Instituto Brasileiro de Geografia e Estatística

IC: Intervalo de confiança

IMC: Índice de massa corporal

IPAQ: Questionário Internacional de Atividade Física

MEEM: Mini-Exame do Estado Mental

ML: Mediolateral

OMS: Organização Mundial de Saúde

ONU: Organização das Nações Unidas

OR: Odds ratio

PT: Pico de torque

QuickScreen: QuickScreen Clinical Falls Risk Assessment

TCLE: Termo de Consentimento Livre e Esclarecido

TUG: Timed Up and Go

UnB: Universidade de Brasília 


\title{
RESUMO
}

\section{ESTUDO DE ASSOCIAÇÃO ENTRE ADIPOSIDADE CORPORAL, FORÇA MUSCULAR, DISTRIBỦIÇÃO DE PRESSÃO PLANTAR, ESTABILIDADE POSTURAL E RISCO DE QUEDAS EM MULHERES IDOSAS}

\author{
Autora: SILVIA GONÇALVES RICCI NERI \\ Orientador: RICARDO MORENO LIMA
}

OBJETIVO: Verificar a associação entre adiposidade corporal, força muscular, distribuição de pressão plantar, estabilidade postural e risco de quedas em mulheres idosas. MÉTODOS: Participaram deste estudo 73 mulheres idosas $(67,58 \pm 6,04$ anos, $1,56 \pm 0,06 \mathrm{~m}, 67,59 \pm 11,25 \mathrm{~kg}$ ), as quais foram submetidas à avaliação antropométrica e à absortometria de raio-x de dupla energia (DEXA) para mensuração da adiposidade corporal. A força muscular foi avaliada por meio da força de preensão palmar, utilizando um dinamômetro de preensão manual, e da força dos extensores de joelho do membro inferior dominante, utilizando um dinamômetro isocinético. Para mensurar a distribuição de pressão plantar foi utilizada uma plataforma de pressão. A estabilidade postural, por sua vez, foi avaliada em uma plataforma de força. Por fim, para estimar o risco de quedas, o QuickScreen Clinical Falls Risk Assessment, o teste Timed Up and Go e a Escala de Eficácia de Quedas - Internacional foram aplicados. Para verificar a associação entre a adiposidade corporal e as variáveis dependentes, foi utilizado o teste de Correlação de Pearson e o teste de Correlação de Spearman. Adicionalmente, a amostra foi estratificada de acordo com diferentes índices de adiposidade, e a comparação entre os estratos foi efetuada por intermédio dos testes ANOVA oneway, Kruskal-Wallis e Qui-quadrado, Também foi calculado o Odds Ratio para quedas nas idosas classificadas nos estratos superiores de adiposidade corporal. $O$ nível de significância adotado foi de $p<0,05$. RESULTADOS: A adiposidade corporal se associou negativamente com a força muscular relativa. Observou-se, ainda, que o excesso de adiposidade estava relacionado a um comprometimento da distribuição de pressão plantar, caracterizado, sobretudo, por maior força máxima na maioria das regiões do pé, maior área de contato e maior pico de pressão no mediopé, e valores mais elevados do índice de arco dinâmico. Quanto à estabilidade postural, idosas com maiores índices de adiposidade exibiram maior amplitude de deslocamento do centro de pressão nas direções anteroposterior e mediolateral. Ademais, a adiposidade corporal se correlacionou positivamente com o risco de quedas. CONCLUSÃO: O excesso de adiposidade corporal está associado a um risco de quedas aumentado em mulheres idosas. Este risco aumentado pode ser parcialmente explicado por uma diminuição da força muscular relativa, por valores elevados de pressão no mediopé e por uma pior estabilidade postural. Salienta-se que os achados do presente estudo se agregam a evidências prévias que apontam a obesidade como um importante fator de risco para quedas em mulheres idosas.

Palavras-chave: Idoso, adiposidade, força muscular, pressão plantar, equilíbrio postural, acidentes por quedas. 


\begin{abstract}
ASSOCIATION BETWEEN BODY ADIPOSITY, MUSCLE STRENGHT, PLANTAR

PRESSURE DISTRIBUTION, POSTURAL STABILITY AND FALLS RISK IN ELDERLY WOMEN
\end{abstract}

\author{
Author: SILVIA GONÇALVES RICCI NERI \\ Advisor: RICARDO MORENO LIMA
}

OBJECTIVE: To measure the association between body adiposity, muscle strength, plantar pressure distribution, postural stability and falls risk in elderly women. METHODS: Seventy three elderly women $(67.58 \pm 6.04$ years, $1.56+0.06 \mathrm{~m}, 67.59$ $+11.25 \mathrm{~kg}$ ) underwent body adiposity assessment by both anthropometric measures and Dual Energy X-Ray Absorptiometry (DEXA). Muscle strength was assessed using a handgrip dynamometer. Also, dominant knee extensors strength was evaluated using an isokinetic dynamometer. Plantar pressure distribution was measured on a pressure platform while postural stability was evaluated on a force platform. To estimate the risk of falls, the Quick Screen Clinical Falls Risk Assessment, Timed Up and Go test, and Falls Efficacy Scale - International were applied. To investigate the association between body adiposity and dependent variables, Pearson correlation test and Spearman correlation test were used. In addition, the sample was stratified according to different adiposity indices and the comparison between the stratums was performed through ANOVA one-way, KruskalWallis and Chi-square tests. The odds ratio was also calculated for falls in elderly women classified in the upper stratum of adiposity. The significance level was set at $p<0.05$. RESULTS: Body adiposity was negatively associated with relative muscle strength. Excessive adiposity was also related to impaired plantar pressure distribution, characterized by higher maximum strength in most foot regions, larger contact area and higher peak pressure in the midfoot, and higher values of dynamic arch index. Regarding postural stability, elderly women with higher adiposity indexes showed greater center of pressure displacement in the anteroposterior and mediolateral directions. In addition, body fat was positively correlated with risk of falls. CONCLUSION: Excessive body adiposity was associated with an increased risk of falls in older women. This increased risk could be partly explained by a decrease of relative muscle strength, high values of pressure on the midfoot and a worse postural stability. Notably, the results of this study add to the previous evidence pointing obesity as a major risk factor for falls.

Keywords: Aged, adiposity, muscle strength, plantar pressure, postural balance, accidental falls. 


\section{INTRODUÇÃO}

O envelhecimento populacional é um fenômeno mundial. No Brasil, esta realidade pode ser expressa em números: no ano de 1960, os idosos com idade superior a 65 anos representavam $2,7 \%$ da população; em 2010, este valor subiu para 7,4\% (Instituto Brasileiro de Geografia e Estatística - IBGE, 2010); e em 2060, segundo projeções, subirá para 26,7\%, o que significa que pouco mais de um quarto da população brasileira será de idosos (IBGE, 2013). Associado a esse fenômeno, é possível observar uma condição denominada feminização da velhice, o qual se caracteriza por maior longevidade das mulheres, em relação aos homens, e por maior representatividade das mesmas (Lebrão, 2007).

Esse aumento da população idosa acarreta numa maior incidência de problemas relacionados ao envelhecimento (Schramm et al., 2004). Com o avançar da idade, observa-se, por exemplo, mudanças consideráveis na composição corporal, caracterizando-se pelo aumento da massa gorda e concomitante redução da massa magra (Rosenberg, 1989; Newman et al., 2003). Esse acúmulo excessivo de gordura pode levar a uma condição denominada obesidade, que, segundo a Organização Mundial de Saúde (OMS), é definida como o excesso de gordura corporal acumulada com implicações à saúde (OMS, 2002).

Atualmente, a obesidade acomete boa parte da população idosa em diversos países do mundo. Nos Estados Unidos, aproximadamente 35\% dos idosos são obesos (Fakhouri et al., 2012). Em nosso país, dados do VIGITEL Brasil 2014 apontam que $19,8 \%$ da população com idade superior a 65 anos apresentam tal condição. Esse estudo revela, ainda, que a obesidade parece ser mais frequente no gênero feminino - a prevalência entre as mulheres é de $22,1 \%$ e entre homens é de apenas $16,4 \%$ (Brasil, 2015).

Evidências demonstram que tal condição é capaz de exacerbar ainda mais o declínio funcional inerente ao próprio processo de envelhecimento (Han, T. et al., 2011; Cetin e Nasr, 2014). Dentre os principais problemas que acometem a população idosa, tem-se a ocorrência de quedas. Estima-se que cerca de $30 \%$ dos idosos brasileiros caia ao menos uma vez por ano, sendo que em metade dos casos o evento é recorrente (O'loughlin et al., 1993; Tromp et al., 1998). Tratando especificamente das mulheres, elas são as mais suscetíveis a cair (Hornbrook et al., 1994; Dunlop et al., 2002). No que concerne às lesões, cerca de 5 a $10 \%$ das 
quedas resultam em ferimentos graves, como fraturas ou traumatismos crânioencefálicos. Observa-se, ainda, a ocorrência de ferimentos de menor complexidade em 30 a 50\% dos casos (Nevitt et al., 1991; Goldacre et al., 2002; Rubenstein e Josephson, 2002). Somado a isso, a maioria dos idosos que sofrem uma queda desenvolvem o medo de cair, o que repercute numa restrição das atividades de vida diária em 40\% dos indivíduos (Zijlstra et al., 2007).

Realmente, dados epidemiológicos demonstram uma maior ocorrência de quedas em idosos com excesso de adiposidade corporal (Fjeldstad et al., 2008; Himes e Reynolds, 2012; Mitchell et al., 2014). Não se sabe, porém, quais são os mecanismos associados a este risco aumentado. $O$ estudo dos fatores relacionados a uma maior ocorrência de quedas nesta população é, portanto, relevante e poderá ser útil no delineamento de intervenções preventivas.

Um dos principais fatores de risco para a ocorrência de quedas é a instabilidade postural (Ganz et al., 2007; Deandrea et al., 2010; Ambrose et al., 2013). Estudos conduzidos em mulheres idosas demonstram que a obesidade parece exercer impacto negativo sobre o mecanismo de controle postural (Mainenti et al., 2011; Carneiro et al., 2012; Dutil et al., 2013; Melzer e Oddsson, 2015; Siqueira e Geraldes, 2015). Existem duas hipóteses que tentam explicar a influência negativa do excesso de adiposidade sobre o controle postural. A primeira diz respeito à diminuição da sensibilidade dos mecanorreceptores plantares em detectar oscilações posturais. Essa sensibilidade diminuída ocorreria devido à hiperativação desses receptores em decorrência de uma maior pressão plantar exercida pelo excesso de peso (Hue et al., 2007; Wu e Madigan, 2014). De fato, a obesidade tem sido associada a uma pressão plantar aumentada (Hills et al., 2001; Gravante et al., 2003; Birtane e Tuna, 2004; Teh et al., 2006; Monteiro et al., 2010; Butterworth et al., 2015; Mickle e Steele, 2015; Song et al., 2015). Tratando especificamente de indivíduos idosos, Mickle e Steele (2015) foram pioneiros em investigar essa associação.

A segunda hipótese está relacionada à sobrecarga mecânica exercida pelas dimensões corporais mais pronunciadas. O excesso de massa faz com que o centro de gravidade fique posicionado mais anteriormente em relação às articulações do tornozelo, o que gera um torque gravitacional maior. Para manter a estabilidade postural, este torque gravitacional deve ser contrabalanceado por torques musculares mais pronunciados (Corbeil et al., 2001; Simoneau e Corbeil, 2005; 
Simoneau e Teasdale, 2015). O excesso de adiposidade, no entanto, parece estar associado a um comprometimento da força muscular em idosos (Stenholm et al., 2011; Paolillo et al., 2012; Maffiuletti et al., 2013; Kalyani et al., 2014; Vilaça et al., 2014; Charlton et al., 2015; Shen et al., 2015). Dado o exposto, essa é uma importante variável a ser estudada.

Cabe agora salientar que os estudos supracitados utilizaram métodos pouco robustos para a avaliação da obesidade, sendo constituídos, basicamente, pela mensuração do índice de massa corporal (IMC). Apesar de este índice ser amplamente utilizado nesse tipo de investigação, a sua acurácia diagnóstica na predição do excesso de adiposidade corporal é limitada, especialmente em indivíduos idosos (Romero-Corral et al., 2008). Dentre os métodos que avaliam a gordura corporal, muitos consideram a absortometria de raio-x de dupla energia (DEXA) como padrão ouro (Cornier et al., 2011), sendo, portanto, um procedimento recomendado em estudos como este. Outra limitação é que a maioria das pesquisas não analisa a influência da distribuição de gordura corporal - andróide ou ginóide sobre o risco de quedas e as condições associadas. Nesse sentido, é aconselhável a utilização da medida de circunferência de cintura (CC), que é um índice indicativo de adiposidade abdominal (Pouliot et al., 1994).

Para finalizar, vale ressaltar que a ocorrência de quedas em idosos acarreta num impacto econômico significativo. Nos Estados Unidos, por exemplo, o custo direto com as quedas foi de 23,3 bilhões de dólares, no ano de 2008; e, segundo estimativas, subirá para 55 bilhões de dólares até o ano de 2020, devido ao envelhecimento populacional (Davis et al., 2010). Dessa forma, faz-se necessário o desenvolvimento de estudos que propiciem um melhor entendimento dos fatores de risco associados à ocorrência de quedas em idosos. Conhecendo tais fatores, será possível implementar ações preventivas, o que reduzirá os gastos públicos e, em ultima análise, proporcionará uma melhor qualidade de vida à população. Sendo assim, o objetivo desse estudo será verificar a associação entre adiposidade corporal, força muscular, distribuição de pressão plantar, estabilidade postural e risco de quedas em mulheres idosas. 


\section{OBJETIVOS}

\subsection{GERAL}

- Verificar a associação entre adiposidade corporal, força muscular, distribuição de pressão plantar, estabilidade postural e risco de quedas em mulheres idosas.

\subsection{ESPECÍFICOS}

- Correlacionar índices de adiposidade corporal (IMC, CC e percentual de gordura corporal - \%G) com a força muscular, a distribuição de pressão plantar, a estabilidade postural e o risco de quedas em mulheres idosas;

- Comparar a força muscular, a distribuição de pressão plantar, a estabilidade postural e o risco de quedas de mulheres idosas estratificadas de acordo com o IMC, a CC e o \%G;

- Calcular o risco relativo para quedas em mulheres idosas classificadas nos estratos superiores de adiposidade corporal. 


\section{REVISÃO DE LITERATURA}

\subsection{DADOS EPIDEMIOLÓGICOS DO ENVELHECIMENTO}

O envelhecimento populacional é um fenômeno global. Conceitualmente, ele pode ser definido como uma mudança na estrutura etária da população que resulta em uma maior proporção de idosos (Carvalho e Garcia, 2003). Dados da Organização das Nações Unidas - ONU (2011) evidenciam claramente esse fenômeno: em 1950, a participação de pessoas com 60 anos ou mais representava $8 \%$ da população mundial; em 2010, esse percentual subiu para 11\%; e em 2050, segundo estimativas, subirá para $22 \%$.

A Figura 1 ilustra o percentual de idosos em diferentes regiões do mundo em 2012, bem como a projeção para 2050.
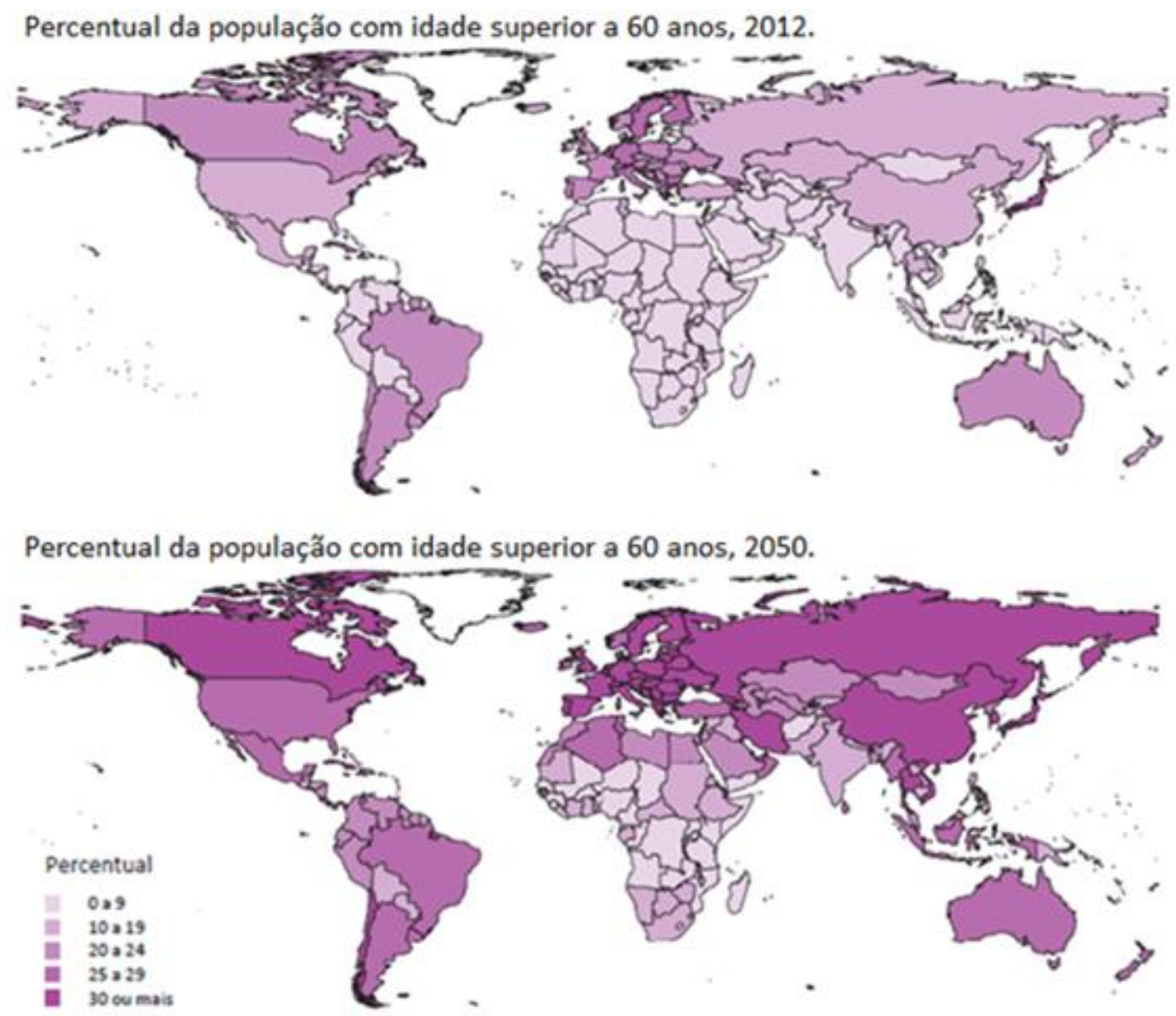

Figura 1. Percentual de idosos em diferentes regiões do mundo. Acima, percentual referente ao ano de 2012. Abaixo, projeção para 2050. Fonte: OMS, 2012. 
Ao analisar a Figura 1, fica evidente que os países desenvolvidos apresentam uma maior proporção de idosos. Por outro lado, os países em desenvolvimento enfrentam uma maior velocidade de envelhecimento. A França, por exemplo, levou mais de um século para que sua população de idosos aumentasse de 7\% para 14\% da população total. No Brasil, esse crescimento ocorrerá em apenas duas décadas (Dobriansky et al., 2007). Dados do IBGE demonstram que em 1960, os idosos com idade superior a 65 anos representavam 2,7\% da população brasileira; em 2010, este valor subiu para 7,4\% (IBGE, 2010); e em 2060, segundo estimativas, subirá para $26,7 \%$, o que significa que pouco mais de um quarto da população será de idosos (IBGE, 2013).

Associado ao envelhecimento populacional, é possível observar um fenômeno denominado feminização da velhice, o qual se caracteriza por maior longevidade das mulheres, em relação aos homens, e por maior representatividade das mesmas (Lebrão, 2007). Na população mundial, a expectativa de vida das mulheres é de 71 anos, ao passo que a dos homens é de apenas 66 (Kowal et al., 2012). No Brasil, os números passam para 78,6 anos, entre as mulheres, e para 71,3 anos, entre os homens (IBGE, 2013). Quanto à representatividade, elas correspondem a 55,5\% da população idosa brasileira (IBGE, 2010).

A Figura 2 ilustra as diferenças populacionais no Brasil em 2010, segundo a idade e o gênero. A Figura 3, por sua vez, apresenta as projeções para 2060.

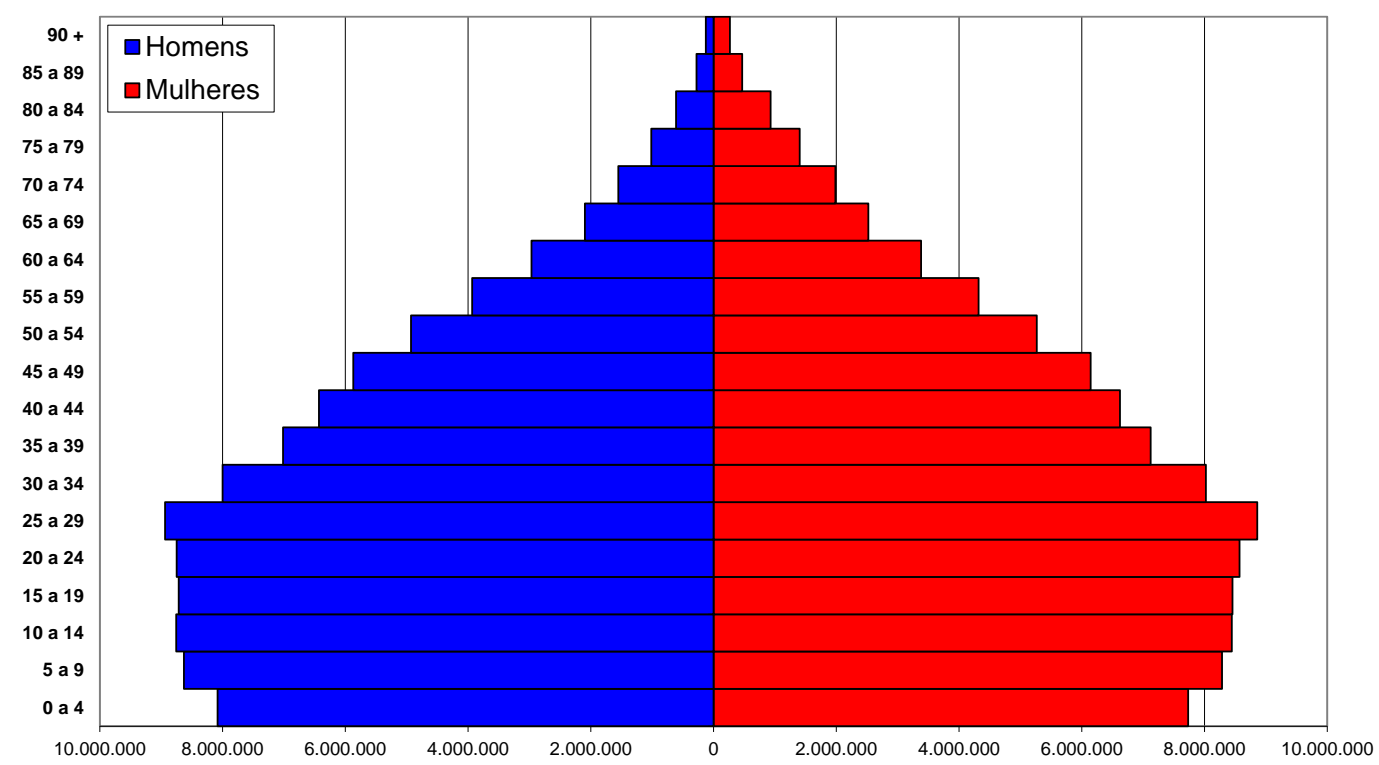

Figura 2. Pirâmide populacional do Brasil em 2010. Fonte: IBGE, 2013. 


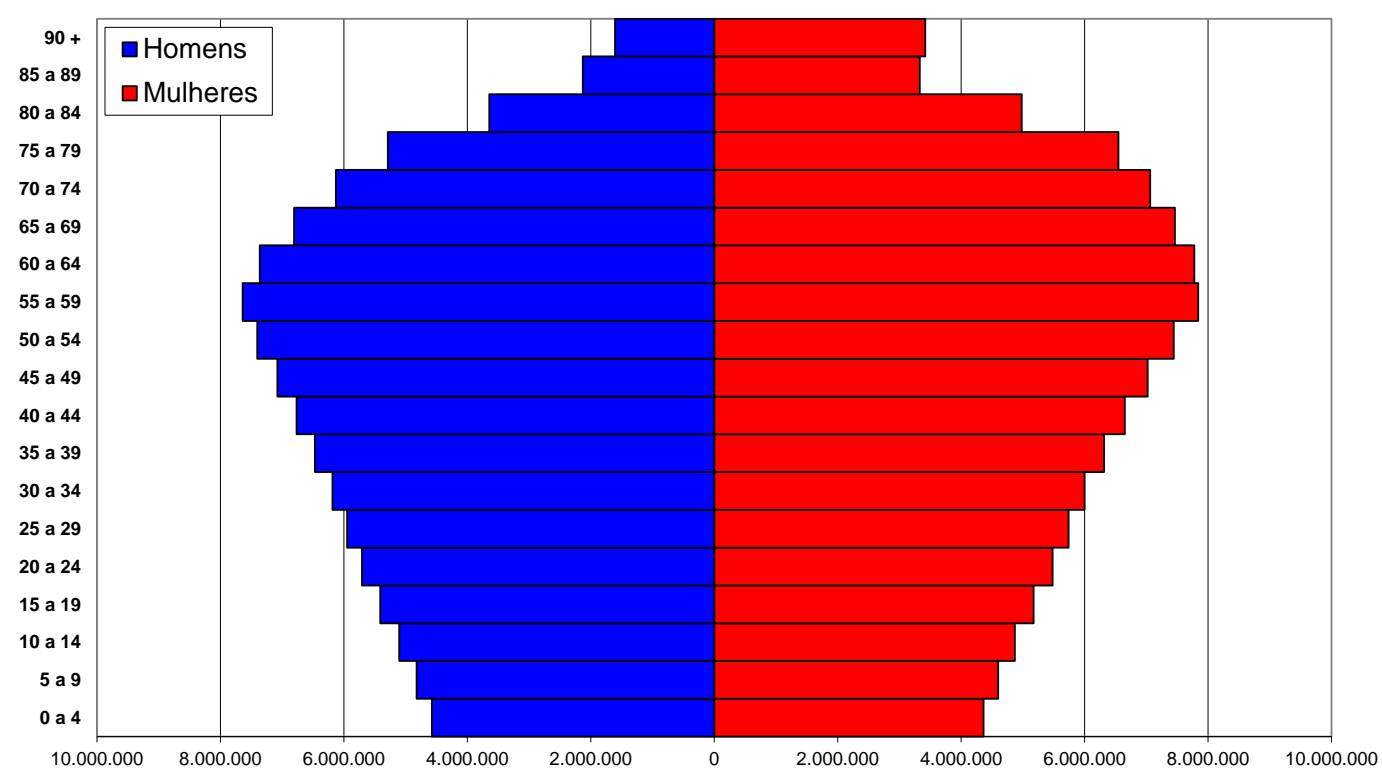

Figura 3. Projeção da pirâmide populacional do Brasil para 2060. Fonte: IBGE, 2013.

Cabe salientar que a maior longevidade da população repercute num aumento da prevalência de doenças crônicas não transmissíveis, as quais se prolongam por vários anos e exigem acompanhamento constante (Schramm et al., 2004). Dessa forma, o envelhecimento populacional repercute significativamente nos gastos públicos com saúde e previdência (Banco Mundial, 2011). Em 2010, o governo federal gastou 44,7\% de suas despesas com esses dois itens (Brasil, 2011), parcela que tende a aumentar ainda mais com o avanço da transição demográfica. Somado a isso, a proporção de pessoas em idade ativa em relação àquelas em idade potencialmente inativas irá diminuir. Atualmente, o Brasil possui um idoso para cada dez pessoas em idade ativa. Em 2050, essa relação será de um idoso dependente para cada três pessoas em idade ativa (ONU, 2011). Esses fatores, em conjunto, trarão sérias repercussões econômicas ao país.

Sendo assim, o estudo das alterações fisiológicas decorrentes do envelhecimento propicia um melhor entendimento da biologia da população idosa, possibilitando a implementação de intervenções preventivas e terapêuticas otimizadas, o que reduz gastos públicos e, em ultima análise, proporciona uma melhor qualidade de vida à população. 


\subsection{ENVELHECIMENTO E ALTERAÇÕES DA COMPOSIÇÃO CORPORAL}

O envelhecimento está relacionado a mudanças consideráveis na composição corporal. Com o avançar da idade, observa-se perda progressiva de massa muscular esquelética e concomitante aumento da massa gorda (Rosenberg, 1989; Newman et al., 2003). Observa-se, ainda, uma redistribuição desses componentes, resultando em um aumento de gordura intra-abdominal, em relação à subcutânea, e em uma maior redução da massa magra periférica, quando comparada com a central (Beaufrere e Morio, 2000).

A perda importante de massa magra durante o processo de envelhecimento é denominada sarcopenia (Newman et al., 2003), fenômeno o qual está diretamente associado à redução de força e potência muscular em indivíduos idosos (Roubenoff e Castaneda, 2001). O acúmulo excessivo de gordura, por sua vez, pode levar a uma condição denominada obesidade, que, segundo a OMS, pode ser definida como o excesso de gordura corporal acumulada com implicações à saúde (OMS, 2002).

As alterações da composição corporal têm origem multifatorial. A inatividade física ou a presença de enfermidades podem levar a reduções da massa muscular, enquanto a massa gorda é preservada (Han, T. et al., 2011). Somado a isso, uma menor taxa metabólica característica dos indivíduos idosos e uma ingestão inalterada de alimentos pode aumentar a probabilidade do desenvolvimento de obesidade (Elia et al., 2000). Existe, ainda, uma possível contribuição das alterações hormonais decorrentes do envelhecimento, principalmente as reduções de hormônios de crescimento e testosterona. Os idosos também apresentam uma menor resposta a hormônios da tireoide, responsáveis pelo metabolismo, e a leptina, um importante regulador da forme (Reaven, 1988). Esses diversos fatores, em conjunto, podem conduzir o indivíduo a um estado progressivo de perda de massa magra e acúmulo de gordura.

Dados de estudos populacionais demonstram que a média da massa corporal e do IMC aumenta gradualmente durante a maior parte da vida adulta e atingem valores pico entre 50 e 60 anos de idade em homens e mulheres (Kuskowska-Wolk e Rössner, 1990; Flegal et al., 1998; Mokdad et al., 2001; Flegal et al., 2002; Hedley et al., 2004). Os mesmos estudos também demonstram que após a sexta década de vida, há uma tendência ao decréscimo destes índices. Estas observações, no 
entanto, foram obtidas em estudos transversais, sendo este um possível viés, pois as pessoas obesas apresentam maiores taxas de mortalidade em idades mais jovens (Manson et al., 1995). Portanto, a mortalidade prematura de jovens obesos e adultos de meia idade pode mascarar o decréscimo na média da massa corporal e do IMC nos sujeitos sobreviventes que chegaram até a terceira idade (Villareal et al., 2005). De fato, dados de estudos longitudinais sugerem que a massa corporal e 0 IMC não se alteram ou são reduzidos de forma modesta nos idosos (Kannel et al., 1979; Rissanen et al., 1987; Grinker et al., 1995; Fogelholm et al., 2000).

Atualmente, a obesidade acomete boa parte da população idosa em diversos países do mundo. Nos Estados Unidos, aproximadamente 35\% dos idosos são obesos (Fakhouri et al., 2012). Em nosso país, dados do VIGITEL Brasil 2014 apontam que $19,8 \%$ da população com idade superior a 65 anos apresentam tal condição. Esse estudo revela, ainda, que a obesidade parece ser mais frequente no gênero feminino - a prevalência entre as mulheres é de $22,1 \%$, e entre homens é de 16,4\% (Brasil, 2015) (Figura 4). Cabe, por fim, ressaltar que existe uma tendência de que a prevalência de obesidade em idosos aumente ainda mais nas próximas décadas (Cetin e Nasr, 2014).

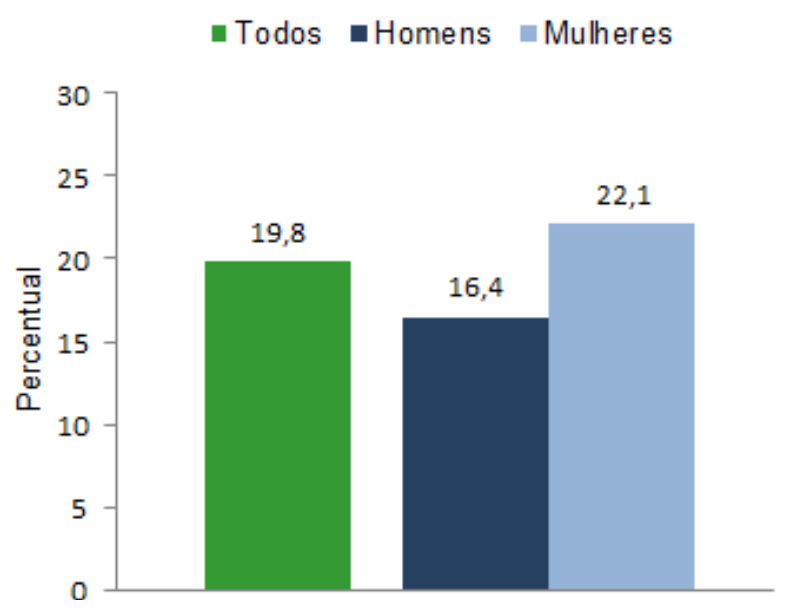

Figura 4. Percentual de idosos obesos nas capitais dos estados brasileiros e Distrito Federal, por gênero. Fonte: VIGITEL Brasil 2014.

\subsection{ENVELHECIMENTO E QUEDAS}

As quedas podem ser definidas como um deslocamento não intencional do corpo, com incapacidade de correção em tempo hábil, que resulta na mudança da 
posição do indivíduo para um nível inferior à posição inicial (Lamb et al., 2005). Elas decorrem da ineficiência dos mecanismos responsáveis pela manutenção da estabilidade postural e estão fortemente associadas ao envelhecimento (Fuller, 2000; Rubenstein, 2006; Finlayson e Peterson, 2010; Ambrose et al., 2013).

A estabilidade postural caracteriza-se pela capacidade do indivíduo manter o centro de massa corporal sobre a sua base de sustentação, tanto em situações estáticas quanto dinâmicas. Para que isso ocorra, é necessária a ação de um complexo mecanismo de controle: a princípio, o indivíduo deve adquirir informações contínuas sobre seu posicionamento e sua trajetória no espaço (sistema sensorial); em seguida, realiza-se o mapeamento do centro de massa e o planejamento de estratégias de ajustes posturais (processamento central); e por fim, o corpo executa as estratégias determinadas (componente efetor) (Horak, 2006).

Para haver uma boa estabilidade postural, todo o aparato envolvido no seu mecanismo de controle deve estar íntegro. Durante o processo natural do envelhecimento, entretanto, ocorre o declínio desses componentes. No sistema sensorial, há diminuição da acuidade visual, alterações no reflexo vestíbulo-ocular, e perdas discretas das sensações proprioceptivas. A nível central, temos a diminuição da velocidade de condução nervosa, o que acarreta em lentificação do processamento das informações sensoriais e em atraso das respostas posturais automáticas. No sistema efetor, por sua vez, ocorre hipotrofia e enfraquecimento muscular, rigidez aumentada nos tecidos conjuntivos e diminuição da amplitude de movimento articular, diminuindo, assim, a eficácia da resposta a um desequilíbrio postural. Todas essas alterações, em conjunto, aumentam o risco de quedas em idosos (Chandler, 2002).

Atualmente, as quedas representam a principal causa de morte acidental na população idosa, configurando-as como um importante problema de saúde pública (Tinetti, 2003). Cerca de $30 \%$ dos idosos com idade superior a 65 anos caem ao menos uma vez por ano, sendo que em metade dos casos o evento é recorrente (O'loughlin et al., 1993; Tromp et al., 1998). Em indivíduos com 80 anos ou mais, a ocorrência de quedas sobe para 50\% (Inouye et al., 2009). Tratando especificamente das mulheres, elas são as mais suscetíveis a cair (Hornbrook et al., 1994; Dunlop et al., 2002). No que concerne às lesões, cerca de 5 a $10 \%$ das quedas resultam em ferimentos graves, como fraturas ou traumatismos crânioencefálicos. Observa-se, ainda, a ocorrência de ferimentos de menor complexidade 
em 30 a 50\% dos casos (Nevitt et al., 1991; Goldacre et al., 2002; Rubenstein e Josephson, 2002). Somado a isso, a maioria dos idosos que sofrem uma queda desenvolvem o medo de cair, o que repercute numa restrição das atividades de vida diária em 40\% dos indivíduos (Zijlstra et al., 2007).

A Figura 5 apresenta a taxa de atendimento em emergência médica por lesões relacionadas a quedas.

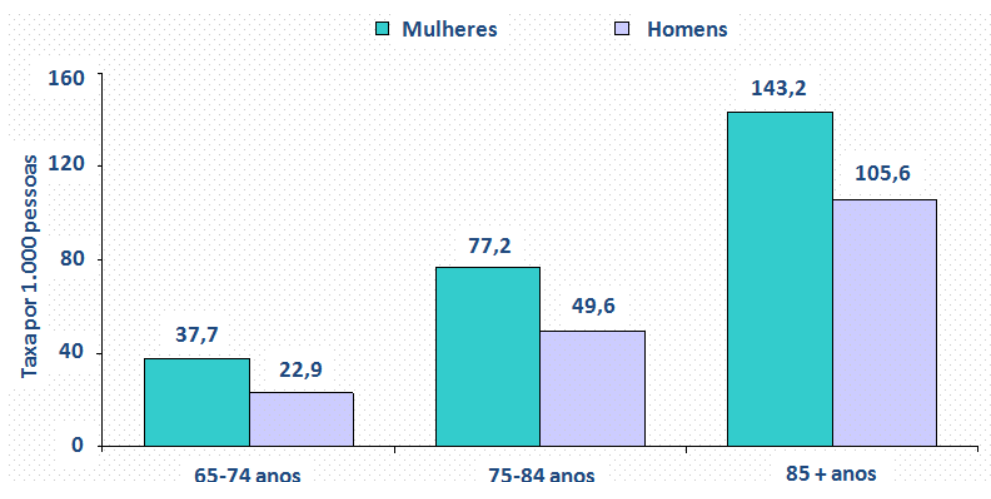

Figura 5. Taxa de atendimento em emergência médica por lesões relacionadas a quedas, por gênero e faixa etária, Estados Unidos, 2006. Fonte: Owens et al., 2009.

A elevada prevalência de quedas, associada as suas graves consequências, acarretam num impacto econômico significativo. Nos Estados Unidos, por exemplo, o custo direto com a ocorrência de quedas foi de 23,3 bilhões de dólares, no ano de 2008; e, segundo estimativas, subirá para 55 bilhões de dólares até o ano de 2020, devido ao envelhecimento populacional (Davis et al., 2010).

Dessa forma, torna-se imperativo o desenvolvimento de estudos que propiciem um melhor entendimento dos fatores de risco associados à ocorrência de quedas em idosos. Conhecendo tais fatores, será possível implementar ações preventivas, o que reduzirá os gastos públicos e, em ultima análise, proporcionará uma melhor qualidade de vida à população.

\subsection{EXCESSO DE ADIPOSIDADE CORPORAL E QUEDAS EM IDOSOS}

Estudos epidemiológicos demonstram uma maior ocorrência de quedas em idosos com excesso de adiposidade corporal (Fjeldstad et al., 2008; Himes e 
Reynolds, 2012; Mitchell et al., 2014). Em estudo retrospectivo, Fjeldstad et al. (2008) observaram que a obesidade estava associada a uma maior prevalência de quedas em indivíduos de meia-idade e idosos $(n=216)$. A prevalência entre os obesos foi de $27 \%$, ao passo que naqueles com peso normal foi de $15 \%$. Além disso, a ocorrência de tropeções (perda de equilíbrio sem resultar em quedas) também foi maior nas pessoas obesas (32\%), quando comparadas com as de peso normal (14\%).

Em estudo longitudinal, Himes e Reynolds (2012) avaliaram a influência da obesidade sobre o risco de um idoso cair, sofrer lesões relacionadas à queda, e apresentar limitações funcionais após o evento. Participaram deste estudo 10.755 pessoas com idades superiores a 65 anos. Comparado com os idosos de peso normal, o odds ratio (OR) para o risco de quedas foi de 1,12 (intervalo de confiança - IC 95\% 1,01-1,24) para obesidade grau I, 1,26 (IC 95\% 1,05-1,51) para obesidade grau II, e 1,50 (IC 95\% 1,21-1,86) para obesidade grau III. A obesidade grau III, no entanto, foi associada à menor ocorrência de lesões relacionadas às quedas $(\mathrm{OR}=$ 0,62, IC 95\% 0,44-0,87). Quanto às limitações funcionais após a ocorrência da queda, as obesidades grau I e II foram associadas a um risco aumentado de desenvolvimento de limitações (OR=1,17, IC 95\% 1,02-1,34 e OR=1,39, IC 95\% 1,10-1,75, respectivamente).

Mais recentemente, estudo de base populacional verificou se idosos sobrepesados e obesos apresentariam maior ocorrência de quedas e maior risco de lesão relacionada a queda, quando comparados com idosos de peso normal $(\mathrm{n}=$ 5.681). A obesidade foi associada a um risco $31 \%$ maior de sofrer uma queda, e a um risco $32 \%$ maior de sofrer múltiplas quedas. Quanto às lesões relacionadas, os obesos caidores apresentaram maior prevalência de dor e inatividade física do que os de peso normal. Não houve diferença estatisticamente significante para o sobrepeso (Mitchell et al., 2014).

Em relação aos cuidados médicos necessários para o tratamento das lesões decorrentes das quedas, Compston et al. (2014) avaliaram a utilização de assistência médica de 4.301 mulheres pós-menopausadas que haviam sofrido uma fratura. Foi observado que o tempo de hospitalização foi maior entre as mulheres obesas ( 6 dias para as obesas e 5 dias para as não obesas, $p=0.017$ ). Também no estudo conduzido por Chuang et al. (2016), observou-se que pacientes obesos 
apresentaram maior período de hospitalização após sofrerem uma queda $(10,1$ vs. 8,9 dias, $p=0,049)$.

\subsubsection{Fatores associados}

Apesar do excesso de adiposidade corporal estar claramente relacionado a uma maior ocorrência de quedas em idosos (Fjeldstad et al., 2008; Himes e Reynolds, 2012; Mitchell et al., 2014), os mecanismos associados a este risco aumentado ainda não são conhecidos. Serão abordados nesta revisão fatores associados ao risco de quedas, bem como a influência do excesso de adiposidade sobre esses fatores. Mais especificamente, será tratado acerca da força muscular, da distribuição de pressão plantar e da estabilidade postural.

\subsubsection{Força muscular}

A fraqueza muscular representa um importante fator de risco para quedas em idosos (Moreland et al., 2004; Horlings et al., 2008). Dados de uma metanálise apontam que para a fraqueza de membros inferiores, o OR combinado é de 1,76 (IC 95\% 1,31-2,37) para a ocorrência de quedas, e de 3,06 (IC 95\% 1,86-5,04) para quedas recorrentes. Quanto à fraqueza de membros superiores, o OR é de 1,53 (IC $95 \%$ 1,01-2,32) e de 1,41 (IC 95\% 1,25-1.59) para quedas e para quedas recorrentes, respectivamente (Moreland et al., 2004). Levando em consideração que para haver uma boa estabilidade postural, todo o aparato envolvido no seu mecanismo de controle deve estar íntegro, parece óbvio que alterações do componente efetor comprometam o controle postural e predisponham às quedas (Horak, 2006). Teoricamente, a fraqueza muscular estaria relacionada a um maior risco de quedas por dificultar a execução de estratégias de ajustes posturais (Horlings et al., 2008).

A influência do excesso de adiposidade corporal sobre a força muscular já foi investigada em estudos anteriores (Dey et al., 2009; Koster et al., 2011; Stenholm et al., 2011; Paolillo et al., 2012; Hardy et al., 2013; Maffiuletti et al., 2013; Cooper et al., 2014; Kalyani et al., 2014; Vilaça et al., 2014; Charlton et al., 2015; Shen et al., 2015). Em revisão de literatura, Maffiuletti et al. (2013) apontam que a obesidade 
está associada a uma maior força muscular absoluta. Isso ocorre devido às adaptações musculoesqueléticas decorrentes de uma maior sobrecarga. Quando a força muscular é relativizada para a massa corporal, no entanto, notam-se valores menores entre indivíduos obesos. Tratando especificamente de idosos, Kalyani et al. (2014) explicam que o processo de envelhecimento pode comprometer o mecanismo de adaptação à sobrecarga. Dessa maneira, o excesso de adiposidade traria repercussões ainda mais severas ao sistema muscular, aumentando o risco de incapacidade física nesta população.

De fato, boa parte dos estudos que investigaram o impacto da obesidade sobre a força muscular em idosos verificou que o excesso de adiposidade não estava relacionado a uma maior força absoluta (Dey et al., 2009; Stenholm et al., 2011; Paolillo et al., 2012; Hardy et al., 2013; Cooper et al., 2014; Vilaça et al., 2014; Charlton et al., 2015; Shen et al., 2015). Estudo conduzido por Paolillo et al. (2012), por exemplo, avaliou o pico de torque isocinético dos extensores de joelho de 55 mulheres pós-menopausadas, classificadas como obesas (IMC $\geq 30 \mathrm{~kg} / \mathrm{m}^{2}$ ) ou não obesas (IMC entre 18,5 e 29,9). Foi observado que, a $60 \% / \mathrm{s}^{-1}$, o pico de torque absoluto foi semelhante entre os estratos de adiposidade. $O$ pico de torque relativo, por sua vez, foi significativamente menor nas mulheres obesas.

Vilaça et al. (2014) também compararam a força muscular dos extensores de joelho de idosas obesas ( $\% \mathrm{G} \geq 38 \%$ ) e não-obesas ( $\% \mathrm{G}<38 \%$ ) $(n=75)$; além de analisar a força de preensão manual (FPM), a massa muscular e a qualidade muscular. Percebeu-se que, apesar das obesas apresentarem maior massa muscular, não houve diferença entre os grupos quanto à força absoluta. No que concerne à qualidade muscular, foi encontrado um efeito negativo da obesidade tanto em membros inferiores quanto superiores.

Adicionalmente, ao correlacionar a FPM com o IMC de mulheres com idades entre 60 e 90 anos, Hardy et al. (2013) não verificaram associação significativa entre as variáveis $(n=7358)$. O mesmo foi observado por Charlton et al. (2015) numa amostra de 52 idosas. Contudo, ao correlacionar a FPM com o \%G, tornou-se evidente uma associação negativa, moderada e significativa (Charlton et al., 2015). Ademais, quando a FPM é relativizada para a massa corporal, nota-se uma relação negativa e significativa, porém classificada como fraca, com o IMC $(n=966)$ (Shen et al., 2015). 
Em estudo longitudinal conduzido em 238 mulheres (20-80 anos), Kim et al. (2014) investigaram se a gordura visceral estaria associada a um declínio na massa muscular esquelética. Para mensurar a gordura visceral foi utilizada tomografia computadorizada, e para avaliar a massa muscular foi empregado o DEXA. Ao longo do período de follow-up (27,6 $\pm 2,8$ meses), observou-se aumento da massa gorda visceral, acompanhado de redução da massa magra apendicular. Além disso, as mulheres que apresentavam obesidade visceral na linha de base exibiram maior perda de massa muscular apendicular, quando comparadas com as que não apresentavam obesidade visceral.

Resultados semelhantes foram encontrados por Koster et al. (2011) ao examinar a associação da gordura corporal total, avaliada pelo DEXA, com modificações na massa magra da perna, no pico de torque isocinético dos extensores de joelho $\left(60^{\circ} / \mathrm{s}^{-1}\right)$ e na qualidade muscular de mulheres idosas durante um período de sete anos $(n=1.178)$. Os resultados indicaram que, apesar do excesso de adiposidade estar relacionado a uma maior massa muscular na linha de base, a obesidade acarretou num declínio muscular mais acentuado ao longo do follow-up. Verificou-se, ainda, que a gordura corporal se associou a uma maior força muscular absoluta e a um comprometimento da qualidade muscular. Não foi evidente, porém, associação da massa gorda com as alterações nas variáveis supracitas.

De maneira similar, Dey et al. (2009) também não observaram associação significativa entre o \%G, mensurado por bioimpedância, e as alterações da força isométrica dos extensores do joelho e da FPM. Vale ressaltar que essas análises foram efetuadas em 49 idosas, as quais foram acompanhadas por cinco anos.

Em relação à influência do tempo de exposição ao excesso de adiposidade corporal, Stenholm et al. (2011) e Cooper et al. (2014) trazem importantes contribuições. O primeiro estudo demonstra que a exposição prolongada à obesidade (IMC $\geq 30 \mathrm{~kg} / \mathrm{m}^{2}$ ) está associada a menor FPM na idade avançada. Ademais, quando comparado com idosos que nunca foram obesos, o OR (IC 95\%) para fraqueza de preensão manual relativa foi de $2,76(1,78-4,28)$ para idosos com obesidade recente, $5,57(3,02-10,28)$ para aqueles com obesidade desde os 50 anos de idade, 6,53 (2,98-14,30) para obesos desde os 40 anos, e 10,36 (3,55-30,24) para os que apresentavam obesidade já aos 30 anos de idade (Stenholm et al., 2011). O segundo estudo, por outro lado, evidencia que aumentos mais expressivos 
do IMC, observados a partir dos 15 anos de idade, não foram associados com a FPM no início da velhice. Além disso, houve um efeito protetor sobre a massa muscular, acompanhado, porém, de pior qualidade muscular (Cooper et al., 2014).

Cabe, por fim, salientar que, devido às dimensões corporais mais pronunciadas, os indivíduos obesos necessitam de torques musculares maiores para manter a estabilidade postural (Corbeil et al., 2001; Simoneau e Corbeil, 2005). O excesso de adiposidade, no entanto, parece estar associado a um comprometimento da força muscular (Stenholm et al., 2011; Paolillo et al., 2012; Maffiuletti et al., 2013; Kalyani et al., 2014; Vilaça et al., 2014; Charlton et al., 2015; Shen et al., 2015). Sendo assim, esse pode ser um dos mecanismos relacionados ao maior risco de quedas em idosos obesos.

\subsubsection{Distribuição de pressão plantar}

As desordens nos pés representam um importante fator de risco para quedas em idosos (Menz et al., 2006; Chaiwanichsiri et al., 2008; Mickle et al., 2010; Ferrari et al., 2014; Brenton-Rule, 2015; Menz, 2015). No que concerne à distribuição de pressão plantar, ela parece estar associada a uma maior ocorrência de quedas por meio de dois mecanismos. Primeiro, a pressão plantar elevada acarreta numa hiperativação dos mecanorreceptores plantares, o que repercute numa sensibilidade plantar reduzida. Essa diminuição da sensibilidade, por sua vez, dificultaria a detecção de oscilações posturais (Hue et al., 2007). Segundo, altas pressões plantares geradas durante a marcha podem colaborar para dores nos pés, o que se relaciona com o risco aumentado para quedas (Mickle et al., 2010).

A influência do excesso de adiposidade corporal sobre a distribuição de pressão plantar já foi investigada em estudos anteriores (Hills et al., 2001; Gravante et al., 2003; Birtane e Tuna, 2004; Teh et al., 2006; Monteiro et al., 2010; Butterworth et al., 2015; Mickle e Steele, 2015; Song et al., 2015). Hills et al. (2001) compararam a pressão plantar de 70 indivíduos obesos e não-obesos com idade média de 40 anos. Durante a posição estática, observou-se que os homens obesos apresentaram valores de pico de pressão plantar significativamente mais elevados sob o calcâneo, mediopé, cabeças do I ao IV metatarsos e hálux. Quanto às mulheres, a diferença foi encontrada no calcâneo, mediopé e cabeças do I, II e IV metatarsos. Durante a 
marcha, a pressão plantar dos obesos também foi mais elevada. Encontrou-se diferença estatisticamente significante no calcâneo, mediopé, cabeça do II ao V metatarso e hálux, entre os homens, e no mediopé e cabeça de todos os metatarsos, entre as mulheres. Além disso, observou-se que a largura do antepé dos obesos foi significativamente maior, quando comparado com os não-obesos.

Estudo conduzido em 72 indivíduos com idade média de 23 anos também observou que a obesidade estava relacionada a valores aumentados do pico de pressão plantar ( $+45,5 \%$ nas mulheres e $+40,5 \%$ nos homens, $p<0,0001)$ e da pressão plantar média ( $+52,6 \%$ nas mulheres e $+44,7 \%$ nos homens, $p<0,0001)$ na posição estática. Somado a isso, as pessoas obesas apresentaram uma área de contato plantar maior do que as não-obesas $(+12,2 \%$ nas mulheres, $p<0,0001$, e $+9,9 \%$ nos homens, $p<0,005)$ e uma maior razão entre a largura do mediopé e a largura do antepé, o que reflete uma área de contato aumentada no mediopé relacionada ao excesso de adiposidade corporal (Gravante et al., 2003).

No estudo de Birtane e Tuna (2004), por sua vez, observou-se que a obesidade classe 1 estava associada a valores significativamente maiores do pico de pressão do antepé, da força plantar total e da área de contato total. Na avaliação dinâmica, no entanto, foram encontradas diferenças apenas no pico de pressão do mediopé. Ao correlacionar o IMC com as variáveis baropodométricas, observou-se correlação positiva com a força plantar total $(r=0,50, p<0,001)$ e com a área de contato total $(r=0,33, p=0,019)$, na avaliação estática, e com o pico de pressão no mediopé $(r=0,32, p=0,025)$, na avaliação dinâmica. A amostra desse estudo foi composta por 50 indivíduos com média de idade de 50 anos.

Valores mais elevados do IMC também foram associados a uma área de contato total aumentada e uma maior força plantar durante a postura ortostática em um estudo realizado com 120 sujeitos (15-45 anos de idade). Quanto à distribuição de pressão plantar, foram encontrados valores aumentados no retropé e no antepé dos indivíduos com peso normal. Contrariando a literatura, observou-se que conforme aumentava o IMC, menor eram os valores de pressão plantar (Teh et al., 2006).

Mais recentemente, Monteiro et al. (2010) analisaram o efeito da obesidade e da obesidade sarcopênica sobre a pressão plantar de 239 mulheres pósmenopausadas, durante a marcha. Comparado com as mulheres que não apresentavam nem obesidade nem sarcopenia, as obesas exibiram maior pico de 
pressão sob a porção lateral do calcanhar, mediopé e metatarsos I, IV e V, e maior impulso absoluto sob o calcanhar e metatarsos. As mulheres com obesidade sarcopênica, por sua vez, exibiram maior pico de pressão e maior impulso absoluto em todas as áreas do pé, com exceção dos dedos. Quando os valores foram normalizados para a massa corporal, entretanto, as pressões aumentadas se mantiveram apenas no mediopé. Cabe adicionar, que o índice de arco dinâmico também foi analisado, não sendo encontrada diferença significativa entre os grupos.

Butterworth et al. (2015), por outro lado, verificaram que indivíduos obesos apresentavam valores mais elevados do índice de arco dinâmico, evidenciando que a obesidade estaria associada a um padrão de pé plano. Foi observado, ainda, em avaliação dinâmica, valores mais elevados para a força máxima e para o pico de pressão na maioria das regiões do pé (exceto II ao V dedo), e maior área de contato no pé completo e no mediopé. Salienta-se que este estudo foi conduzido em 68 sujeitos, com média de idade de 52,6 anos.

Em ensaio clínico randomizado, Song et al. (2015) investigaram os efeitos da redução de peso sobre a distribuição de pressão plantar de adultos obesos $(n=41$, 56,2 $\pm 4,7$ anos). Após três meses de intervenção, baseada em refeições com porções controladas, houve redução média de $5,9 \mathrm{~kg}$. Isso refletiu em diminuição significativa do pico de pressão na porção lateral do mediopé e no metatarso IV. Após seis meses de intervenção, as alterações no peso corporal se correlacionaram significativamente com as modificações do pico de pressão na porção medial do mediopé $(r=0,26, p<0,0001)$ e nos metatarsos II $(r=0,57, p=0,0219)$ e III $(r=0,56$, $p=0,0064)$.

Cabe salientar que os estudos supracitados foram conduzidos em indivíduos adultos, e, sendo a idade um fator que afeta significativamente a distribuição de pressão plantar (Hessert et al., 2005; Bosch et al., 2009), é necessária cautela ao extrapolar os resultados para a população de idosos. Nesse sentido, Mickle e Steele (2015) foram pioneiros em examinar os efeitos do sobrepeso e da obesidade sobre a distribuição de pressão plantar de pessoas com 60 anos ou mais $(n=312)$. Os autores observaram diferenças significativas apenas no pico de pressão do mediopé e do metatarso I (baropodometria dinâmica). Mais especificamente, idosos obesos exibiram maior pico de pressão que os eutróficos nessas regiões. Ademais, para o mediopé, foi encontrada diferença significativa também em relação aos 
sobrepesados, onde o pico de pressão do grupo sobrepeso foi maior que o do grupo eutrófico e menor que o de obesos.

Dado o exposto, o excesso de adiposidade corporal parece estar associado a uma distribuição de pressão plantar irregular (Hills et al., 2001; Gravante et al., 2003; Birtane e Tuna, 2004; Teh et al., 2006; Monteiro et al., 2010; Butterworth et al., 2015; Mickle e Steele, 2015; Song et al., 2015). Apesar de essa relação ter sido pouco explorada em indivíduos idosos, acredita-se este pode ser um dos mecanismos relacionados ao maior risco de quedas em idosos obesos.

\subsubsection{Estabilidade postural}

A instabilidade postural é um dos principais fatores de risco para quedas (Ganz et al., 2007; Deandrea et al., 2010; Ambrose et al., 2013). Dados de uma metanálise revelam que as alterações do equilíbrio estático e dinâmico representam o segundo fator que se associa mais fortemente com o risco de quedas $(O R=1,7-$ 2,4), sendo que o primeiro é a ocorrência de quedas anteriores (Ganz et al., 2007).

Para haver uma boa estabilidade postural, todo o aparato envolvido no seu mecanismo de controle deve estar íntegro (Horak, 2006). O excesso de adiposidade corporal, no entanto, parece estar associado a um comprometimento no mecanismo de controle postural, resultando numa estabilidade diminuída (Teasdale et al., 2013). Duas hipóteses tentam explicar a influência negativa do excesso de adiposidade sobre esse mecanismo. A primeira diz respeito a uma sensibilidade plantar reduzida relacionada à hiperativação dos mecanorreceptores plantares, em decorrência da pressão plantar exercida pelo excesso de peso. Essa diminuição da sensibilidade dificultaria a detecção de oscilações posturais (Hue et al., 2007; Wu e Madigan, 2014). A segunda hipótese está relacionada à sobrecarga mecânica exercida pelas dimensões corporais mais pronunciadas. $O$ excesso de massa faz com que o centro de gravidade fique posicionado mais anteriormente em relação às articulações do tornozelo, o que causa um torque gravitacional maior. Para manter a estabilidade postural, este torque gravitacional deve ser contrabalanceado por torques musculares mais pronunciados. $O$ excesso de adiposidade, portanto, acarretaria numa maior sobrecarga para o componente efetor (Corbeil et al., 2001; Simoneau e Corbeil, 2005; Simoneau e Teasdale, 2015). 
A Figura 6 apresenta uma representação hipotética da influência do excesso de adiposidade corporal sobre o mecanismo de controle postural.

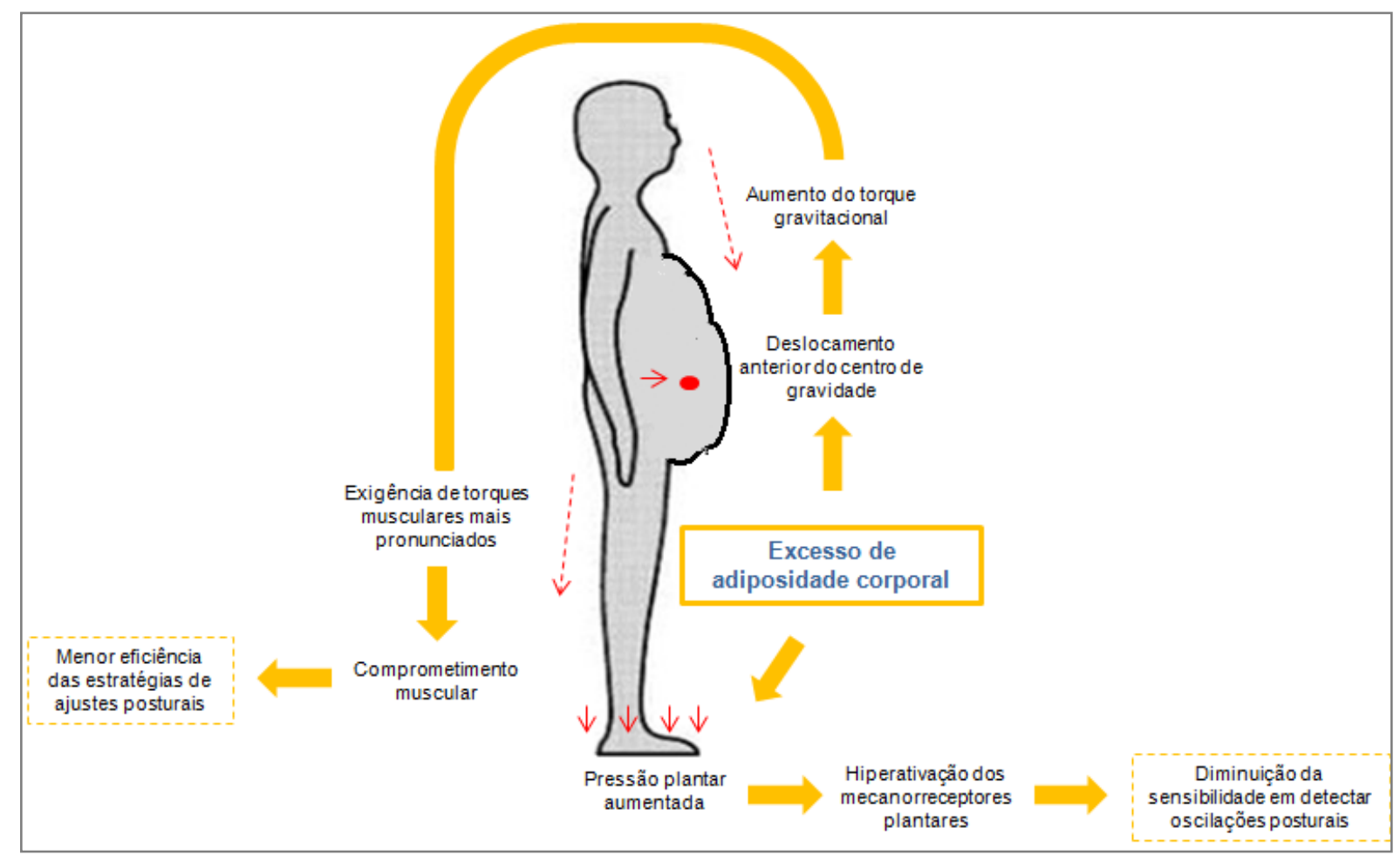

Figura 6. Representação hipotética da influência do excesso de adiposidade corporal sobre o mecanismo de controle postural.

Alguns estudos já investigaram o efeito do excesso de adiposidade sobre a estabilidade postural de indivíduos de meia-idade (Hita-Contreras et al., 2013; Kováčiková et al., 2014) e idosos (Mainenti et al., 2011; Carneiro et al., 2012; Dutil et al., 2013; Melzer e Oddsson, 2015; Siqueira e Geraldes, 2015). Em geral, a estabilidade postural é avaliada durante a posição estática, sobre diferentes bases de sustentação, com e sem restrição da visão. As variáveis mais frequentemente analisadas são aquelas relacionadas à velocidade de oscilação do centro de pressão (COP), e à amplitude de deslocamento direções anteroposterior (AP) e mediolateral (ML). Valores indicativos de comprometimento do controle postural sugerem um possível risco de quedas (Piirtola e Era, 2006).

Mainenti et al. (2011) verificou a influência do excesso de adiposidade corporal sobre o equilíbrio de 45 mulheres com idades superiores a 60 anos. A adiposidade foi avaliada por meio da bioimpedância, e a estabilidade postural por 
meio de uma plataforma de força. Para a análise, a amostra foi divida em dois grupos conforme com a mediana da massa gorda $(29,08 \mathrm{~kg})$ : o grupo com baixa massa gorda ( $\leq 29,08 \mathrm{~kg}$ ) e o grupo com alta massa gorda (> 29,08 kg). Foi realizada, então, a comparação entre os grupos, quanto as variáveis estabilométricas. Dentre as condições de equilíbrio testadas, apenas aquelas executadas com restrição da visão apresentaram diferenças estatisticamente significantes. Além disso, essas diferenças foram observadas somente na amplitude de deslocamento do COP na direção AP, onde idosas com alta massa gorda exibiram maior amplitude de oscilação.

Dutil et al. (2013), por sua vez, compararam a estabilidade postural de idosas com peso normal $(n=15)$, sobrepesadas $(n=15)$ e obesas $(n=15)$ em duas condições experimentais distintas: base aberta com olhos abertos e base aberta com olhos fechados. Observou-se que as mulheres obesas apresentaram maior velocidade de oscilação do COP em ambas as condições. Quanto à amplitude de deslocamento nas direções AP e ML, as obesas apresentaram valores significativamente maiores apenas na condição de olhos fechados. Cabe salientar que a diferença foi encontrada entre as idosas com peso normal e as obesas, nas condições com e sem restrição da visão, e entre as sobrepesadas e as obesas, excepcionalmente para a velocidade do COP testada com olhos fechados.

Estudo conduzido em 102 mulheres de meia-idade (48-65 anos) também observou impacto negativo da obesidade sobre a velocidade de oscilação do COP na condição de olhos fechados - o que não foi verificado com os olhos abertos. Ao analisar a velocidade apenas na direção AP, no entanto, os valores se mostraram significativamente maiores entre as mulheres obesas em ambas as condições testadas. Por outro lado, na direção ML, a velocidade do COP das obesas foi curiosamente menor que daquelas classificadas como eutróficas ou sobrepesadas. Os autores acreditam que isso tenha ocorrido devido à adoção de uma base mais alargada, característica típica de indivíduos com excesso de adiposidade corporal (Kováčiková et al., 2014).

Diferentemente do exposto, Carneiro et al. (2012) não encontraram diferenças significativas na velocidade de oscilação do COP nas direções AP e ML entre idosas eutróficas e obesas. Além disso, as participantes obesas apresentaram menor amplitude de deslocamento AP, em todas as condições testadas, e menor amplitude de deslocamento ML, quando avaliadas em superfícies instáveis. Elas exibiram, 
todavia, menor limite de estabilidade. Salienta-se que a amostra deste estudo foi composta por 31 mulheres com idades entre 65 e 75 anos e o instrumento utilizado para a avaliação do equilíbrio foi um sistema eletromagnético tridimensional, ao contrário dos estudos anteriores, em que foram empregadas plataformas de força.

Mais recentemente, Melzer e Oddsson (2015) avaliaram o equilíbrio postural de idosas com peso normal $(n=18)$, sobrepesadas $(n=26)$ e obesas $(n=22)$. A velocidade de oscilação do COP se mostrou semelhante entre os grupos; contudo, ao analisar a amplitude de deslocamento AP e ML, observou-se valores mais expressivos entre as obesas. As diferenças ocorreram entre as idosas com peso normal e as obesas, nas condições com e sem restrição da visão, e entre as sobrepesadas e as obesas, exclusivamente para a amplitude ML testada com olhos abertos.

Além de avaliar o impacto da obesidade, é importante verificar, também, a influência de diferentes padrões de distribuição de adiposidade corporal sobre o controle postural. Hita-Contreras et al. (2013) efetuaram essas análises em 100 mulheres pós-menopausadas. Foi observado que, com os olhos abertos, as obesas apresentaram valores mais expressivos na velocidade de oscilação do COP, em superfície instável, e na raiz quadrada média do deslocamento AP, tanto em superfície estável quanto instável. Com os olhos fechados, no entanto, só foi encontrada diferença significativa para a raiz quadrada média do deslocamento AP, em superfície estável. Tratando agora da distribuição de gordura, o padrão andróide afetou negativamente a maioria das variáveis estabilométricas, quando avaliadas sem restrição da visão. Com os olhos fechados, por outro lado, o padrão normal foi associado a um maior comprometimento do equilíbrio.

Adicionalmente, Siqueira e Geraldes (2015) correlacionaram diferentes índices de adiposidade com as variáveis estabilométricas de 108 mulheres idosas. Cabe expor que a CC foi o índice com os melhores coeficientes de correlação. Foi observada associação significativa e positiva com amplitude de deslocamento do COP nas direções AP e ML (com e sem restrição da visão) e com a velocidade do $\mathrm{COP}$ na direção AP (com restrição da visão). A correlação com a amplitude $\mathrm{ML}$, na condição de olhos abertos, e com a amplitude AP, com olhos fechados, foram classificadas com moderada. Para as demais, houve associação fraca. O IMC, por sua vez, se associou de maneira fraca, positiva e significativa com a amplitude de deslocamento do COP na direções $\mathrm{AP}$ e $\mathrm{ML}$, mas não com a sua velocidade. 
Quanto ao \%G, houve associação apenas com a velocidade na direção AP, testada com os olhos fechados.

Em suma, o excesso de adiposidade corporal parece estar associado a um comprometimento na estabilidade postural de mulheres idosas (Mainenti et al., 2011; Dutil et al., 2013; Hita-Contreras et al., 2013; Kováčiková et al., 2014; Melzer e Oddsson, 2015; Siqueira e Geraldes, 2015). Portanto, este pode ser um dos mecanismos relacionados ao maior risco de quedas em idosos obesos. 


\section{MATERIAIS E MÉTODOS}

\subsection{DELINEAMENTO DO ESTUDO}

Trata-se de um estudo transversal analítico.

\subsection{LOCAL DO ESTUDO}

O estudo foi realizado na Faculdade de Educação Física da Universidade de Brasília (FEF-UnB).

\subsection{AMOSTRA}

Duzentas e doze mulheres idosas (idade $\geq 60$ anos), capazes de se comunicar e de deambular de forma independente, foram convidadas a participar do estudo. O recrutamento da amostra foi efetuado por meio de contato telefônico com voluntárias que participaram de projetos prévios do Grupo de Estudos em Fisiologia do Exercício e Saúde - GEFS-UnB ( $n=43)$, divulgação do estudo em programa do Grupo de Estudos e Pesquisas em Atividade Física para Idosos - GEPAFI-UnB ( $\mathrm{n}=$ 45) e divulgação nas redes sociais $(n=124)$. Utilizou-se, para tanto, um cartaz contendo informações sobre a pesquisa (Anexo I). Das idosas convidadas, 139 se interessaram em participar do projeto e foram agendadas para a execução dos procedimentos. Destas, 108 compareceram nas datas agendas e efetuaram as avaliações.

Após a execução dos procedimentos, foram excluídas aquelas que apresentavam condições que interferiam diretamente no equilíbrio postural, como doenças neurológicas centrais ou periféricas, vestibulopatias, deficiência visual não corrigida, desordens musculoesqueléticas graves e cirurgias nos membros inferiores. Foram excluídas, também, as que tinham diabetes ou câncer, as que fizeram algum tipo de procedimento cirúrgico há menos de seis meses, e as que possuíam alguma 
condição que comprometesse as avaliações, como alteração cognitiva, massa corporal $\geq 150 \mathrm{~kg}$ e presença de marca-passo. Com a aplicação dos critérios de exclusão, 35 idosas foram excluídas. Dessa forma, a amostra foi composta por 73 voluntárias.

A Figura 7 apresenta o fluxograma do recrutamento e seleção amostral.

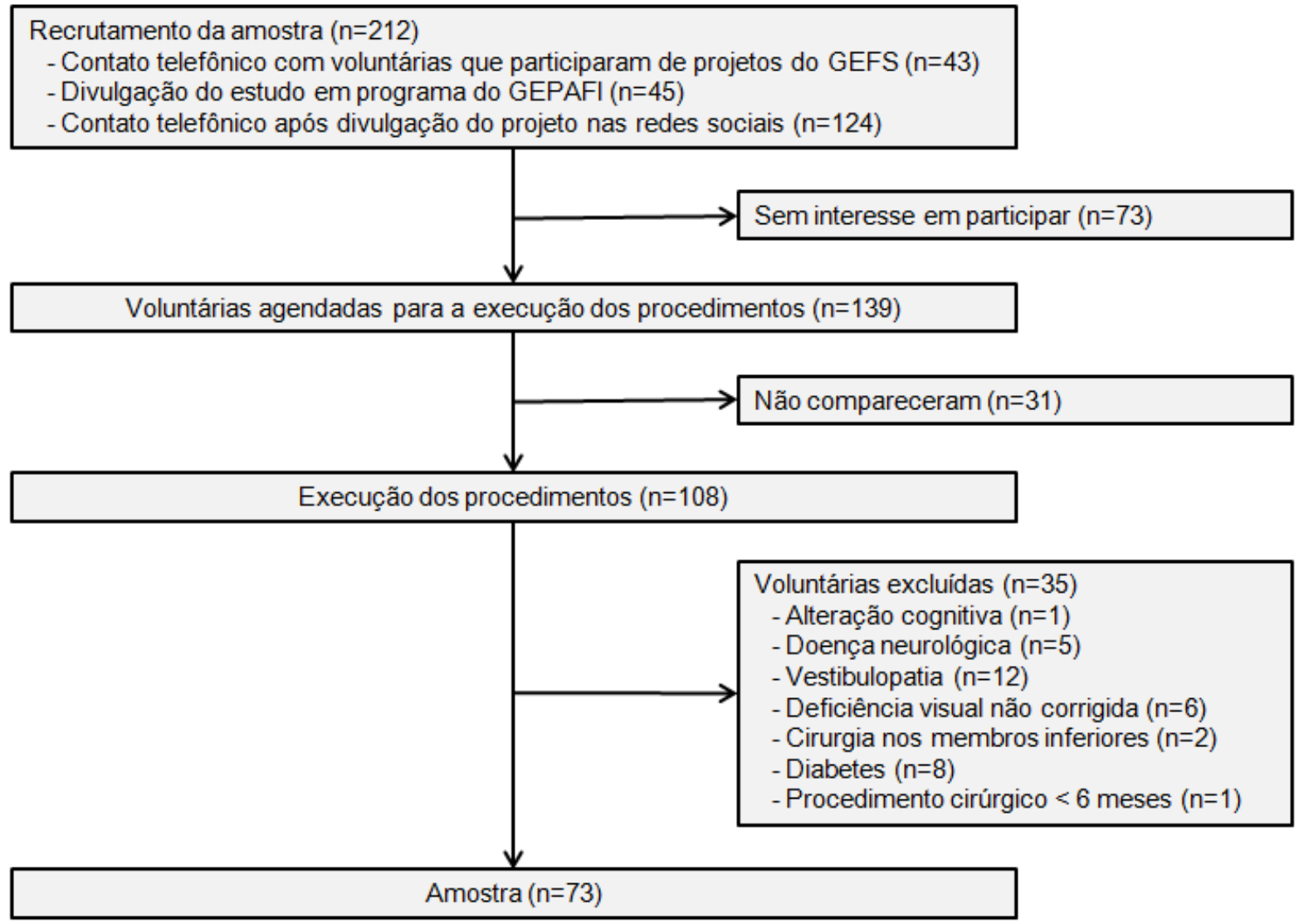

Figura 7. Fluxograma do recrutamento e seleção amostral.

\subsection{CUIDADOS ÉTICOS}

Dado que os sujeitos do estudo são seres humanos, obedeceu-se ao previsto na Resolução 466/12 do Ministério da Saúde do Brasil, submetendo-o à análise e julgamento do Comitê de Ética em Pesquisa com Seres Humanos da Faculdade de Ciências da Saúde da UnB, que é reconhecido pela Comissão Nacional de Ética em Pesquisa. O estudo foi aprovado sob o parecer no 1.223 .636 (Anexo II). Ademais, 
todos os sujeitos foram informados sobre os objetivos e procedimentos da pesquisa e assinaram o Termo de Consentimento Livre e Esclarecido - TCLE (Anexo III).

\subsection{PROCEDIMENTOS}

Os procedimentos de avaliação foram executados em duas visitas à FEFUnB. Na visita $A$, as voluntárias receberam a explicação detalhada sobre os objetivos e procedimentos do estudo e assinaram o TCLE. Nesta mesma oportunidade, foram aplicados os questionários de caracterização da amostra, e efetuada a mensuração da adiposidade corporal (antropometria) e da força muscular (FPM e força dos extensores do joelho). Na visita B, foi conduzida a avaliação da adiposidade corporal (DEXA), da distribuição de pressão plantar, da estabilidade postural e do risco de quedas. Cabe salientar que estas visitas foram efetuadas no período matutino, em dias consecutivos e previamente agendados.

A Figura 8 apresenta o fluxograma dos procedimentos do estudo.

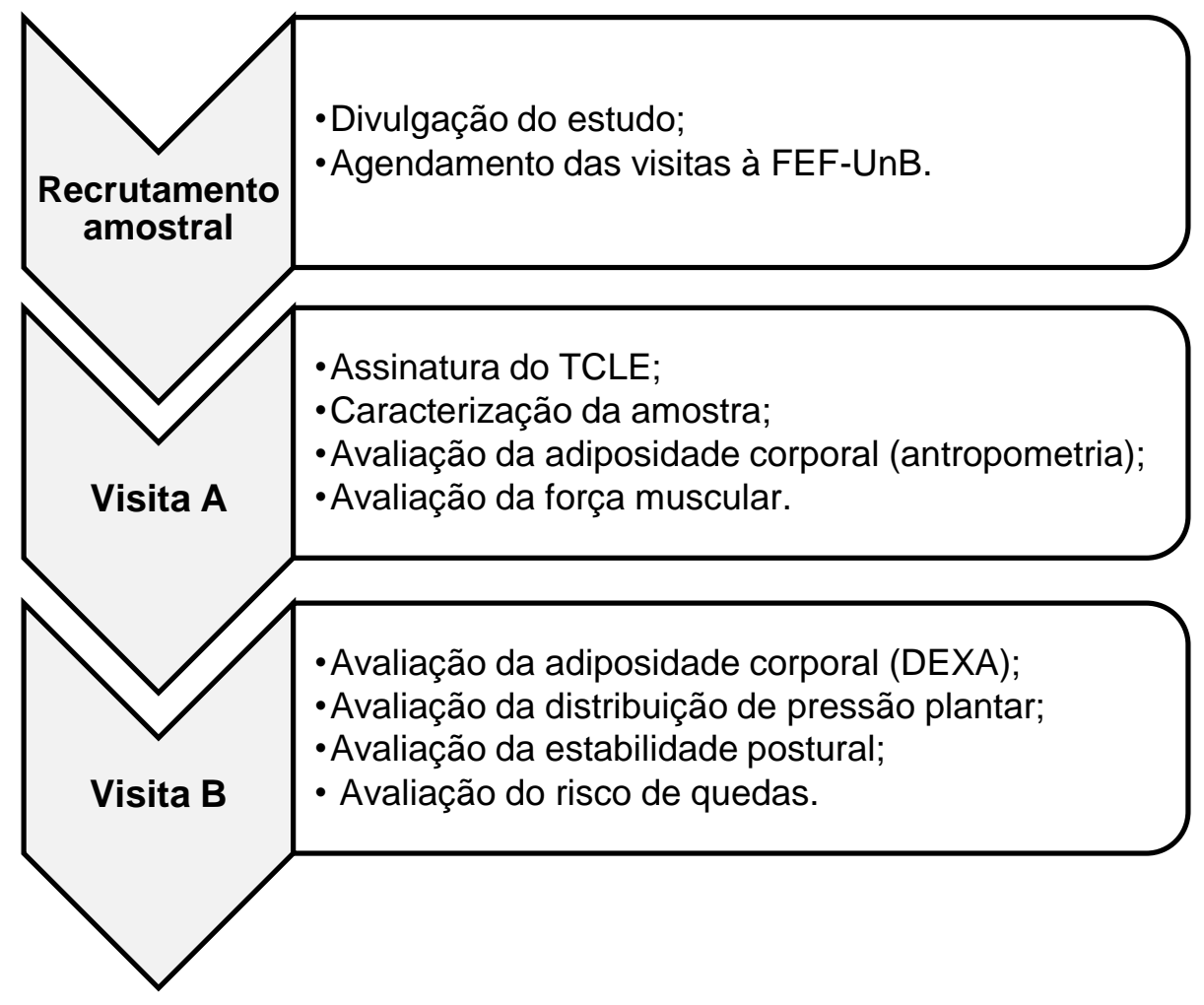

Figura 8. Fluxograma dos procedimentos do estudo. 
As avaliações efetuadas em cada visita foram organizadas em três polos de coleta, cada um deles coordenado por um avaliador previamente treinado. Dessa forma, era possível atender a demanda de três voluntárias por horário. Digno de nota, havia dois horários de atendimento (às oito e às 10 horas), possibilitando o agendamento máximo de seis voluntárias por dia. Adicionalmente, o tempo gasto para a execução dos procedimentos foi de, aproximadamente, uma hora e 30 minutos por voluntária, a contar o tempo despendido com as avaliações e o tempo de intervalo entre as mesmas.

A Figura 9 apresenta a logística da coleta de dados.

Visita A

08:00|10:00

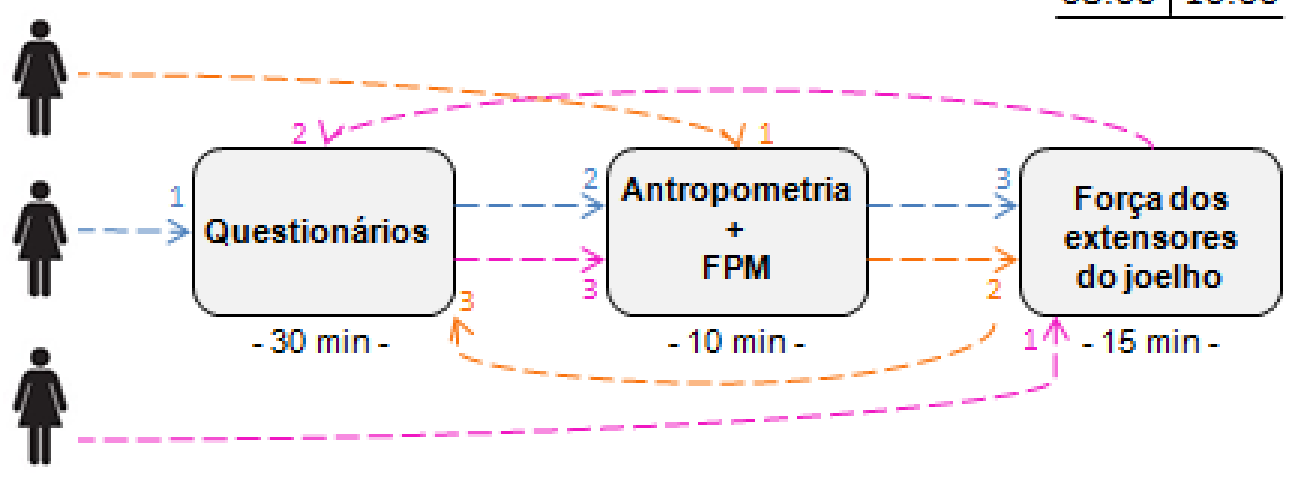

Visita B

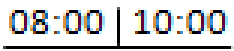

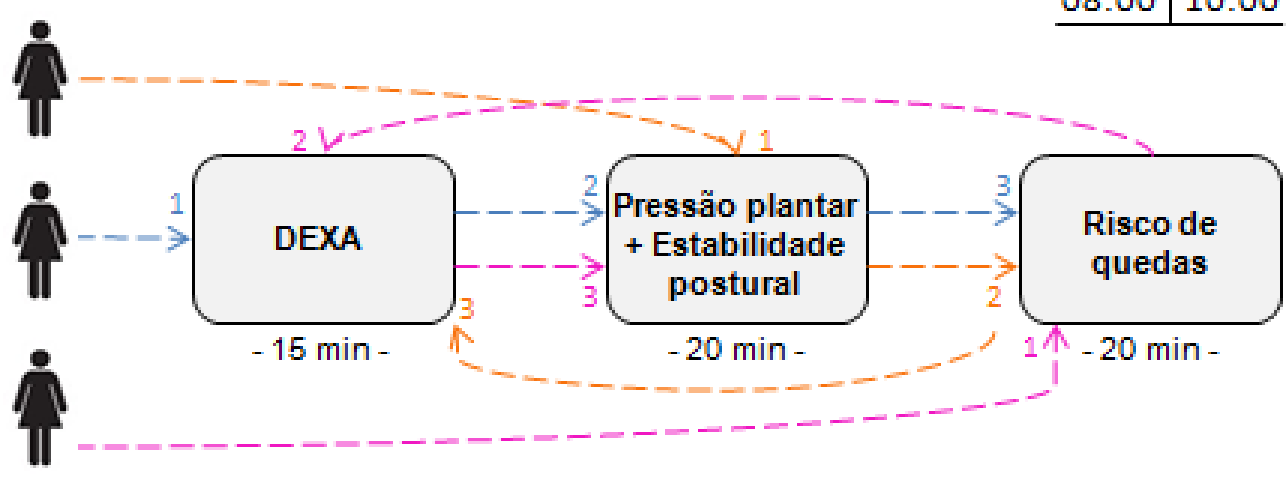

Figura 9. Representação esquemática da logística de coleta de dados.

Cabe salientar que, durante a execução dos procedimentos, tentou-se assegurar a estabilidade das condições ambientais (mínimo de perturbações visuais ou auditivas). 


\subsubsection{Caracterização da amostra}

Para caracterizar a amostra, foi aplicada uma anamnese e questionários de avaliação do estado cognitivo, da funcionalidade e do nível de atividade física. Estes questionários foram aplicados na forma de entrevista, por um avaliador previamente treinado. Todos os procedimentos foram efetuados na Sala de Estudos do GEFSUnB, e o tempo necessário para esta avaliação foi de aproximadamente 30 minutos.

\subsubsection{Anamnese}

A anamnese empregada neste estudo contém questões acerca dos dados gerais, hábitos de saúde e informações médicas da voluntária (Anexo IV). Este questionário foi utilizado não somente para a caracterização da amostra, como também para verificação dos critérios de elegibilidade.

\subsubsection{Avaliação da função cognitiva}

Para avaliar a função cognitiva foi utilizado o Mini-Exame do Estado Mental MEEM (Anexo V). Este instrumento foi traduzido e validado no Brasil por Bertolucci et al. (1994) e é amplamente utilizado com esta finalidade. Ele é composto por sete categorias, cada uma delas planejada com o objetivo de avaliar funções cognitivas específicas. Tais categorias incluem: orientação temporal, orientação espacial, registro de três palavras, atenção e cálculo, memória de evocação, linguagem e capacidade construtiva visual. O seu escore varia de zero a 30 pontos, sendo que valores abaixo de 13, para analfabetos, 18, para aqueles com até oito anos de escolaridade, e 26, para aqueles com mais de oito anos de escolaridade, apontam para possível comprometimento cognitivo. Foram excluídas deste estudo, as voluntárias classificadas com déficit cognitivo. 


\subsubsection{Avaliação da funcionalidade}

A funcionalidade foi avaliada por meio da Escala de Katz (Anexo VI) e pela Escala de Lawton e Brody (Anexo VII). A Escala de Katz analisa a habilidade de 0 indivíduo executar seis atividades básicas de vida diária (ABVDs): banhar-se, vestirse, utilizar o sanitário, efetuar transferências, controlar esfíncteres e alimentar-se. Para cada um dos itens é atribuído o valor de zero ou um, onde zero representa dependência na execução da tarefa e um representa independência. O seu escore final varia de zero a seis pontos, sendo que zero indica dependência total, um e dois indicam dependência grave, três e quatro, dependência moderada, cinco, dependência ligeira, e seis, independência (Shelkey e Wallace, 1998). A Escala de Lawton e Brody, por sua vez, avalia oito atividades instrumentais de vida diária (AIVDs): usar o telefone, fazer compras, preparar refeições, efetuar tarefas domésticas, lavar roupas, utilizar meios de transporte, realizar o manejo de medicamentos e se responsabilizar por assuntos financeiros. $O$ seu resultado varia de zero a oito pontos e também permite classificar o indivíduo em cinco categorias: dependência total (zero a um), dependência grave (dois a três), dependência moderada (quatro a cinco), dependência ligeira (seis a sete) e independência (oito)(Graf, 2009).

\subsubsection{Avaliação do nível de atividade física}

Para avaliar o nível de atividade física foi utilizada a versão curta do Questionário Internacional de Atividade Física - IPAQ (Anexo VIII). Este instrumento foi desenvolvido para monitorar, de forma padronizada, a atividade e a inatividade física em diversos países do mundo. No Brasil, ele foi validado por Matsudo et al. (2001). Esse questionário leva em consideração a duração e a frequência das atividades físicas de diferentes intensidades realizadas em uma semana, considerando apenas sessões superiores a 10 minutos contínuos. O seu resultado permite classificar as voluntárias em quatro níveis de atividade física: muito ativa, ativa, irregularmente ativa ou sedentária. Para tanto, adota-se o seguinte critério de classificação: 
a) Muito ativa: aquela que cumpriu as recomendações de atividade física vigorosa $\geq$ cinco dias por semana e $\geq 30$ minutos por sessão; ou $\geq$ três dias por semana e $\geq 20$ minutos por sessão mais atividade física moderada ou caminhada $\geq$ cinco dias por semana $e \geq 30$ minutos por sessão.

b) Ativa: aquela que cumpriu as recomendações de atividade física vigorosa $\geq$ três dias por semana e $\geq 20$ minutos por sessão; ou atividade física moderada ou caminhada $\geq$ cinco dias por semana $e \geq 30$ minutos; ou qualquer atividade somada (caminhada + moderada + vigorosa) $\geq$ cinco dias por semana e $\geq 150$ minutos por semana.

c) Irregularmente ativa: aquela que realiza atividade física, porém, de forma insuficiente para ser classificada como ativa, pois não cumpre as recomendações quanto à frequência ou duração.

d) Sedentária: aquela que não realizou nenhuma atividade física por pelo menos 10 minutos contínuos durante a semana.

\subsubsection{Avaliação da adiposidade corporal}

Os índices de adiposidade corporal foram obtidos a partir de uma avaliação antropométrica e por meio do DEXA.

\subsubsection{Antropometria}

A avaliação antropométrica foi efetuada no Laboratório de Força da FEF-UnB para obtenção das seguintes medidas: massa corporal, estatura, CC e circunferência de quadril (CQ). Para a mensuração da massa corporal, a participante deveria posicionar-se sobre uma balança digital da marca Filizola (capacidade máxima de $150 \mathrm{~kg}$ e resolução de $50 \mathrm{~g}$ ), com o peso distribuído em ambos os pés, e olhar para a linha do horizonte. Para mensurar a estatura, ela deveria estar posicionada em ortostase, com calcanhares, panturrilhas, nádegas, costas e parte posterior da cabeça encostados na parede, com os braços ao longo do corpo, e com a cabeça no plano de Frankfurt, enquanto o avaliador deslizava o cursor do 
estadiômetro (Cardiomed, Brasil) contra a sua cabeça. Para avaliar a CC e a CQ, adotou-se como ponto de referência a cicatriz umbilical e o ponto de maior extensão das nádegas, respectivamente. Para tanto, a idosa também deveria permanecer em ortostase, enquanto o examinador realizava as medidas com uma trena antropométrica da marca Sanny ${ }^{\circledR}$. Em todas as avaliações, a participante deveria estar descalça e vestindo roupas leves. $O$ tempo gasto com estes procedimentos foi de aproximadamente três minutos.

A Figura 10 apresenta o registro fotográfico de uma voluntária durante a avaliação antropométrica.
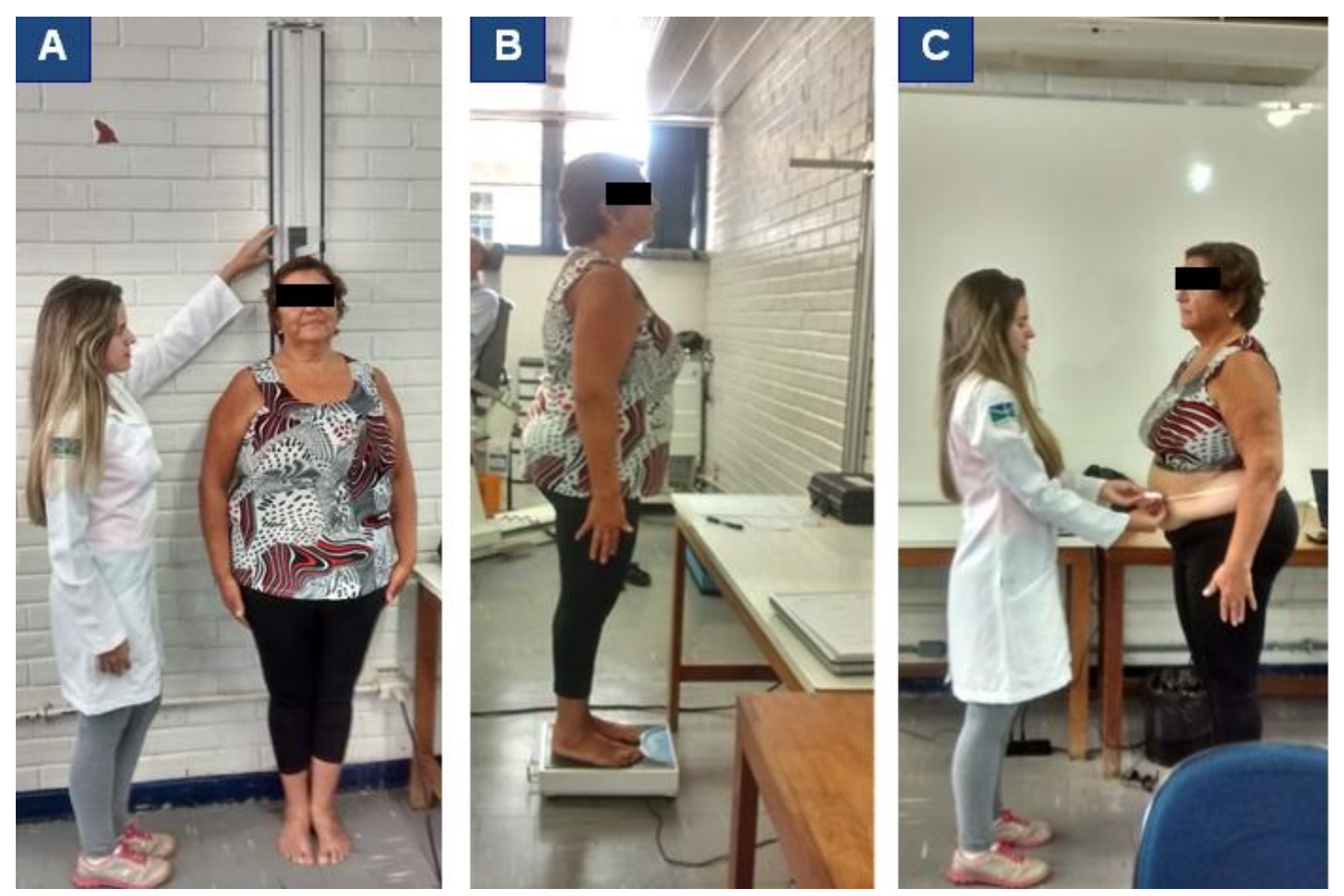

Figura 10. Registro fotográfico de uma voluntária durante a avaliação antropométrica. A) Mensuração da massa corporal. B) Mensuração da estatura. C) Perimetria.

A partir das medidas obtidas nessa avaliação, foi calculado o IMC. Este índice de adiposidade é calculado dividindo-se a massa corporal, expressa em quilogramas, pelo quadrado da altura, expresso em metros, onde valores $\geq 30 \mathrm{~kg} / \mathrm{m}^{2}$ indicam obesidade, valores $\geq 25 \mathrm{~kg} / \mathrm{m}^{2} \mathrm{e}<30 \mathrm{~kg} / \mathrm{m}^{2}$, sobrepeso, $\geq 18,5 \mathrm{~kg} / \mathrm{m}^{2} \mathrm{e}<25$ $\mathrm{kg} / \mathrm{m}^{2}$, peso normal $\mathrm{e}<18,5 \mathrm{~kg} / \mathrm{m}^{2}$, baixo peso. Outro índice de adiposidade corporal 
adotado nesse estudo foi a $\mathrm{CC}$, a qual permite classificar as voluntárias quanto à presença de obesidade abdominal (CC $\geq 88 \mathrm{~cm}$ ) (OMS, 1999).

\subsubsection{Absortometria de raio-x de dupla energia}

A avaliação do DEXA foi efetuada no Laboratório de Imagem da FEF-UnB, utilizando um equipamento da marca Lunnar, modelo DPX-IQ (Lunar Corporation, Madison, WI, USA), o qual estava devidamente calibrado de acordo com o manual do fabricante.

Para execução do procedimento, a voluntária deveria retirar todos os metais (pulseiras, brincos, anéis, etc) e, em seguida, posicionar-se em decúbito dorsal sobre a mesa do equipamento, de forma que seu corpo ficasse totalmente centralizado. Os membros superiores ficavam posicionados ao longo do corpo, estendidos, sem que houvesse contato com o tronco. Os membros inferiores também permaneciam estendidos. Ademais, fitas de velcro foram posicionadas nos joelhos e acima dos maléolos para manter os membros inferiores próximos e dar suporte aos pés, de forma que ficassem em uma angulação de aproximadamente 45 em relação ao plano vertical. A idosa deveria permanecer nessa posição durante

o escaneamento de toda a área corporal, o qual durava aproximadamente 15 minutos. Cabe ressaltar que esta avaliação foi efetuada por um avaliador previamente treinado.

Após a análise de toda a área corporal, o DEXA possibilitava a determinação da densidade mineral óssea e dos tecidos. Os tecidos, por sua vez, foram fracionados em Massa de Gordura e Massa Livre de Gordura. Além disso, linhas geradas pelo computador, com posterior ajuste manual, forneciam valores específicos para os braços, pernas e tronco. Para este estudo, a variável analisada foi o \%G total.

A Figura 11 apresenta o registro fotográfico de uma voluntária durante a avaliação do DEXA, bem como a saída gráfica da sua composição corporal. 

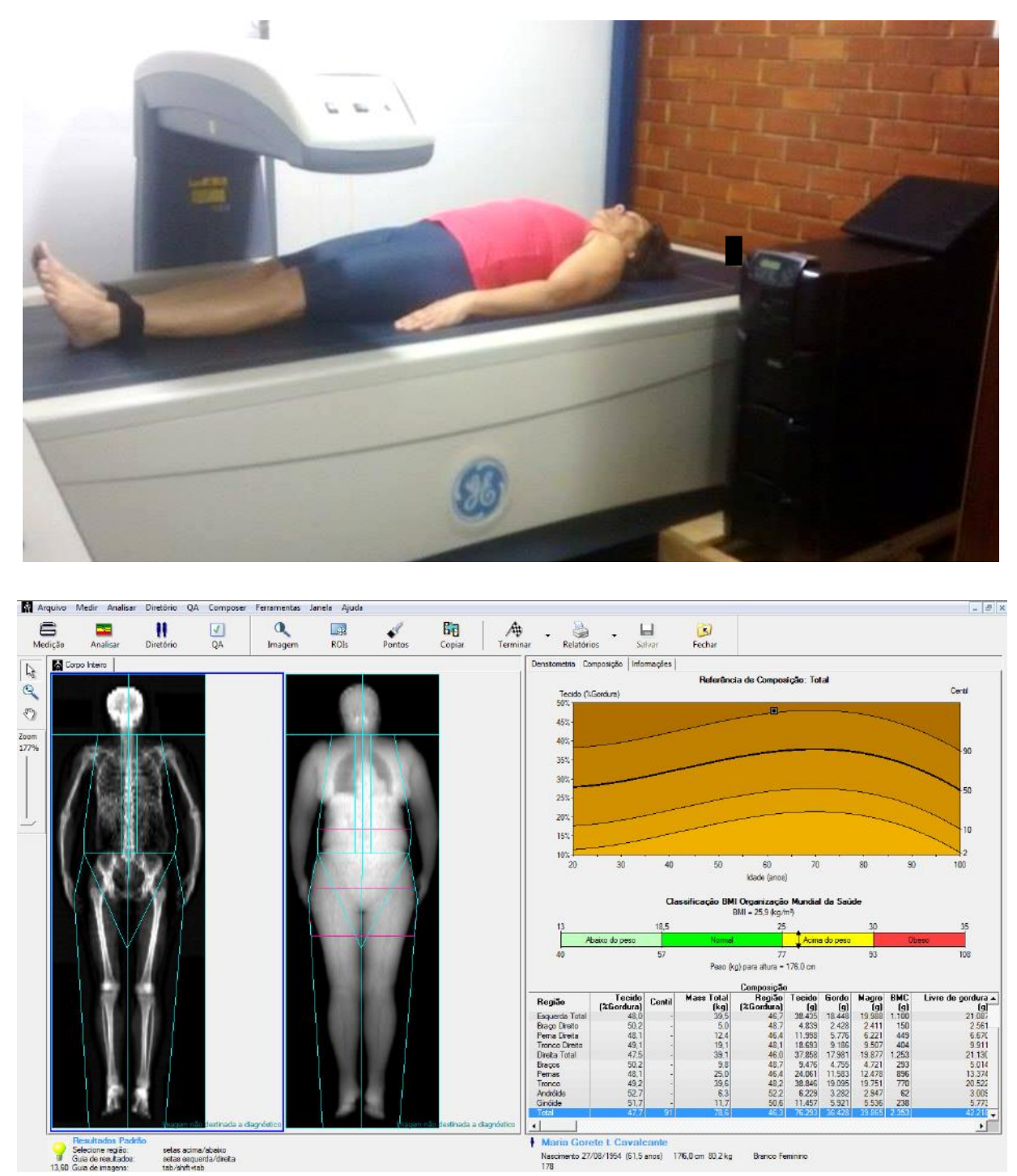

Figura 11. Registro fotográfico de uma voluntária durante a avaliação do DEXA. Abaixo, saída gráfica da composição corporal da voluntária avaliada.

\subsubsection{Avaliação da força muscular}

A força muscular foi avaliada por meio da FPM e da força dos extensores do joelho do membro inferior dominante.

\subsubsection{Força de preensão manual}

A avaliação da FPM foi efetuada no Laboratório de Força da FEF-UnB, utilizando um dinamômetro Jamar. Os procedimentos seguiram as orientações da 
Sociedade Americana de Terapeutas da Mão (Fess, 1992). Durante a avaliação, a participante permanecia sentada em uma cadeira sem apoio para os braços, com a coluna ereta, joelhos flexionados a 90ㅜ, e membro a ser testado suspenso no ar com a mão posicionada no dinamômetro (ombro em adução e em posição neutra de rotação, cotovelo flexionado a 90, antebraço em meia pronação, e punho variando de zero a $30^{\circ}$ de extensão). A voluntária era instruída a realizar a preensão por cinco segundos. Foram realizadas três medições para cada braço, alternando entre o lado dominante e o não-dominante, com intervalo de um minuto entre as medidas. Ademais, estímulos verbais foram fornecidos durante as contrações. Para a análise do desempenho, foi levada em consideração a média das três tentativas do braço dominante (Mathiowetz et al. 1984). Cabe ressaltar que, antes das medidas de teste, foi efetuada uma medida de familiarização. O tempo gasto com estes procedimentos foi de aproximadamente sete minutos.

A Figura 12 apresenta o registro fotográfico de uma voluntária durante a avaliação da FPM.
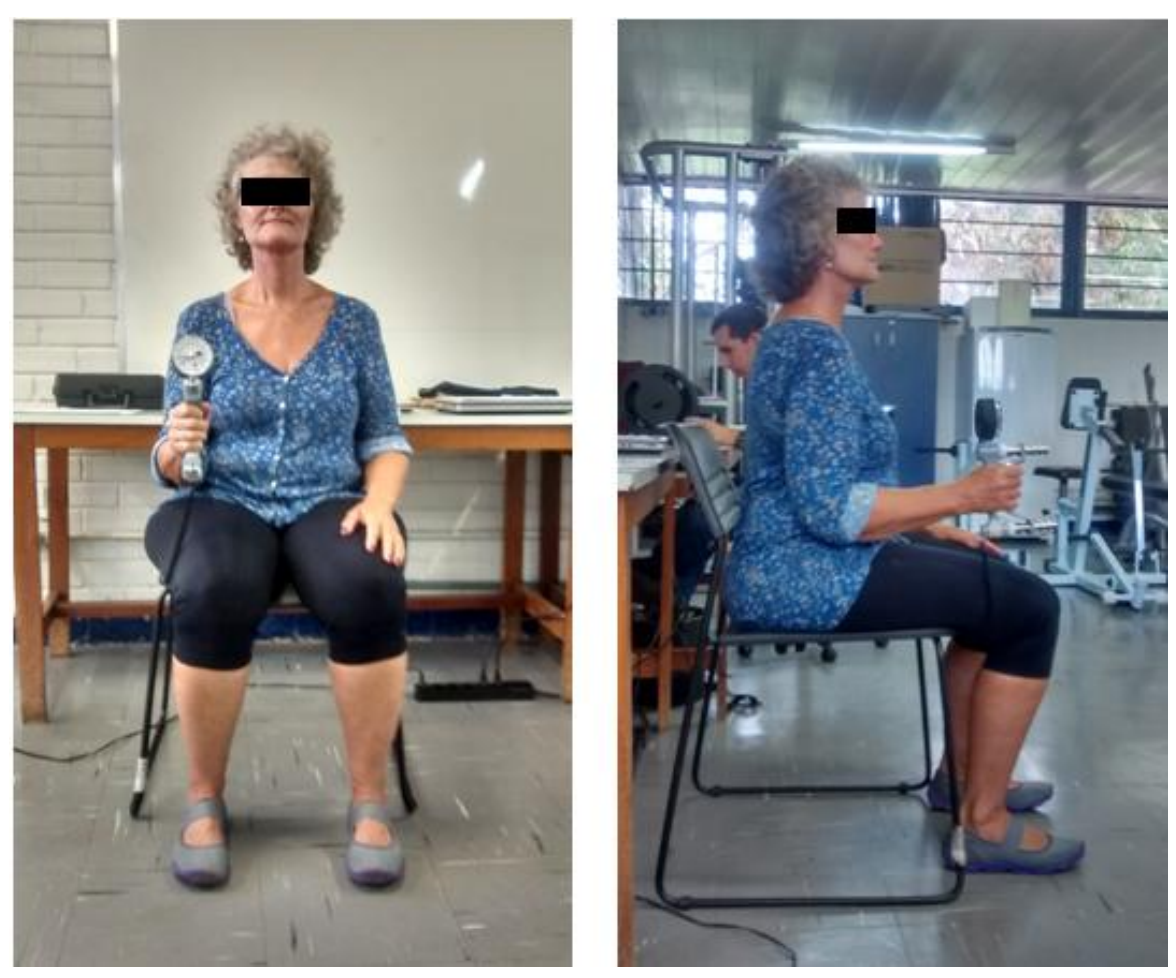

Figura 12. Registro fotográfico de uma voluntária durante a avaliação da força de preensão manual. 


\subsubsection{Força dos extensores do joelho}

A força dos extensores do joelho do membro inferior dominante foi mensurada no Laboratório de Força da FEF-UnB, mediante o dinamômetro isocinético Biodex System 4 (Biodex Medical Systems, New York, USA), o qual estava devidamente calibrado, conforme o manual do fabricante.

Para a execução dos procedimentos, as voluntárias foram cuidadosamente posicionadas no assento do equipamento: o eixo de rotação do braço do dinamômetro foi alinhado com o epicôndilo lateral do fêmur da perna dominante; o local da aplicação da força foi posicionado a aproximadamente dois centímetros do maléolo medial; e o tronco, a pelve e a coxa da participante foram fixados com cintos para evitar movimentos compensatórios.

Durante a avaliação, as participantes foram submetidas a duas séries de aquecimento: a primeira com 10 repetições a $210 \%$, e a segunda com seis repetições a 120\%s. Em seguida, foram efetuadas duas séries de uma contração isométrica máxima numa angulação de $60^{\circ}$ de flexão de joelho, com duração de quatro segundos. Por fim, foram realizadas duas séries de quatro contrações máximas a $60 \% \mathrm{~s}$, e mais duas séries de quatro contrações máximas a 180\%/s. Foi adotado um intervalo de 60 segundos entre as séries. Além disso, as voluntárias eram instruídas a segurar nos cintos de fixação do tronco e a realizar as contrações com a maior força possível.

Essa avaliação foi conduzida por dois avaliadores previamente treinados, os quais eram responsáveis por posicionar a voluntária no equipamento e explicar detalhadamente o protocolo a ser executado. Ademais, estímulos verbais eram fornecidos durante as contrações. O tempo necessário para a execução deste procedimento foi de aproximadamente 15 minutos.

As variáveis analisadas foram o pico de torque (PT) isométrico e o PT isocinético a $60 \%$ s e a $180 \%$, expressos em valores absolutos (N.m) e relativos à massa corporal ((N.m/kg).100). Foi levado em consideração o maior valor obtido para cada avaliação.

A Figura 13 apresenta o registro fotográfico de uma voluntária durante a avaliação da força dos extensores do joelho do membro inferior dominante. 


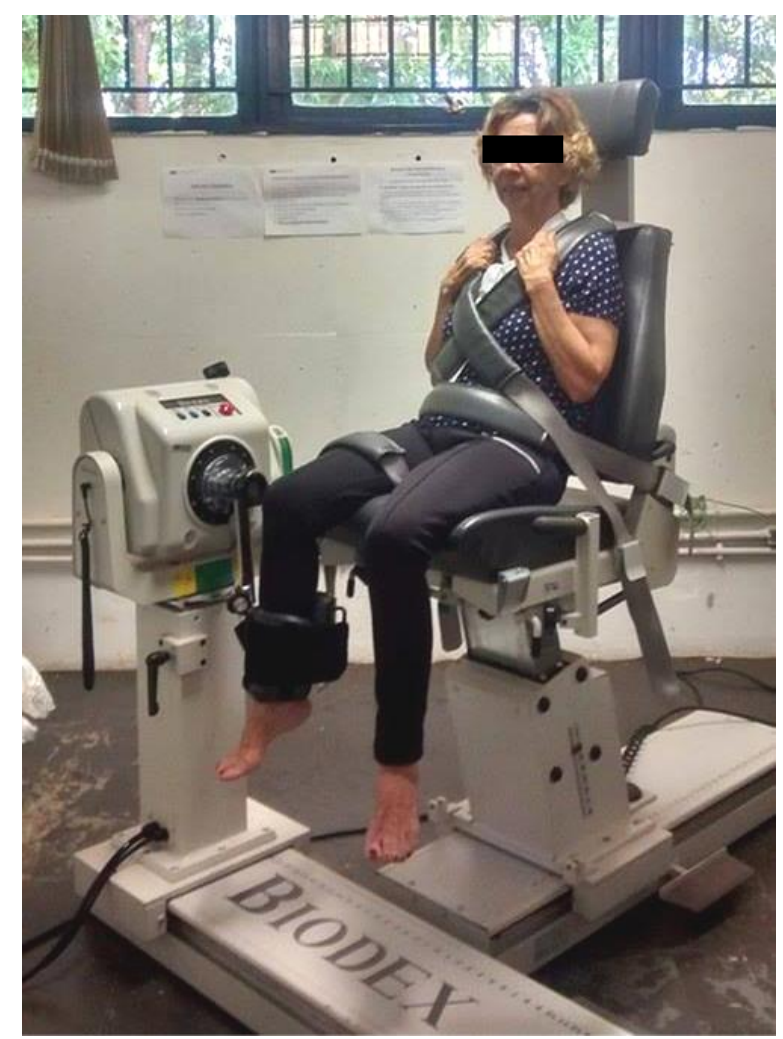

Figura 13. Registro fotográfico de uma voluntária durante a avaliação da força dos extensores do joelho do membro inferior dominante.

\subsubsection{Avaliação da distribuição de pressão plantar}

A avaliação da distribuição de pressão plantar ocorreu no Laboratório de Análise do Movimento Humano da FEF-UnB, utilizando uma plataforma de pressão Emed AT-4 (Novel GmbH, Munique, Alemanha; 50 Hz; 4 sensores/cm²; 415x255 $\mathrm{mm}$ ), a qual estava devidamente calibrada, conforme as orientações do fabricante, e posicionada numa passarela de espuma densa, especialmente desenhada para proporcionar uma superfície firme e nivelada de caminhada. Para a aquisição dos dados, foi utilizado o software EMED/R - Database Light 23.3.43.

O procedimento de avaliação adotado foi o protocolo de três passos (Van Der Leeden et al., 2004; Bus e De Lange, 2005), isto é, a voluntária se posicionava no início da passarela, começava a andar, de modo que seu terceiro passo entrasse em contato com o centro da plataforma, e continuava caminhando até o final da mesma. A participante era instruída a olhar para frente e a andar numa velocidade confortável. Ademais, ela não era orientada quanto à necessidade de pisar na 
plataforma. Foram efetuadas três medidas bem sucedidas para cada um dos pés, sendo que para a análise, foi utilizada a média das três tentativas (Van Der Leeden et al., 2004). Cabe esclarecer que as tentativas foram consideradas bem sucedidas quando um único pé entrava em contato com a plataforma sem exceder a região contendo sensores.

Para registrar a velocidade da marcha com que a voluntária executava a mensuração da distribuição de pressão plantar, foi utilizado o sistema de fotocélulas Speed Test Fit da marca Cefise. As fotocélulas foram posicionadas perpendicularmente a plataforma, na altura da espinha ilíaca ântero-superior da idosa avaliada, a uma distância de 1,5 m entre si. Elas indicavam o tempo que a participante gastava para percorrer a distância entre elas (i.e. 1,5 m), e, com base nesse valor, a velocidade podia ser calculada.

Os procedimentos de avaliação da distribuição de pressão plantar foram conduzidos por um avaliador previamente treinado, o qual explicava detalhadamente o protocolo a ser executado, e era o responsável por registrar o tempo indicado pelas fotocélulas. Esta avaliação durava aproximadamente 5 minutos.

A Figura 14 apresenta o registro fotográfico de uma voluntária durante a execução dos procedimentos.

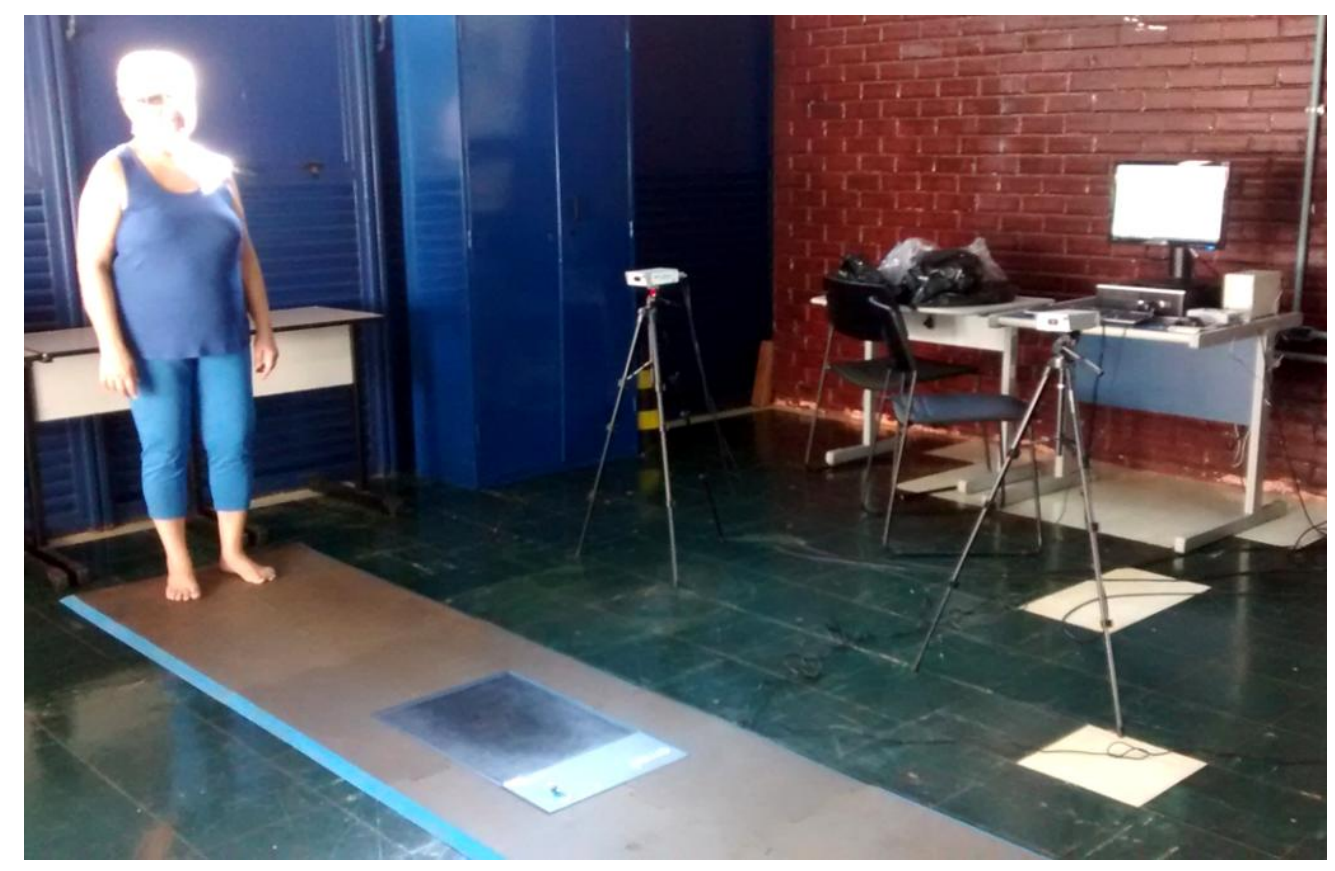

Figura 14. Registro fotográfico de uma voluntária durante a avaliação da distribuição de pressão plantar. 
As médias das impressões plantares dos pés direito e esquerdo foram divididas em cinco regiões anatômicas: retropé, mediopé, antepé, hálux e dedos (Figura 15). Essa divisão foi gerada automaticamente, com posterior ajuste manual para separar o hálux dos demais dedos.

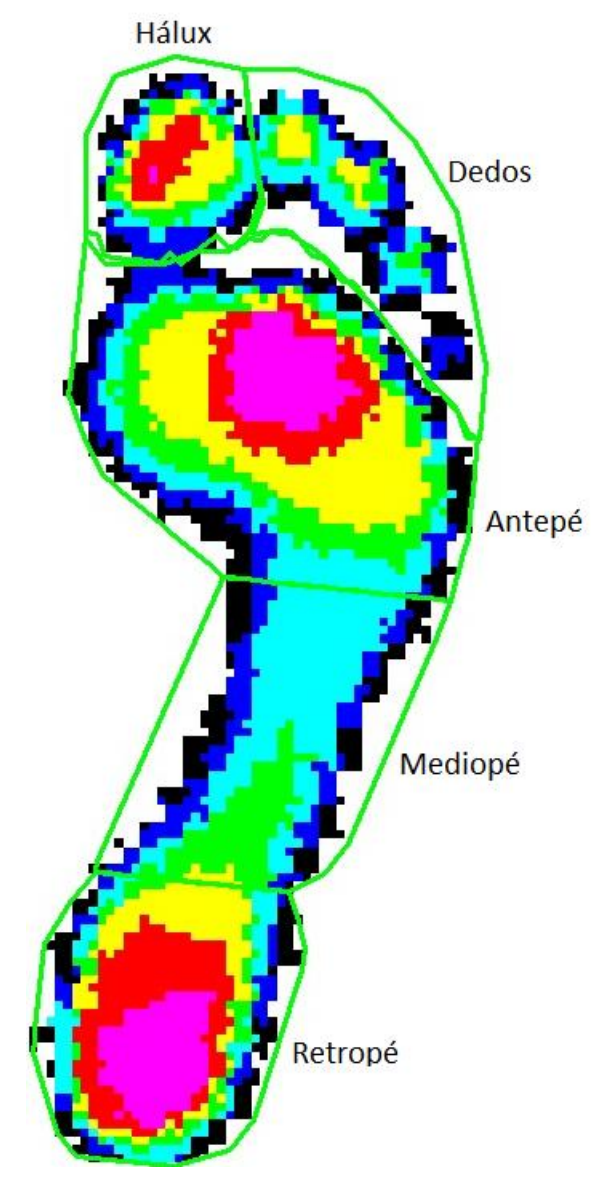

Figura 15. Localização das regiões anatômicas na impressão plantar do pé direito de uma voluntária (software EMED/R).

As varáveis analisadas para cada uma das regiões, bem como para o pé completo, foram o pico de pressão, a força máxima (absoluta e relativizada para a massa corporal) e a área de contato. Foi calculado, ainda, o índice de arco dinâmico, dado pela razão da área de contato do mediopé pela soma da área de contato do antepé, mediopé e retropé. Este índice permite classificar o pé em plano $(\geq 0,26)$, neutro $(0,21-0,26)$ ou cavo $(\leq 0,21)$ (Cavanagh e Rodgers, 1987). Cabe adicionar que, como não houve diferença estatisticamente significante entre as variáveis referentes aos pés direito e esquerdo, foi considerado para análise apenas o pé direito. 


\subsubsection{Avaliação da estabilidade postural}

A avaliação da estabilidade postural ocorreu no Laboratório de Análise do Movimento Humano da FEF-UnB, utilizando uma plataforma de força Accusway Plus da marca AMTI (Advanced Medical Technology Inc, Watertown, MA), com capacidade de $180 \mathrm{~kg}$, e dimensões de $50 \times 50 \mathrm{~cm}$. Todos os procedimentos foram efetuados com a plataforma devidamente calibrada, conforme o manual do fabricante. Para a aquisição dos dados, foi utilizado o software AMTI Balance Clinic, com frequência de amostragem de $100 \mathrm{~Hz}$. Ademais, os dados foram filtrados a um filtro passa-baixas de $10 \mathrm{~Hz}$.

Durante a avaliação, as participantes foram submetidas a quatro condições experimentais, testadas ordem aleatória: base aberta com olhos abertos (BAOA), base aberta com olhos fechados (BAOF), base fechada com olhos abertos (BFOA) e base fechada com olhos fechados (BFOF). Para tanto, elas deveriam se posicionar no centro da plataforma de força, descalças, com os braços relaxados ao lado do tronco, a uma distância de 2 metros de um ponto fixo colocado à altura de seus olhos. Elas eram instruídas a olhar fixamente para este ponto e a manter a postura estática durante 30 segundos. Foram efetuadas três tentativas para cada protocolo, a um intervalo de aproximadamente 30 segundos entre elas. As idosas que fizessem uso de lentes corretivas deveriam manter o seu uso.

Cabe adicionar que, para facilitar o posicionamento das voluntárias sobre a plataforma, foram feitas marcações com fita crepe sobre a mesma - traçou-se uma linha na direção ML e três na direção AP. A linha do eixo $x$ indicava o limite anterior dos pés da idosa avaliada, ao passo que as linhas do eixo y indicavam a abertura da base de suporte. Quando as voluntárias eram submetidas à condição de base aberta, elas deveriam posicionar os seus pés de forma que a borda medial dos mesmos ficasse próxima às linhas laterais, as quais estavam afastadas a uma distância de $10 \mathrm{~cm}$. Na condição de base fechada, por sua vez, os pés deveriam ficar justapostos sobre a linha intermédia.

Os procedimentos de avaliação da estabilidade postural foram conduzidos por um avaliador previamente treinado, o qual explicava detalhadamente o protocolo a ser executado e se colocava à disposição para o esclarecimento de eventuais dúvidas. Além disso, o avaliador se posicionava lateralmente à plataforma para auxiliar na segurança daquelas participantes que demonstravam maior 
comprometimento do equilíbrio. Esta avaliação durava aproximadamente 15 minutos e as voluntárias eram livres para descansar entre as condições experimentais, caso julgassem necessário.

A Figura 16 apresenta a representação esquemática das condições experimentais testadas e o registro fotográfico de uma voluntária durante a execução dos procedimentos.
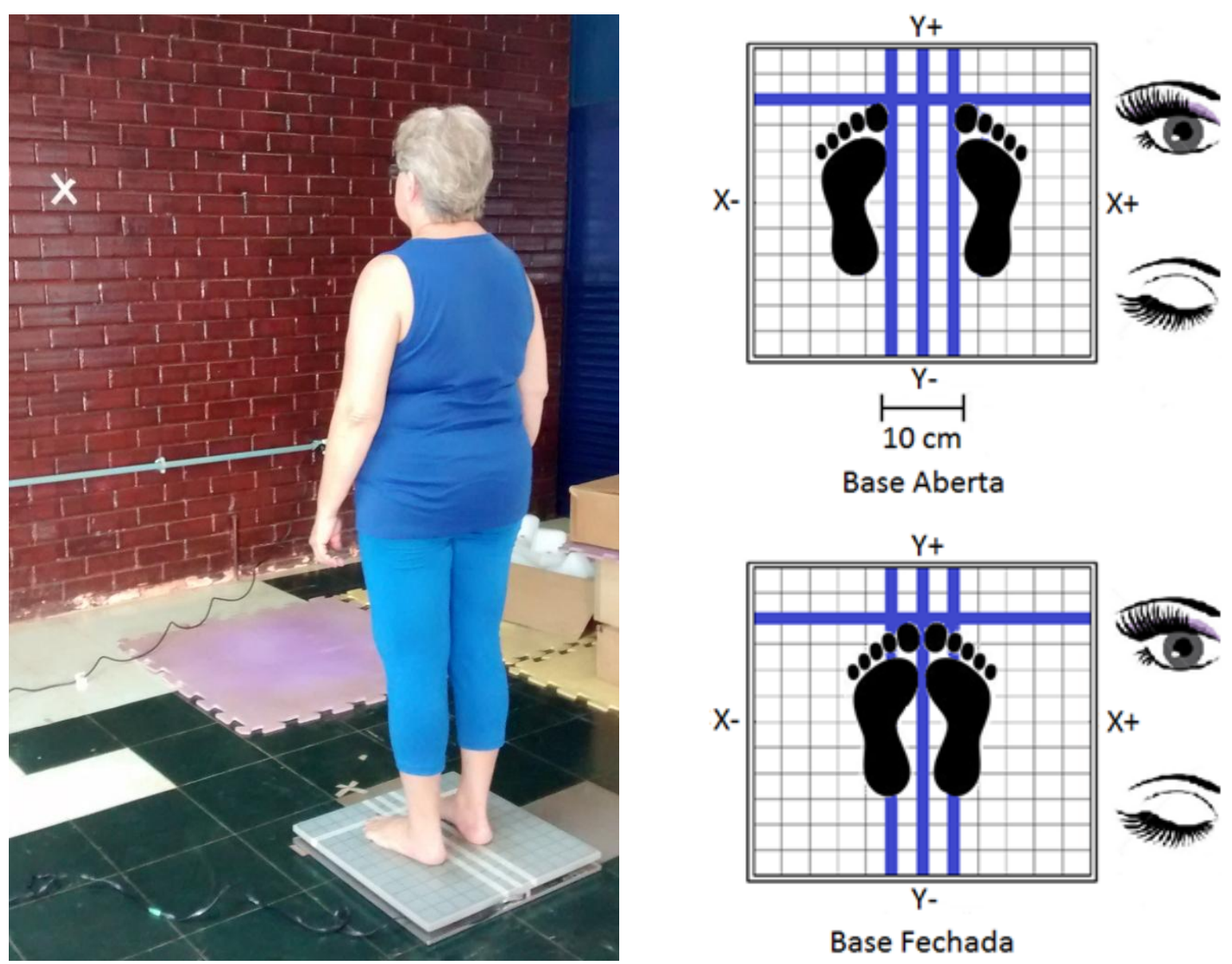

Figura 16. Registro fotográfico de uma voluntária durante a avaliação da estabilidade postural. À direita, representação esquemática das condições experimentais testadas.

As variáveis analisadas em cada condição experimental foram a velocidade média de oscilação do COP e a amplitude de deslocamento nas direções AP e ML, as quais foram obtidas a partir da média de três tentativas.

A Figura 17 apresenta a saída gráfica da oscilação do COP de uma voluntária durante a execução de uma das condições experimentais. 


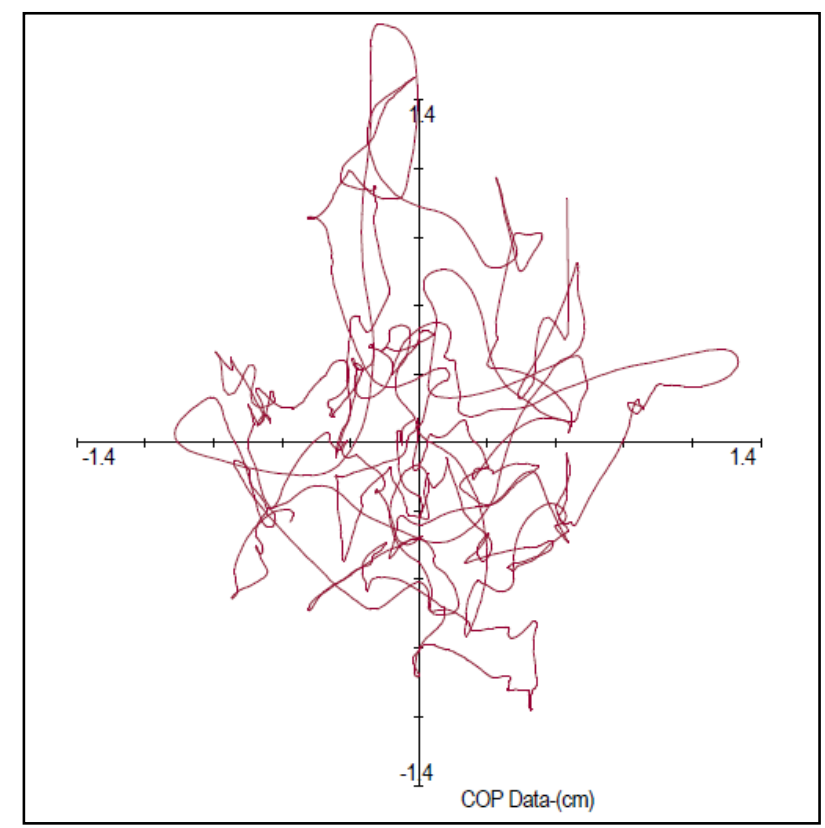

Figura 17. Saída gráfica da oscilação do COP no software AMTI Balance Clinic. O painel ilustra a oscilação do COP de uma voluntária durante a execução da condição experimental BFOF.

\subsubsection{Avaliação do risco de quedas}

O risco de quedas foi avaliado por meio do QuickScreen Clinical Falls Risk Assessment (QuickScreen), do teste Timed Up and Go (TUG) e da Escala de Eficácia de Quedas - Internacional (FES-I). Todos os procedimentos foram executados na Sala de Musculação da FEF-UnB, e o tempo necessário para esta avaliação foi de aproximadamente 20 minutos.

\subsubsection{QuickScreen Clinical Falls Risk Assessment}

O QuickScreen, desenvolvido por Tiedemann et al. (2010), é um instrumento multidimensional acurado para rastrear múltiplas quedas em idosos que vivem na comunidade. Ele é composto por oito itens: ocorrência de quedas no ano anterior, quantidade de medicamentos em uso, utilização de psicotrópicos, avaliação da acuidade visual, teste da sensibilidade periférica, e avaliação do equilíbrio, do tempo de reação e da força. $O$ resultado indica a quantidade de fatores de risco para 
quedas a qual o paciente está exposto e a probabilidade do mesmo sofrer uma queda. Como não existe adaptação do instrumento para a população brasileira e os seus itens não apresentam viés cultural, foi utilizado, neste estudo, uma tradução linguística e semântica realizada por um tradutor bilíngue (Anexo IX).

O procedimento adotado para a avaliação de cada um dos seus itens foi o seguinte:

a) Ocorrência de quedas no ano anterior. Para avaliar a ocorrência de quedas no ano anterior, o avaliador fazia a seguinte pergunta: "Você teve alguma queda nos últimos 12 meses?". Caso a resposta fosse afirmativa, um fator de risco era contabilizado.

b) Quantidade de medicamentos em uso. Para avaliar a quantidade de medicamentos em uso, foram analisadas as caixas ou as bulas dos medicamentos trazidas pela idosa, conforme solicitação prévia. Caso a voluntária fizesse uso de quatro medicamentos ou mais, excluindo vitaminas, contabilizava-se um fator de risco.

c) Utilização de psicotrópicos. A avaliação do uso de psicotrópicos também foi feita por meio da análise das caixas ou bulas dos medicamentos. Caso fosse constatado o uso de algum psicotrópico, mais um fator de risco era contabilizado.

d) Avaliação da acuidade visual. A acuidade visual foi avaliada por meio do Quadro de Snellen. Para tanto, a idosa, fazendo uso de suas lentes corretivas habituais, deveria sentar-se a uma distância de cinco metros desse quadro, o qual ficava fixado em uma parede à altura de seus olhos. Após o posicionamento adequado, o avaliador solicitava que a voluntária lesse a linha mais baixa que estivesse enxergando com facilidade. Em seguida, o avaliador apontava para a linha inferior e solicitava que a participante realizasse uma nova leitura. Isso se repetia até que não fosse mais possível ler a linha apontada. Para passar no teste, a idosa deveria ser capaz de ler até a quinta linha do Quadro Snellen. Caso contrário, seria contabilizado um fator de risco. Além disso, as voluntárias que apresentassem comprometimento visual seriam excluídas deste estudo.

e) Teste da sensibilidade periférica. Para avaliar a sensibilidade periférica, 0 avaliador aplicava três estímulos com um monofilamento de Semmes-Weinstein de $4,0 \mathrm{~g}$ (vermelho fechado) sobre o maléolo lateral da perna dominante, enquanto a idosa permanecia sentada com os olhos fechados. Cada estímulo foi aplicado durante um segundo, com a pressão necessária para o monofilamento se curvar. A 
voluntária foi instruída dizer "sim" sempre que sentisse o estímulo. Para passar no teste, ela deveria sentir ao menos dois dos três estímulos aplicados. Cabe adicionar que, antes da execução do procedimento, era aplicado um estímulo para a familiarização com o teste.

f) Avaliação do equilíbrio. O equilíbrio foi avaliado por meio do teste semitandem, em que a idosa, com os olhos fechados, tentava permanecer por 10 segundos com os pés um a frente do outro, a uma distância de 2,5 cm entre o hálux do pé de trás e o calcanhar do pé da frente, e levemente afastados lateralmente, também a uma distância de $2,5 \mathrm{~cm}$. A voluntária era livre para escolher qual pé ficaria posicionado a frente. Para a execução do teste, o avaliador deveria demonstrar o posicionamento e, em seguida, auxiliar a idosa a assumir a posição. $O$ tempo começava a ser contado assim que a voluntária estivesse posicionada de forma estável e com os olhos fechados. Ao completar 10 segundos, o avaliador sinalizava e o teste se encerrava. Caso a participante não conseguisse permanecer na posição por 10 segundos, era contabilizado um fator de risco.

g) Avaliação do tempo de reação. O tempo de reação foi avaliado pelo teste de step alternado, em que era solicitado que a idosa realizasse oito batidas de pé na maior velocidade possível, alternando entre direito e esquerdo, em um degrau de 18 $\mathrm{cm}$ de altura a sua frente. O avaliador deveria demonstrar a execução do teste, enfatizando a necessidade de colocar todo o pé sobre o degrau ao realizar as batidas, sem, no entanto, descarregar peso. O tempo começava a ser cronometrado quando o primeiro pé deixasse o solo e era encerrado ao final da oitava batida. A participante deveria executar a tarefa em até 10 segundos para passar no teste.

h) Avaliação da força. Para avaliar a força muscular, foi realizado o teste de passar da posição sentada para em pé, em que a idosa deveria se levantar cinco vezes de uma cadeira de $45 \mathrm{~cm}$ de altura sem apoio para os braços com os braços cruzados ao peito na maior velocidade possível. O avaliador deveria demonstrar a execução do teste, enfatizando a necessidade de estender completamente os joelhos e quadris, ao se levantar, e de sentar por completo logo em seguida. $O$ tempo começava a ser cronometrado quando os ombros se movessem para frente e era encerrado ao final da quinta repetição. A participante deveria executar a tarefa em até 12 segundos para passar no teste.

A Figura 18 apresenta o registro fotográfico de uma voluntária durante a execução do QuickScreen. 

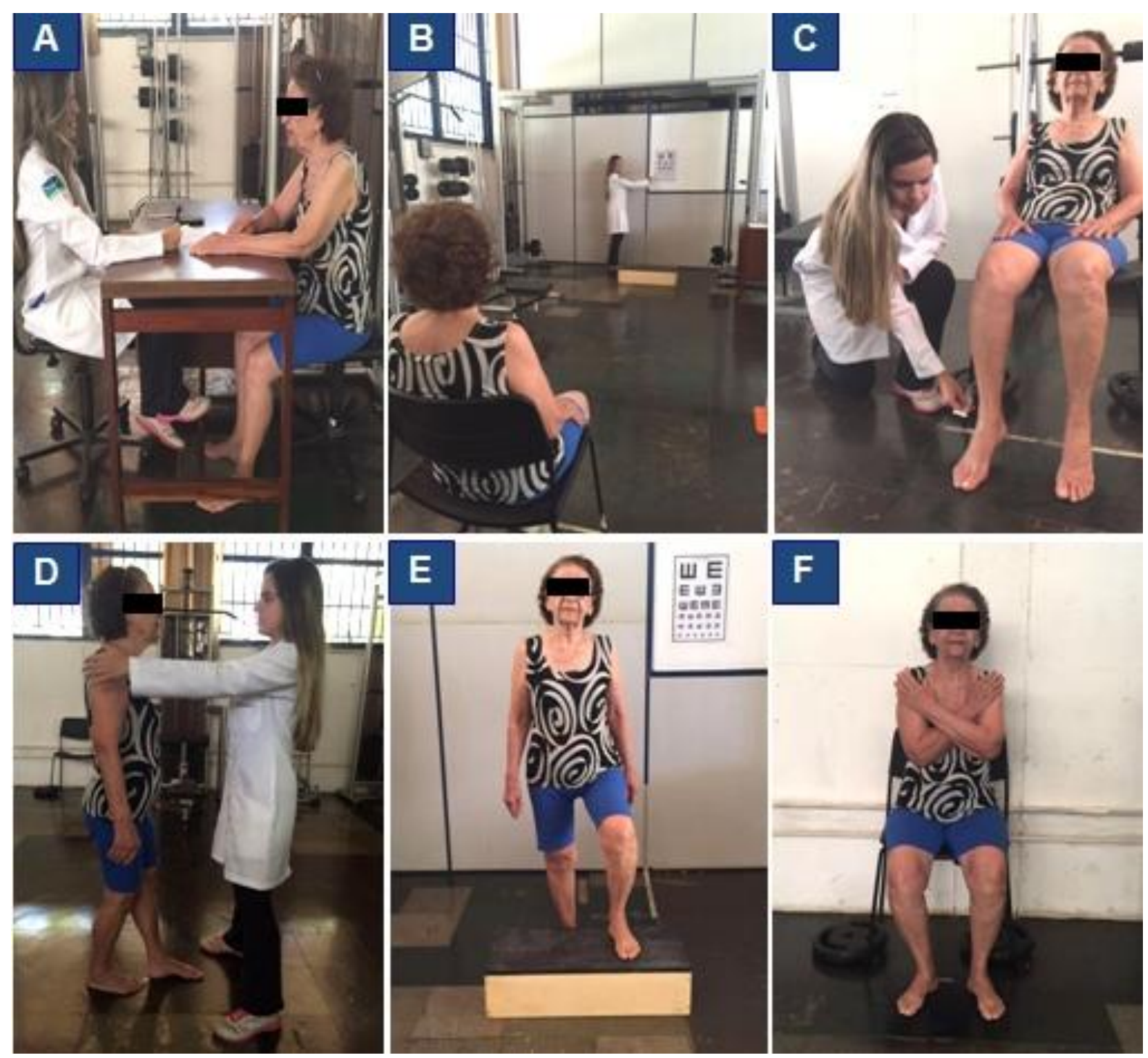

Figura 18. Registro fotográfico de uma voluntária durante a execução do QuickScreen. A) Avaliação da ocorrência de quedas no ano anterior, quantidade de medicamentos em uso e utilização de psicotrópicos. B) Avaliação da acuidade visual. C) Teste da sensibilidade periférica. D) Avaliação do equilíbrio. E) Avaliação do tempo de reação. F) Avaliação da força.

\subsubsection{Timed Up and Go}

O teste TUG, desenvolvido por Podsiadlo e Richardson (1991), consiste em medir o tempo gasto para o indivíduo levantar de uma cadeira de $45 \mathrm{~cm}$ de altura, sem apoio para os braços, a partir da posição encostada, andar três metros, contornar um cone, voltar sobre o mesmo percurso e sentar novamente na cadeira como na posição inicial. A instrução dada é que a idosa execute a tarefa de forma 
segura e o mais rápido possível, sem correr (Figura 19). Admite-se que quanto maior o tempo gasto para executar o teste, maior é o risco de quedas.

Para a sua execução, o avaliador explicava os procedimentos e realizava uma demonstração. Em seguida, a voluntária realizava três tentativas com intervalo de um minuto entre elas. Para a análise do desempenho foi levada em consideração a média das tentativas.
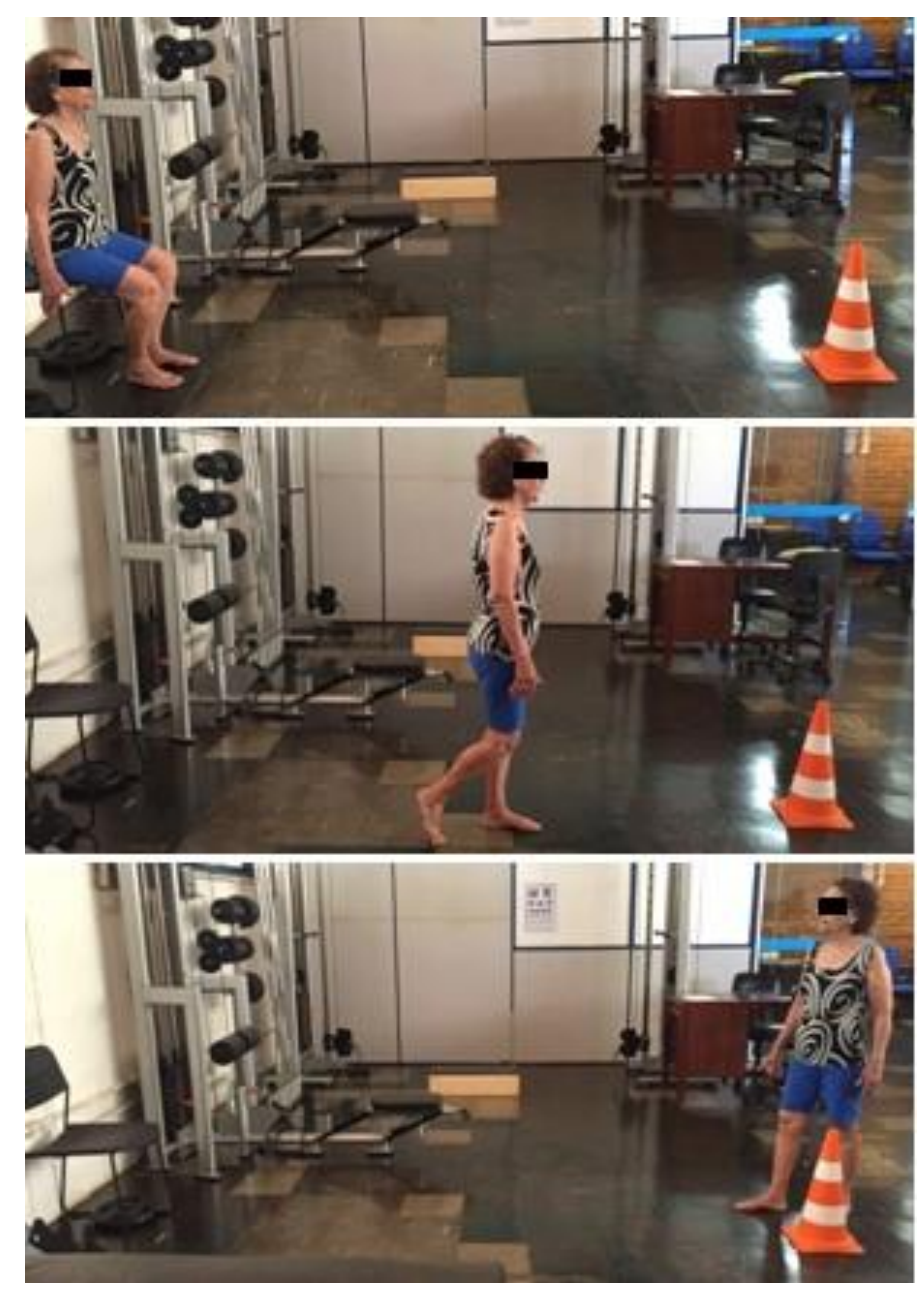

Figura 19. Registro fotográfico de uma voluntária durante a execução do teste Timed Up and Go.

\subsubsection{Escala de Eficácia de Quedas - Internacional}

A FES-I foi traduzida, adaptada culturalmente e validada para os idosos brasileiros por Camargos et al. (2010). Ela avalia a preocupação do indivíduo com a possibilidade de cair em 16 atividades comuns à vida diária, atribuindo o valor de um 
a quatro pontos para cada um dos itens, onde um equivale à ausência de preocupação e quatro representa a preocupação extrema. O escore total varia entre 16 e 64 pontos, sendo que valores maiores correspondem a um maior medo de cair (Anexo X).

Essa escala foi aplicada por um avaliador previamente treinado, o qual realizava a leitura de todo o enunciado e atribuía um valor de um a quatro pontos para cada um dos itens, de acordo com a resposta da voluntária. Cabe adicionar que o avaliador se colocava à disposição para o esclarecimento de eventuais dúvidas.

A Figura 20 apresenta o registro fotográfico da aplicação da FES-I.

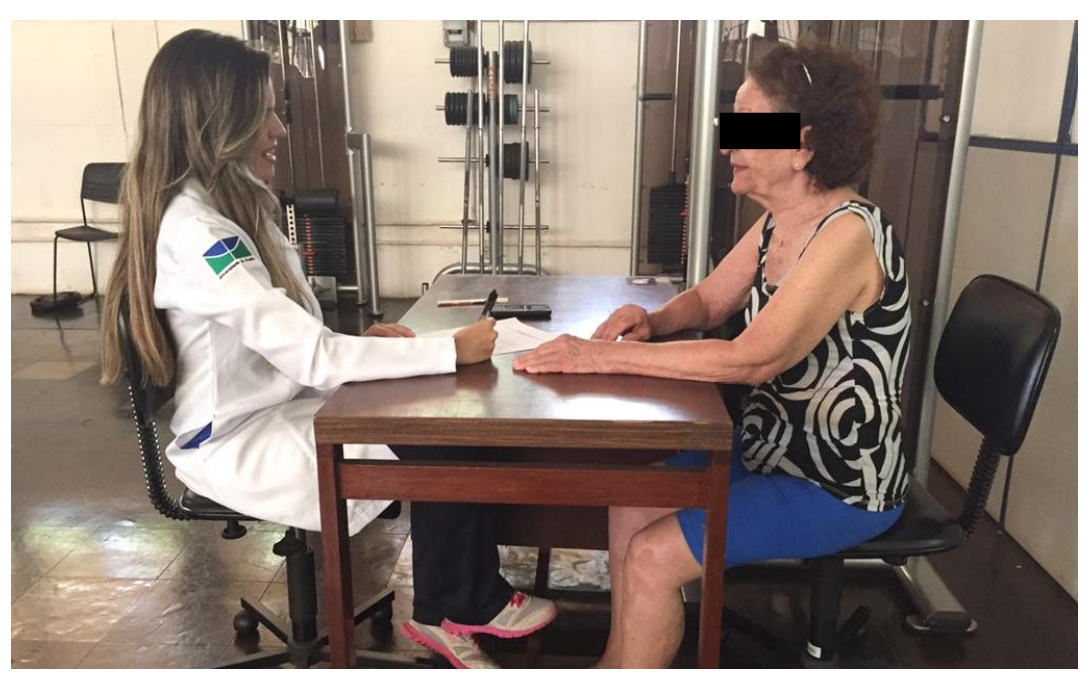

Figura 20. Registro fotográfico da aplicação da Escala de Eficácia de Quedas Internacional.

\subsection{RECURSOS HUMANOS}

Os procedimentos do estudo foram efetuados por alunos de iniciação científica e de pós-graduação do GEFS-UnB, sob a supervisão do Profo Dr. Ricardo Moreno Lima. Cada protocolo de avaliação foi executado por, no máximo, dois avaliadores previamente treinados. Adicionalmente, foi conduzido um estudo piloto para o nivelamento entre os avaliadores. 


\subsection{ANÁLISE ESTATÍSTICA}

\subsubsection{Cálculo amostral}

Para o cálculo do tamanho amostral, foram utilizados parâmetros de estabilidade postural (i.e. velocidade de oscilação do COP e amplitude de deslocamento na direção AP), já que, dentre as variáveis analisadas, o comprometimento do equilíbrio representa o principal fator de risco para quedas (Ganz et al., 2007). Adotou-se como referência os dados apresentados por Dutil et al. (2013), que apontam uma diferença de $0,56 \mathrm{~cm} / \mathrm{s}$ na velocidade de oscilação do COP entre idosas obesas e de peso normal (desvio padrão médio de 0,49 $\mathrm{cm} / \mathrm{s}$ ). Quanto à amplitude de deslocamento AP, a diferença observada é de $0,50 \mathrm{~cm}$ (desvio padrão médio de 0,49 cm). Considerando um poder de $80 \%$ e um alfa de $5 \%$, o resultado do cálculo amostral apontou a necessidade de ao menos três participantes por grupo, para detectar diferenças na velocidade do COP; ao passo que, para encontrar diferenças na amplitude AP, seriam necessárias 15 voluntárias.

\subsubsection{Análise dos dados}

As variáveis numéricas foram expressas em média \pm desvio padrão, e as categóricas em frequência absoluta e relativa. Para verificar a distribuição dos dados, os testes Shapiro-Wilk e Kolmogorov-Smirnov foram aplicados. Caso os dados possuíssem distribuição normal, eram conduzidos testes paramétricos; caso contrário, optava-se por testes não paramétricos. Para verificar a associação entre os índices de adiposidade corporal (IMC, CC e \%G) e as variáveis dependentes (força muscular, distribuição de pressão plantar, estabilidade postural e risco de quedas) foram empregados os testes Correlação de Pearson e Correlação de Spearman. Adicionalmente, a amostra foi estratificada de acordo com os diferentes índices de adiposidade. A saber, a classificação efetuada pelo IMC seguiu as recomendações da OMS (1999), ao passo que a estratificação efetuada pela CC e pelo \%G foi conduzida por meio de tercis (Figuras 21, 22 e 23). Após a classificação, a comparação das variáveis dependentes entre os estratos de adiposidade foi 
efetuada por meio dos testes ANOVA one-way e Kruskal-Wallis, para as variáveis numéricas, e por meio do teste Qui-quadrado, para as variáveis categóricas. Associado ao ANOVA one-way, utilizou-se o post-hoc de Bonferroni; e associado ao Kruskal-Wallis, empregou-se o Mann-Whitney com correção de Bonferroni. Finalmente, o Odds Ratio dos estratos superiores de adiposidade corporal foi calculado para os desfechos de ocorrência de quedas no ano anterior e risco de quedas aumentado (QuickScreen $\geq 27 \%$ ), adotando como referência os estratos inferiores de adiposidade. O nível de significância estabelecido foi de $5 \%(p<0,05)$. Todas as análises estatísticas foram realizadas no software Statistical Package for Social Sciences versão 20.0.

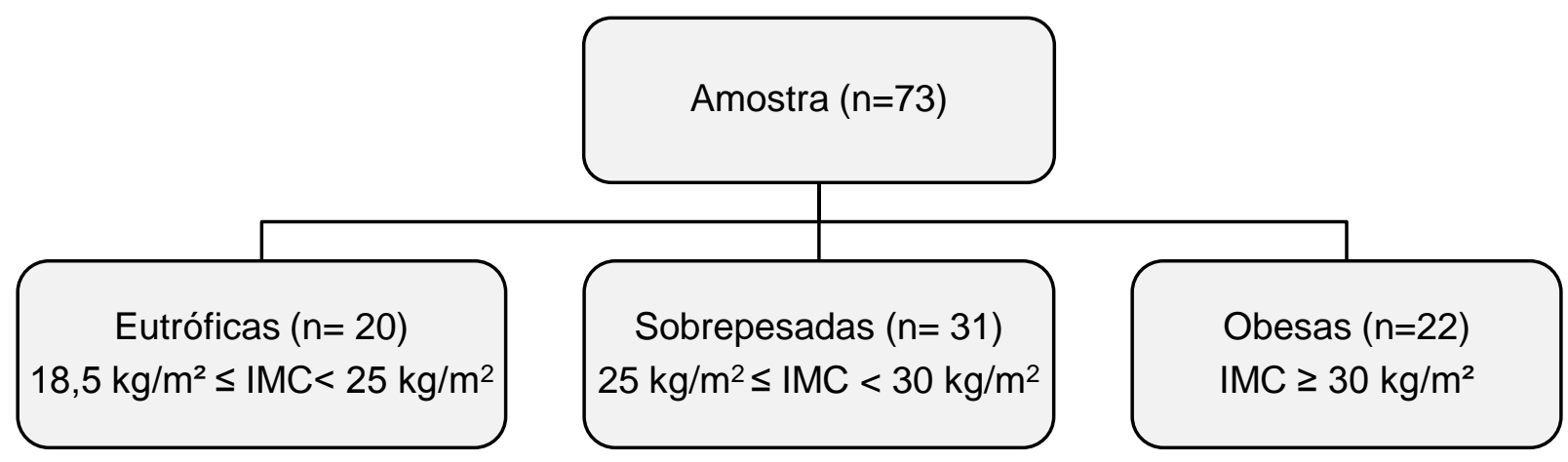

Figura 21. Estratificação da amostra de acordo com o índice de massa corporal (IMC).

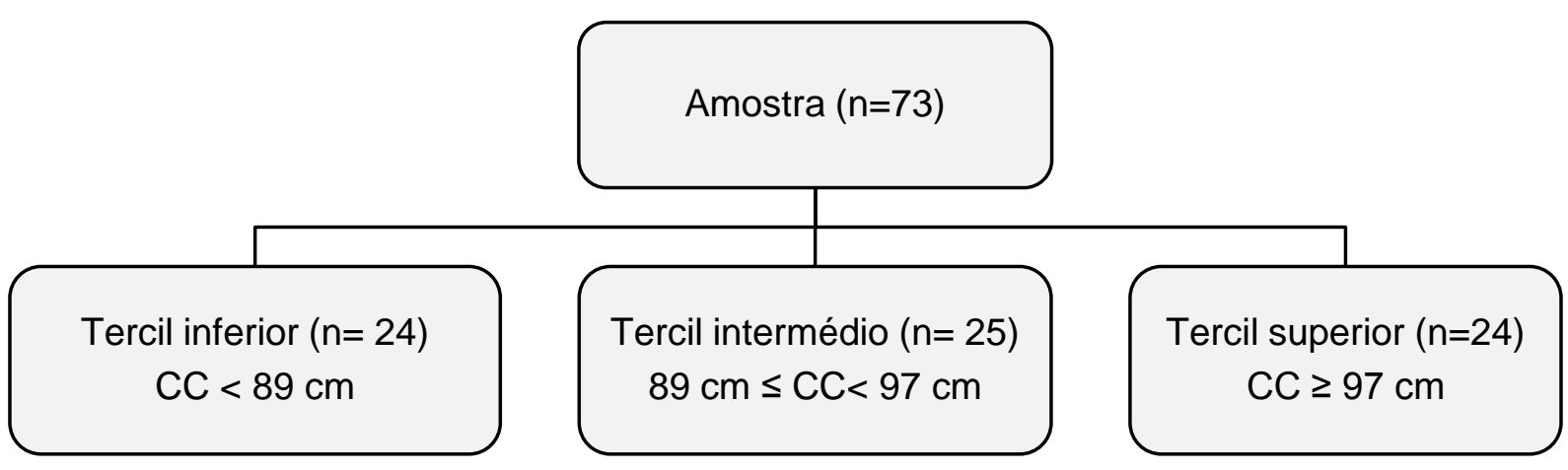

Figura 22. Estratificação da amostra de acordo com a circunferência de cintura (CC). 


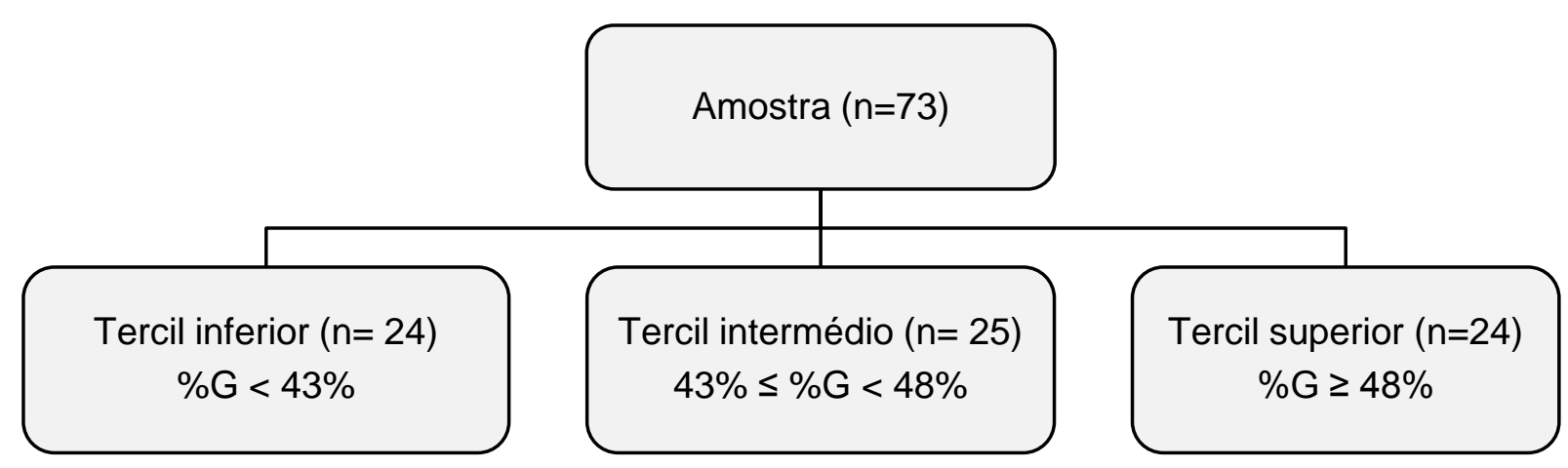

Figura 23. Estratificação da amostra de acordo com o percentual de gordura corporal (\%G). 


\section{RESULTADOS}

\subsection{CARACTERÍSTICAS DA AMOSTRA}

A Tabela 1 apresenta as características da amostra no que se refere às variáveis continuas.

Tabela 1. Características da amostra $(n=73)$. Dados expressos em média \pm desvio padrão.

\begin{tabular}{lc}
\hline Variável & Média \pm DP \\
\hline Idade (anos) & $67,58 \pm 6,04$ \\
Tempo de Menopausa (anos) & $18,88 \pm 7,96$ \\
Estatura $(\mathrm{m})$ & $1,56 \pm 0,06$ \\
Massa Corporal $(\mathrm{kg})$ & $67,59 \pm 11,25$ \\
IMC $\left(\mathrm{kg} / \mathrm{m}^{2}\right)$ & $27,92 \pm 4,46$ \\
$\mathrm{CC}(\mathrm{cm})$ & $94,07 \pm 11,66$ \\
$\mathrm{CQ}(\mathrm{cm})$ & $104,34 \pm 9,59$ \\
Gordura Corporal $(\%)$ & $44,90 \pm 5,84$ \\
\hline IMC: Índice de Massa Corporal; CC: Circunferência de \\
Cintura; CQ: Circunferência de Quadril.
\end{tabular}

A Tabela 2 apresenta as características da amostra para as variáveis categóricas. Como se pode observar, a amostra foi composta predominantemente por idosas sem comprometimento cognitivo (100,0\%), com independência funcional (76,7\%), tanto nas ABVDs quanto nas AIVDs, e irregularmente ativas (45,2\%). Em relação aos hábitos de vida, 24,7\% relataram consumir bebida alcoólica, 2,7\% afirmaram ser tabagistas e 39,7\% fazem ou já fizeram terapia de reposição hormonal. O consumo de quatro ou mais medicamentos foi observado em $21,9 \%$ da amostra e o uso de psicotrópico em 6,8\%. No que concerne à dor em alguma região corporal, ela estava presente em $72,6 \%$ das voluntárias. 
Tabela 2. Características da amostra $(n=73)$. Dados expressos em frequência absoluta e relativa.

\begin{tabular}{|c|c|}
\hline Variável & $\mathrm{n}(\%)$ \\
\hline \multicolumn{2}{|l|}{ Comprometimento cognitivo } \\
\hline $\operatorname{Sim}$ & - \\
\hline Não & $73(100,0)$ \\
\hline \multicolumn{2}{|c|}{ Nível de funcionalidade nas ABVDs } \\
\hline Independência & $56(76,7)$ \\
\hline Dependência ligeira & $17(23,3)$ \\
\hline \multicolumn{2}{|l|}{ Dependência moderada } \\
\hline Dependência grave & - \\
\hline Dependência total & \\
\hline \multicolumn{2}{|c|}{ Nível de funcionalidade nas AIVDs } \\
\hline Independência & $56(76,7)$ \\
\hline Dependência ligeira & $15(20,5)$ \\
\hline Dependência moderada & $2(2,7)$ \\
\hline Dependência grave & - \\
\hline Dependência total & . \\
\hline \multicolumn{2}{|l|}{ Nível de atividade física } \\
\hline Muito ativa & $2(2,7)$ \\
\hline Ativa & $30(41,1)$ \\
\hline Irregularmente ativa & $33(45,2)$ \\
\hline Sedentária & $8(11,0)$ \\
\hline \multicolumn{2}{|l|}{ Ingestão de bebida alcoólica } \\
\hline Sim & $18(24,7)$ \\
\hline Não & $55(75,3)$ \\
\hline \multicolumn{2}{|l|}{ Tabagismo } \\
\hline Sim & $2(2,7)$ \\
\hline Não & $71(97,3)$ \\
\hline \multicolumn{2}{|c|}{ Terapia de reposição hormonal } \\
\hline Sim & $29(39,7)$ \\
\hline Não & $44(60,3)$ \\
\hline \multicolumn{2}{|l|}{ Medicamentos } \\
\hline$\geq$ quatro medicamentos & $16(21,9)$ \\
\hline Psicotrópico & $5(6,8)$ \\
\hline \multicolumn{2}{|c|}{ Dor em alguma região do corpo } \\
\hline Sim & $53(72,6)$ \\
\hline Não & $20(27,4)$ \\
\hline
\end{tabular}

\subsection{ADIPOSIDADE CORPORAL E FORÇA MUSCULAR}

Do total amostral, 70 voluntárias concluíram os procedimentos de mensuração da força muscular e foram consideradas para esta análise. $O$ desempenho das voluntarias, estratificadas de acordo com o IMC, a CC e o \%G, é 
apresentado nas Tabelas 3, 4 e 5, respectivamente. É notório que as variáveis de força muscular absoluta não apresentaram diferença significativa entre os grupos, em nenhuma das classificações. As variáveis de força relativa, por outro lado, se apresentaram significativamente diferentes entre os estratos de adiposidade corporal, sendo que idosas com maiores índices de adiposidade demonstraram menor força muscular relativa.

De acordo com a classificação do IMC, é possível observar diferença significativa nos valores relativos da FPM e do PT isométrico dos extensores do joelho entre as idosas eutróficas, sobrepesadas e obesas. Nos valores relativos do PT a $60 \% / \mathrm{s}^{-1}$ e do PT a $180 \% / \mathrm{s}^{-1}$, essa diferença é observada apenas entre as eutróficas e as obesas (Tabela 3).

Em relação à estratificação efetuada pela medida da $\mathrm{CC}$, os valores relativos da FPM e do PT isométrico apresentaram diferença significativa apenas entre os tercis inferior e superior, ao passo que o PT a $60 \% / \mathrm{s}^{-1}$ e o PT a $180 \% / \mathrm{s}^{-1}$ relativos exibiram diferença também entre os tercis intermédio e superior (Tabela 4).

Para a classificação efetuada pelo \%G, o PT isométrico relativo apresentou diferença significativa entre os três grupos. Os valores relativos da FPM e do PT a $180 \% \mathrm{~s}^{-1}$, por sua vez, apresentaram diferença entre os tercis inferior e superior, e entre os tercis intermédio e o superior. Quanto ao PT a $60 \% / \mathrm{s}^{-1}$, foi observada diferença apenas entre os tercis inferior e superior (Tabela 5).

Adicionalmente, a associação entre os índices de adiposidade corporal e as variáveis de força muscular é demonstrada na Tabela 6 . Reforçando as observações supracitadas, é possível observar que as variáveis de força absoluta não apresentaram correlação estatisticamente significante com os índices de adiposidade corporal. No entanto, quando relativizadas para a massa corporal, notase uma associação inversa e significativa. Esta associação é classificada como moderada para o IMC e para a CC. Também para o\%G observa-se correlação moderada com a maioria das variáveis, exceto com a FPM, em que foi observado grau forte de associação. 
Tabela 3. Força muscular de mulheres idosas estratificadas de acordo com o IMC (eutróficas, sobrepesadas e obesas). Dados expressos em média \pm desvio padrão.

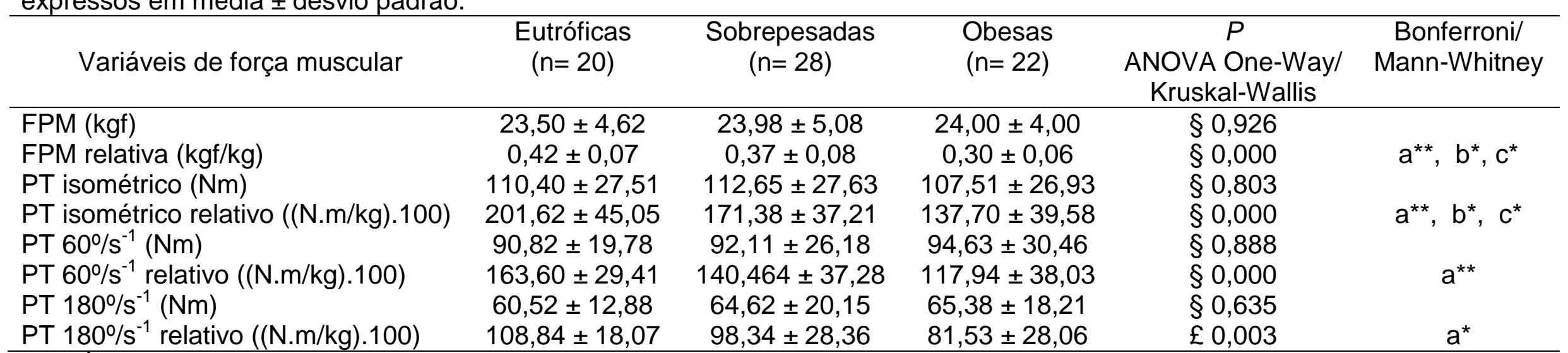

IMC: Índice de massa corporal; FPM: Força de preensão manual; PT: Pico de torque dos extensores do joelho dominante.

$\S$ ANOVA One-Way; £ Kruskal-Wallis.

Diferenças entre grupos: (a) Eutróficas-Obesas; (b) Eutróficas-Sobrepesadas; (c) Sobrepesadas-Obesas.

${ }^{*} p<0,05 ;{ }^{* *} p<0,001$. 
Tabela 4. Força muscular de mulheres idosas estratificadas de acordo com os tercis da CC (tercil inferior, intermédio e superior). Dados expressos em média \pm desvio padrão.

\begin{tabular}{|c|c|c|c|c|c|}
\hline Variáveis de força muscular & $\begin{array}{l}\text { Tercil inferior } \\
\quad(n=24)\end{array}$ & $\begin{array}{l}\text { Tercil intermédio } \\
\qquad(\mathrm{n}=22)\end{array}$ & $\begin{array}{l}\text { Tercil superior } \\
\quad(n=24)\end{array}$ & $\begin{array}{c}P \\
\text { ANOVA One-Way }\end{array}$ & Bonferron \\
\hline FPM relativa $(\mathrm{kgf} / \mathrm{kg})$ & $0,40 \pm 0,07$ & $0,36 \pm 0,09$ & $0,32 \pm 0,07$ & 0,002 & $a^{*}$ \\
\hline PT isométrico relativo $((\mathrm{N} . \mathrm{m} / \mathrm{kg}) .100)$ & $197,80 \pm 44,98$ & $169,45 \pm 39,35$ & $141,14 \pm 38,51$ & 0,000 & $a^{* *}$ \\
\hline PT $60 \% / s^{-1}(\mathrm{Nm})$ & $90,67 \pm 19,83$ & $95,26 \pm 27,62$ & $91,90 \pm 29,69$ & 0,828 & \\
\hline $\mathrm{PT} 60 \% / \mathrm{s}^{-1}$ relativo $((\mathrm{N} . \mathrm{m} / \mathrm{kg}) .100)$ & $159,33 \pm 30,82$ & $143,42 \pm 40,33$ & $117,52 \pm 35,41$ & 0,001 & $a^{* *}, c^{*}$ \\
\hline
\end{tabular}

CC: Circunferência de cintura; FPM: Força de preensão manual; PT: Pico de torque dos extensores do joelho dominante.

Diferenças entre grupos: (a) Tercis inferior-superior; (c) Tercis intermédio-superior.

${ }^{*} p<0,05 ;{ }^{* *} p<0,001$. 
Tabela 5. Força muscular de mulheres idosas estratificadas de acordo com os tercis do \%G (tercil inferior, intermédio e superior). Dados expressos em média \pm desvio padrão.

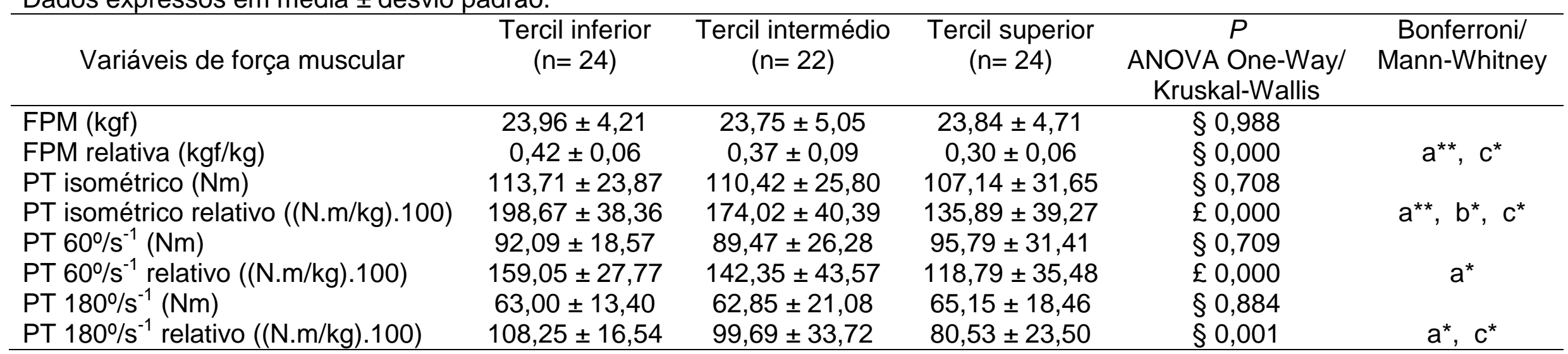

\%G: Percentual de gordura corporal; FPM: Força de preensão manual; PT: Pico de torque dos extensores do joelho dominante. $\S$ ANOVA One-Way; £ Kruskal-Wallis.

Diferenças entre grupos: (a) Tercis inferior-superior; (b) Tercis inferior-intermédio (c) Tercis intermédio-superior.

${ }^{*} p<0,05 ;{ }^{* *} p<0,001$. 
Tabela 6. Correlação entre os índices de adiposidade corporal (IMC, CC e \%G) e a força muscular de mulheres idosas $(n=70)$.

\begin{tabular}{|c|c|c|c|}
\hline Variáveis de força muscular & IMC & CC & $\% G$ \\
\hline FPM (kgf) & $\S 0,018$ & $\S 0,092$ & $\S-0,047$ \\
\hline FPM relativa $(\mathrm{kgf} / \mathrm{kg})$ & $£-0,593^{* *}$ & $£-0,487^{\star *}$ & $£-0,633^{* *}$ \\
\hline $\mathrm{PT}$ isométrico $(\mathrm{Nm})$ & $\S-0,078$ & $\S-0,048$ & $\S-0,103$ \\
\hline $\mathrm{PT}$ isométrico relativo $((\mathrm{N} . \mathrm{m} / \mathrm{kg}) .100)$ & $\S-0,563^{* *}$ & $\S-0,524^{\star *}$ & $\S-0,574^{\star *}$ \\
\hline PT $60 \% / \mathrm{s}^{-1}(\mathrm{Nm})$ & $\S 0,048$ & $\S 0,046$ & $\S 0,034$ \\
\hline PT $60 \% / \mathrm{s}^{-1}$ relativo $((\mathrm{N} . \mathrm{m} / \mathrm{kg}) .100)$ & $\S-0,495^{\star *}$ & $\S-0,464^{\star *}$ & $\S-0,472 * *$ \\
\hline PT $180 \% / \mathrm{s}^{-1}(\mathrm{Nm})$ & $\S 0,072$ & $\S 0,028$ & $\S 0,046$ \\
\hline PT $180^{\circ} / \mathrm{s}^{-1}$ relativo $((\mathrm{N} . \mathrm{m} / \mathrm{kg}) .100)$ & $\S-0,456^{* *}$ & $\S-0,462^{* *}$ & $\S-0,462^{* *}$ \\
\hline
\end{tabular}

IMC: Índice de massa corporal; CC: Circunferência de cintura; \%G: Percentual de gordura corporal; FPM: Força de preensão manual; PT: Pico de torque dos extensores do joelho dominante.

$\S$ Coeficiente de correlação de Pearson; £ Coeficiente de correlação de Spearman.

${ }^{* *} p<0,001$. 


\subsection{ADIPOSIDADE CORPORAL E DISTRIBUIÇÃO DE PRESSÃO PLANTAR}

Do total amostral, 62 voluntárias concluíram os procedimentos de mensuração da distribuição de pressão plantar e foram consideradas para esta análise. O desempenho das voluntarias, estratificadas de acordo com o IMC, a CC e o \%G, é apresentado nas Tabelas 7, 8 e 9, respectivamente.

De acordo com a classificação do IMC, é possível observar diferença significativa na força máxima da maioria das regiões do pé (exceto hálux e demais dedos), onde idosas com maior índice de adiposidade demonstraram maior força máxima. Para o pé completo, essa diferença foi encontrada entre eutróficas, sobrepesadas e obesas; enquanto que para o retropé, mediopé e antepé, nota-se diferença apenas das obesas em relação às eutróficas e às sobrepesadas.

A força máxima do pé, quando relativizada para a massa corporal, por outro lado, não apresentou diferença significativa entre os grupos. No entanto, ao avaliar as regiões anatômicas dos pés de maneira isolada, observa-se diferença estatisticamente significante no retropé, mediopé, antepé e dedos. Notavelmente, idosas com maiores índices de adiposidade exibiram menor força relativa na maioria das regiões supracitas, com exceção do mediopé, em que as obesas demonstraram maior força relativa, quando comparadas às eutróficas.

Também para o pico de pressão, apenas os valores do mediopé se apresentaram maiores entre as obesas e as sobrepesadas, em relação às eutróficas. Para as demais regiões, não foi encontrada diferença significativa.

Tratando da área de contanto, é possível observar diferença significante no pé completo, onde idosas obesas exibiram maior área que as eutróficas. Para as divisões do pé, essa diferença é verificada apenas no mediopé; embora, haja tendência para significância no retropé $(p<0,08)$ e no antepé $(p<0,06)$. Adicionalmente, o índice de arco dinâmico se mostrou significativamente mais elevado entre as obesas e as sobrepesadas, quando comparado às eutróficas.

Cabe, ainda, expor que a velocidade da marcha, durante a mensuração da distribuição de pressão plantar, apresentou diferença significativa entre os grupos $(p=0,011)$. As mulheres eutróficas efetuaram o teste a uma velocidade de 1,02 \pm $0,30 \mathrm{~m} / \mathrm{s}$, enquanto as sobrepesadas e as obesas executaram em $0,80 \pm 0,16 \mathrm{~m} / \mathrm{s} \mathrm{e}$ em $0,85 \pm 0,15 \mathrm{~m} / \mathrm{s}$, respectivamente. 
Tabela 7. Distribuição de pressão plantar de mulheres idosas estratificadas de acordo com o IMC (eutróficas, sobrepesadas e obesas). Dados expressos em média \pm desvio padrão.

\begin{tabular}{|c|c|c|c|c|c|}
\hline Variáveis baropodométricas & $\begin{array}{c}\text { Eutróficas } \\
(n=15)\end{array}$ & $\begin{array}{l}\text { Sobrepesadas } \\
\quad(n=29)\end{array}$ & $\begin{array}{l}\text { Obesas } \\
(n=18)\end{array}$ & $\begin{array}{c}P \\
\text { ANOVA One-Way/ } \\
\text { Kruskal-Wallis }\end{array}$ & $\begin{array}{c}\text { Bonferroni/ Mann- } \\
\text { Whitney }\end{array}$ \\
\hline \multicolumn{6}{|l|}{ Pé } \\
\hline Força máxima $(\mathrm{N})$ & $639,03 \pm 72,22$ & $740,41 \pm 71,47$ & $892,29 \pm 79,02$ & $\S 0,000$ & $a^{* *}, b^{\star *}, c^{* *}$ \\
\hline Força máxima relativa (\%kg) & $115,37 \pm 7,01$ & $115,20 \pm 5,13$ & $112,82 \pm 3,65$ & $\S 0,264$ & \\
\hline Pico de pressão $(\mathrm{kPa})$ & $437,00 \pm 108,90$ & $524,31 \pm 173,27$ & $520,83 \pm 142,02$ & $\S 0,168$ & \\
\hline Área de contato $\left(\mathrm{cm}^{2}\right)$ & $123,87 \pm 14,03$ & $131,24 \pm 15,28$ & $140,99 \pm 15,08$ & $\S 0,006$ & $a^{*}$ \\
\hline Índice de arco dinâmico & $0,21 \pm 0,05$ & $0,25 \pm 0,04$ & $0,26 \pm 0,04$ & $£ 0,003$ & $a^{*}, b^{*}$ \\
\hline \multicolumn{6}{|l|}{ Retropé } \\
\hline Força máxima $(\mathrm{N})$ & $401,22 \pm 66,14$ & $404,26 \pm 61,15$ & $462,67 \pm 54,39$ & $\S 0,004$ & $a^{*}, c^{*}$ \\
\hline Força máxima relativa (\%kg) & $72,32 \pm 8,92$ & $62,90 \pm 7,65$ & $59,00 \pm 9,28$ & $\S 0,000$ & $a^{* *}, b^{*}$ \\
\hline Pico de pressão $(\mathrm{kPa})$ & $268,00 \pm 54,01$ & $275,86 \pm 63,72$ & $271,39 \pm 69,55$ & $£ 0,967$ & \\
\hline Área de contato $\left(\mathrm{cm}^{2}\right)$ & $32,08 \pm 2,18$ & $32,25 \pm 3,40$ & $34,37 \pm 4,02$ & $\S 0,075$ & \\
\hline \multicolumn{6}{|l|}{ Médiopé } \\
\hline Força máxima $(\mathrm{N})$ & $89,59 \pm 51,38$ & $145,21 \pm 70,77$ & $223,39 \pm 104,50$ & $\S 0,000$ & $a^{* *}, c^{*}$ \\
\hline Força máxima relativa (\%kg) & $16,25 \pm 9,17$ & $22,63 \pm 10,91$ & $27,81 \pm 11,93$ & $\S 0,013$ & $a^{*}$ \\
\hline Pico de pressão $(\mathrm{kPa})$ & $117,00 \pm 28,59$ & $170,69 \pm 55,27$ & $182,50 \pm 33,66$ & $£ 0,000$ & $a^{* *}, b^{* *}$ \\
\hline Área de contato $\left(\mathrm{cm}^{2}\right)$ & $21,46 \pm 7,08$ & $26,66 \pm 6,95$ & $31,69 \pm 7,55$ & $\S 0,001$ & $a^{* *}$ \\
\hline \multicolumn{6}{|l|}{ Antepé } \\
\hline Força máxima $(\mathrm{N})$ & $536,57 \pm 81,44$ & $564,50 \pm 96,05$ & $690,30 \pm 88,74$ & $\S 0,000$ & $a^{* *}, c^{* *}$ \\
\hline Força máxima relativa (\%kg) & $96,94 \pm 12,14$ & $87,75 \pm 12,13$ & $87,33 \pm 9,05$ & $\S 0,026$ & $b^{*}$ \\
\hline Pico de pressão $(\mathrm{kPa})$ & $383,00 \pm 91,61$ & $421,90 \pm 146,89$ & $454,72 \pm 124,59$ & $£ 0,240$ & \\
\hline Área de contato $\left(\mathrm{cm}^{2}\right)$ & $47,68 \pm 5,48$ & $48,67 \pm 5,99$ & $52,19 \pm 5,48$ & $\S 0,055$ & \\
\hline \multicolumn{6}{|l|}{ Hálux } \\
\hline Força máxima $(\mathrm{N})$ & $81,64 \pm 33,84$ & $109,16 \pm 44,24$ & $106,22 \pm 50,59$ & $£ 0,135$ & \\
\hline Força máxima relativa (\%kg) & $14,79 \pm 6,25$ & $17,09 \pm 7,03$ & $13,48 \pm 6,26$ & $\S 0,182$ & \\
\hline Pico de pressão $(\mathrm{kPa})$ & $322,67 \pm 158,16$ & $427,93 \pm 214,55$ & $352,50 \pm 196,36$ & $£ 0,176$ & \\
\hline Área de contato $\left(\mathrm{cm}^{2}\right)$ & $9,87 \pm 1,38$ & $10,75 \pm 1,707$ & $10,67 \pm 1,84$ & $\$ 0,232$ & \\
\hline \multicolumn{6}{|l|}{ Dedos } \\
\hline Força máxima $(\mathrm{N})$ & $50,45 \pm 22,81$ & $59,98 \pm 26,50$ & $48,96 \pm 20,14$ & $£ 0,343$ & \\
\hline Força máxima relativa (\%kg) & $9,12 \pm 4,01$ & $9,48 \pm 4,33$ & $6,33 \pm 2,80$ & $£ 0,024$ & $c^{*}$ \\
\hline Pico de pressão $(\mathrm{kPa})$ & $154,33 \pm 78,58$ & $213,10 \pm 119,25$ & $173,61 \pm 101,62$ & $£ 0,120$ & \\
\hline Área de contato $\left(\mathrm{cm}^{2}\right)$ & $12,60 \pm 3,08$ & $12,63 \pm 2,91$ & $12,03 \pm 3,06$ & $\S 0,784$ & \\
\hline
\end{tabular}

IMC: Índice de massa corporal; § ANOVA One-Way; £ Kruskal-Wallis.

Diferenças entre grupos: (a) Eutróficas-Obesas; (b) Eutróficas-Sobrepesadas; (c) Sobrepesadas-Obesas.

${ }^{*} p<0,05 ;{ }^{* *} p<0,001$. 
Em relação à estratificação efetuada pela medida da $\mathrm{CC}$, nota-se diferença significativa na força máxima da maioria das regiões do pé (exceto hálux), onde idosas com maior índice de adiposidade demonstraram maior força máxima no pé e em boa parte das suas subdivisões. Para o pé completo, essa diferença foi encontrada entre os tercis inferior, intermédio e superior; ao passo que, para o mediopé, observa-se diferença do tercil superior, em relação ao inferior e ao intermédio; e para o retropé e antepé, apenas do superior em relação ao inferior. Interessantemente, nos dedos, as mulheres do tercil superior exibiram menor força que as do intermédio.

Quando a força máxima é relativizada para a massa corporal, no entanto, verifica-se diferença estatisticamente significante no retropé, mediopé, hálux e dedos. Notavelmente, idosas com maior índice de adiposidade apresentaram menor força relativa na maioria das regiões supracitas, com exceção do mediopé, em que o tercil superior demonstrou maior força relativa, quando comparado ao inferior.

Tratando do pico de pressão, é possível observar diferença significante no mediopé e nos dedos. Interessantemente, os valores do mediopé se apresentaram maiores entre o tercil superior e intermédio, em relação ao inferior; enquanto que nos dedos, os valores se mostraram menores no tercil superior, quando comparados com o intermédio.

Quanto à área de contato, é notória diferença significativa no pé completo, no mediopé e no antepé, onde idosas do tercil superior exibiram maior área que as do inferior. Adicionalmente, o índice de arco dinâmico foi significativamente mais elevado no tercil superior, quando comparado com o inferior.

Para finalizar, é fundamental ressaltar que a velocidade da marcha, durante a mensuração da distribuição de pressão plantar, apresentou diferença significativa entre os grupos $(p=0,049)$. As mulheres do tercil inferior efetuaram o teste a uma velocidade de $1,04 \pm 0,30 \mathrm{~m} / \mathrm{s}$, enquanto as do tercil intermédio e superior executaram em $0,81 \pm 0,15 \mathrm{~m} / \mathrm{s}$ e em $0,83 \pm 0,16 \mathrm{~m} / \mathrm{s}$, respectivamente. 
Tabela 8. Distribuição de pressão plantar de mulheres idosas estratificadas de acordo com os tercis da CC (tercil inferior, intermédio e superior). Dados expressos em média \pm desvio padrão.

\begin{tabular}{|c|c|c|c|c|c|}
\hline Variáveis baropodométricas & $\begin{array}{l}\text { Tercil inferior } \\
(n=18)\end{array}$ & $\begin{array}{l}\text { Tercil intermédio } \\
(n=23)\end{array}$ & $\begin{array}{l}\text { Tercil superior } \\
\quad(n=21)\end{array}$ & $\begin{array}{c}P \\
\text { ANOVA One-Way/ } \\
\text { Kruskal-Wallis }\end{array}$ & $\begin{array}{c}\text { Bonferroni/ Mann } \\
\text { Whitney }\end{array}$ \\
\hline \multicolumn{6}{|l|}{ Pé } \\
\hline Força máxima $(\mathrm{N})$ & $648,73 \pm 71,87$ & $759,15 \pm 69,41$ & $856,23 \pm 113,30$ & $\S 0,000$ & $a^{* *}, b^{*}, c^{*}$ \\
\hline Força máxima relativa (\%kg) & $116,19 \pm 7,75$ & $114,76 \pm 3,71$ & $112,92 \pm 3,86$ & $£ 0,308$ & \\
\hline Pico de pressão $(\mathrm{kPa})$ & $439,44 \pm 85,75$ & $540,65 \pm 184,45$ & $513,81 \pm 150,41$ & $\S 0,100$ & \\
\hline Área de contato $\left(\mathrm{cm}^{2}\right)$ & $124,44 \pm 13,87$ & $132,75 \pm 17,28$ & $138,50 \pm 13,88$ & $\S 0,021$ & $a^{*}$ \\
\hline Índice de arco dinâmico & $0,22 \pm 0,05$ & $0,24 \pm 0,05$ & $0,26 \pm 0,03$ & $\S 0,011$ & $a^{*}$ \\
\hline \multicolumn{6}{|l|}{ Retropé } \\
\hline Força máxima $(\mathrm{N})$ & $389,81 \pm 63,27$ & $417,86 \pm 61,14$ & $449,65 \pm 61,73$ & $\S 0,014$ & $a^{*}$ \\
\hline Força máxima relativa (\%kg) & $69,89 \pm 9,95$ & $63,31 \pm 8,58$ & $59,85 \pm 8,47$ & $\S 0,004$ & $a^{*}$ \\
\hline Pico de pressão $(\mathrm{kPa})$ & $268,61 \pm 55,73$ & $279,35 \pm 67,64$ & $268,81 \pm 64,17$ & $£ 0,865$ & \\
\hline Área de contato $\left(\mathrm{cm}^{2}\right)$ & $31,80 \pm 2,47$ & $32,50 \pm 3,38$ & $34,04 \pm 3,99$ & $\S 0,109$ & \\
\hline \multicolumn{6}{|l|}{ Médiopé } \\
\hline Força máxima $(\mathrm{N})$ & $92,43 \pm 44,19$ & $150,54 \pm 72,23$ & $211,89 \pm 106,57$ & $\S 0,000$ & $a^{* *}, c^{*}$ \\
\hline Força máxima relativa (\%kg) & $16,66 \pm 8,248$ & $22,69 \pm 10,69$ & $27,56 \pm 12,66$ & $\S 0,010$ & $a^{*}$ \\
\hline Pico de pressão $(\mathrm{kPa})$ & $125,28 \pm 32,92$ & $168,70 \pm 60,269$ & $183,57 \pm 33,88$ & $£ 0,000$ & $a^{* *}, b^{*}$ \\
\hline Área de contato $\left(\mathrm{cm}^{2}\right)$ & $22,35 \pm 6,74$ & $26,68 \pm 7,756$ & $30,93 \pm 7,32$ & $£ 0,013$ & $a^{*}$ \\
\hline \multicolumn{6}{|l|}{ Antepé } \\
\hline Força máxima $(\mathrm{N})$ & $522,23 \pm 86,45$ & $590,40 \pm 77,94$ & $660,24 \pm 118,49$ & $\S 0,000$ & $a^{* *}$ \\
\hline Força máxima relativa (\%kg) & $93,53 \pm 13,18$ & $89,44 \pm 10,62$ & $87,15 \pm 11,70$ & $£ 0,455$ & \\
\hline Pico de pressão $(\mathrm{kPa})$ & $369,72 \pm 60,74$ & $452,39 \pm 158,24$ & $433,57 \pm 130,53$ & $£ 0,289$ & \\
\hline Área de contato $\left(\mathrm{cm}^{2}\right)$ & $47,07 \pm 4,75$ & $49,04 \pm 6,61$ & $51,95 \pm 5,27$ & $\S 0,031$ & $a^{*}$ \\
\hline \multicolumn{6}{|l|}{ Hálux } \\
\hline Força máxima $(\mathrm{N})$ & $97,58 \pm 38,57$ & $110,18 \pm 42,01$ & $95,78 \pm 52,69$ & $\S 0,518$ & \\
\hline Força máxima relativa (\%kg) & $17,50 \pm 7,06$ & $16,60 \pm 5,79$ & $12,55 \pm 6,63$ & $\S 0,041$ & $a^{*}$ \\
\hline Pico de pressão $(\mathrm{kPa})$ & $359,44 \pm 142,44$ & $428,48 \pm 217,66$ & $346,19 \pm 218,09$ & $£ 0,372$ & \\
\hline Área de contato $\left(\mathrm{cm}^{2}\right)$ & $10,34 \pm 1,29$ & $11,04 \pm 1,676$ & $10,10 \pm 1,92$ & $\S 0,159$ & \\
\hline \multicolumn{6}{|l|}{ Dedos } \\
\hline Força máxima $(\mathrm{N})$ & $57,28 \pm 25,66$ & $61,67 \pm 20,11$ & $44,20 \pm 24,36$ & $£ 0,035$ & $C^{*}$ \\
\hline Força máxima relativa (\%kg) & $10,29 \pm 4,64$ & $9,37 \pm 3,11$ & $5,95 \pm 3,24$ & $£ 0,001$ & $a^{*}, c^{*}$ \\
\hline Pico de pressão $(\mathrm{kPa})$ & $189,17 \pm 126,69$ & $213,26 \pm 85,05$ & $157,62 \pm 107,95$ & $£ 0,022$ & $C^{*}$ \\
\hline Área de contato $\left(\mathrm{cm}^{2}\right)$ & $12,69 \pm 2,66$ & $13,18 \pm 3,06$ & $11,43 \pm 2,94$ & $\S 0,133$ & \\
\hline
\end{tabular}

: circunferência de cintura; $§$ ANOVA One-Way; $£$ Kruskal-Wallis.

Diferenças entre grupos: (a) Tercis inferior-superior; (b) Tercis inferior-intermédio (c) Tercis intermédio-superior

${ }^{*} p<0,05 ;{ }^{* *} p<0,001$. 
Finalmente, para a classificação efetuada pelo \%G, é possível observar diferença significativa na força máxima da maioria das regiões do pé (exceto hálux e demais dedos), onde idosas com maior índice de adiposidade demonstraram maior força máxima. Para o pé completo, essa diferença foi encontrada entre os tercis inferior, intermédio e superior; ao passo que para o retropé e o antepé, nota-se diferença do tercil superior em relação ao inferior e ao intermédio; e para o mediopé, apenas do superior em relação ao inferior.

Quando a força máxima é relativizada para a massa corporal, no entanto, somente o retropé e os dedos exibem diferença estatisticamente significante - essas diferenças ocorrem entre os tercis inferior e superior, e entre o intermédio e o superior, respectivamente. Observa-se, ainda, tendência para significância no antepé $(p<0,06)$. De forma interessante, idosas com maiores índices de adiposidade apresentaram menor força relativa.

Tratando do pico de pressão, é possível observar diferença significante no pé completo e no mediopé; embora, haja tendência para significância no antepé ( $p<$ $0,06)$. Cabe ressaltar que essas diferenças foram encontradas entre os tercis inferior e superior, onde participantes com maior \%G exibiram maior pico de pressão.

Também para a área contato, somente os valores do pé completo e do mediopé se apresentaram significativamente diferentes entre os estratos do \%G, sendo que as idosas do tercil superior demonstraram valores mais expressivos do que as do inferior. Adicionalmente, o índice de arco dinâmico se mostrou significativamente mais elevado no tercil superior, quando comparado com o inferior.

Em relação à velocidade da marcha durante a mensuração da distribuição de pressão plantar, as mulheres do tercil inferior efetuaram o teste a uma velocidade de $0,95 \pm 0,17 \mathrm{~m} / \mathrm{s}$, as do tercil intermédio a $0,83 \pm 0,17 \mathrm{~m} / \mathrm{s}$, e as do superior a $0,83 \pm$ $0,21 \mathrm{~m} / \mathrm{s}$, não sendo observada diferença significativa entre os grupos $(p=0,582)$. 
Tabela 9. Distribuição de pressão plantar de mulheres idosas estratificadas de acordo com os tercis do \%G (tercil inferior, intermédio e superior). Dados expressos em média \pm desvio padrão.

\begin{tabular}{|c|c|c|c|c|c|}
\hline Variáveis baropodométricas & $\begin{array}{l}\text { Tercil inferior } \\
(n=18)\end{array}$ & $\begin{array}{l}\text { Tercil intermédio } \\
(n=23)\end{array}$ & $\begin{array}{l}\text { Tercil superior } \\
\quad(n=21)\end{array}$ & $\begin{array}{c}P \\
\text { ANOVA One-Way/ } \\
\text { Kruskal-Wallis }\end{array}$ & $\begin{array}{c}\text { Bonferroni/ Mann- } \\
\text { Whitney }\end{array}$ \\
\hline \multicolumn{6}{|c|}{ 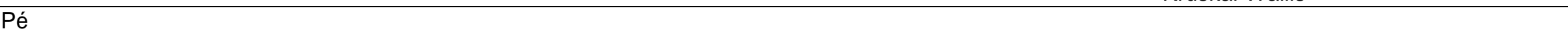 } \\
\hline Força máxima $(\mathrm{N})$ & $663,66 \pm 82,96$ & $730,07 \pm 64,63$ & $875,28 \pm 98,04$ & $\S 0,000$ & $a^{* *}, b^{* *}, c^{* *}$ \\
\hline Força máxima relativa (\%kg) & $115,02 \pm 6,17$ & $115,79 \pm 5,74$ & $112,80 \pm 3,55$ & $£ 0,280$ & \\
\hline Pico de pressão $(\mathrm{kPa})$ & $434,17 \pm 134,30$ & $513,04 \pm 174,22$ & $548,57 \pm 128,09$ & $£ 0,018$ & $a^{*}$ \\
\hline Área de contato $\left(\mathrm{cm}^{2}\right)$ & $126,48 \pm 14,50$ & $130,86 \pm 16,56$ & $138,83 \pm 14,93$ & $\S 0,046$ & $a^{*}$ \\
\hline Índice de arco dinâmico & $0,22 \pm 0,04$ & $0,24 \pm 0,05$ & $0,26 \pm 0,03$ & $£ 0,027$ & $a^{*}$ \\
\hline \multicolumn{6}{|l|}{ Retropé } \\
\hline Força máxima $(\mathrm{N})$ & $390,52 \pm 60,44$ & $410,55 \pm 57,82$ & $457,03 \pm 62,99$ & $\S 0,003$ & $a^{*}, c^{*}$ \\
\hline Força máxima relativa (\%kg) & $67,65 \pm 6,81$ & $65,54 \pm 10,96$ & $59,32 \pm 8,81$ & $£ 0,015$ & $a^{*}$ \\
\hline Pico de pressão $(\mathrm{kPa})$ & $253,89 \pm 46,45$ & $272,83 \pm 62,45$ & $288,57 \pm 71,87$ & $\S 0,226$ & \\
\hline Área de contato $\left(\mathrm{cm}^{2}\right)$ & $32,39 \pm 2,88$ & $32,08 \pm 2,92$ & $34,01 \pm 4,19$ & $\S 0,146$ & \\
\hline \multicolumn{6}{|l|}{ Médiopé } \\
\hline Força máxima $(\mathrm{N})$ & $104,88 \pm 51,41$ & $146,90 \pm 82,07$ & $205,21 \pm 105,17$ & $\S 0,002$ & $a^{*}$ \\
\hline Força máxima relativa (\%kg) & $18,04 \pm 8,53$ & $23,17 \pm 12,41$ & $25,86 \pm 11,83$ & $\S 0,100$ & \\
\hline Pico de pressão $(\mathrm{kPa})$ & $128,06 \pm 27,23$ & $157,83 \pm 44,36$ & $193,10 \pm 54,32$ & $£ 0,000$ & $a^{* *}$ \\
\hline Área de contato $\left(\mathrm{cm}^{2}\right)$ & $23,50 \pm 6,80$ & $25,77 \pm 8,24$ & $30,94 \pm 7,16$ & $\S 0,009$ & $a^{*}$ \\
\hline \multicolumn{6}{|l|}{ Antepé } \\
\hline Força máxima $(\mathrm{N})$ & $550,05 \pm 88,63$ & $556,73 \pm 94,55$ & $673,26 \pm 99,45$ & $\S 0,000$ & $a^{* *}, c^{* *}$ \\
\hline Força máxima relativa (\%kg) & $95,36 \pm 11,58$ & $88,32 \pm 13,29$ & $86,81 \pm 8,97$ & $\S 0,057$ & \\
\hline Pico de pressão $(\mathrm{kPa})$ & $374,72 \pm 85,84$ & $419,13 \pm 152,61$ & $465,71 \pm 124,38$ & $£ 0,057$ & \\
\hline Área de contato $\left(\mathrm{cm}^{2}\right)$ & $48,12 \pm 5,96$ & $48,53 \pm 6,02$ & $51,60 \pm 5,42$ & $\S 0,119$ & \\
\hline \multicolumn{6}{|l|}{ Hálux } \\
\hline Força máxima $(\mathrm{N})$ & $85,03 \pm 29,30$ & $107,97 \pm 40,19$ & $108,97 \pm 57,10$ & $\S 0,175$ & \\
\hline Força máxima relativa (\%kg) & $14,84 \pm 5,49$ & $17,30 \pm 7,08$ & $14,05 \pm 7,09$ & $\S 0,248$ & \\
\hline Pico de pressão $(\mathrm{kPa})$ & $337,50 \pm 175,49$ & $420,65 \pm 211,06$ & $373,57 \pm 206,04$ & $£ 0,341$ & \\
\hline Área de contato $\left(\mathrm{cm}^{2}\right)$ & $9,86 \pm 1,17$ & $11,06 \pm 1,70$ & $10,48 \pm 1,91$ & $\S 0,075$ & \\
\hline \multicolumn{6}{|l|}{ Dedos } \\
\hline Força máxima $(\mathrm{N})$ & $53,02 \pm 26,16$ & $60,01 \pm 20,46$ & $49,66 \pm 25,92$ & $£ 0,240$ & \\
\hline Força máxima relativa (\%kg) & $9,34 \pm 4,81$ & $9,54 \pm 3,31$ & $6,57 \pm 3,54$ & $£ 0,021$ & $c^{*}$ \\
\hline Pico de pressão $(\mathrm{kPa})$ & $171,11 \pm 88,00$ & $213,70 \pm 121,77$ & $172,62 \pm 103,92$ & $£ 0,375$ & \\
\hline Área de contato $\left(\mathrm{cm}^{2}\right)$ & $12,35 \pm 2,78$ & $13,17 \pm 2,69$ & $11,73 \pm 3,31$ & $\S 0,271$ & \\
\hline
\end{tabular}

Area de contato $\left(\mathrm{cm}^{2}\right)$

\%G: percentual de gordura corporal; § ANOVA One-Way; £ Kruskal-Wallis.

Diferenças entre grupos: (a) Tercis inferior-superior; (b) Tercis inferior-intermédio (c) Tercis intermédio-superior

${ }^{*} p<0,05 ;{ }^{* *} p<0,001$. 
De forma complementar, a correlação entre os índices de adiposidade corporal $\mathrm{e}$ as variáveis baropodométricas é demonstrada na Tabela 10 . Corroborando as observações supracitadas, os índices de adiposidade analisados associaram-se de maneira significativa, direta e forte com a força máxima do pé. Houve, também, padrão de associação similar, porém classificada como moderada, com a área de contato e o índice de arco dinâmico. Além disso, a CC e o \%G apresentaram correlação significativa, direta e fraca com o pico de pressão.

Quanto às regiões anatômicas dos pés, observa-se, no retropé, associação significativa, direta e moderada entre os índices de adiposidade e a força máxima. Quando a força máxima é relativizada para a massa corporal, no entanto, essa correlação se torna inversa. Verifica-se, ainda, que a área de contato se correlaciona de forma significativa e direta com a CC e com o IMC (correlação moderada e fraca, respectivamente).

Tratando do mediopé, é notória a associação significativa, direta e moderada dos índices de adiposidade com todas as variáveis baropodométricas.

Em relação ao antepé, é possível observar relacionamento significativo e direto dos índices de adiposidade corporal com a força máxima e a área de contato. Cabe especificar que o IMC e a CC apresentou associação forte com a força máxima e moderada com a área de contato; enquanto $0 \% G$ se correlacionou de forma modera e fraca, respectivamente. Ademais, nota-se correlação moderada do $\% G$ com o pico de pressão - também significativa e direta.

O hálux, por sua vez, demonstra associação significativa apenas entre a $\mathrm{CC} e$ a força máxima relativa, a qual é classificada como inversa e fraca. Para os demais dedos, observa-se padrão de associação similar, porém moderada, entre a força máxima relativa e todos os índices de adiposidade corporal estudados. Verifica-se, ainda, correlação significativa, inversa e fraca da CC com a força máxima dos dedos. 


\subsection{ADIPOSIDADE CORPORAL E ESTABILIDADE POSTURAL}

A estabilidade postural das participantes, estratificadas de acordo com o IMC, a CC e o \%G, é apresentada nas Tabelas 11, 12 e 13, respectivamente. Curiosamente, a velocidade de oscilação do COP, durante as diferentes condições experimentais, não apresentou diferença significante entre os grupos, em nenhuma das classificações. No entanto, a análise da amplitude de deslocamento do COP nas direções AP e ML revelou diferenças significativas em algumas das condições testadas, onde idosas com maiores índices de adiposidade corporal demonstraram maior amplitude de oscilação.

De acordo com a classificação do IMC, é possível observar, nas condições de base aberta, diferença estatisticamente significante na amplitude de deslocamento do COP, tanto nas direções AP quanto ML. Nas condições de base fechada, por sua vez, nota-se diferença significativa apenas para a oscilação ML testada com os olhos fechados; embora, haja tendência para significância na oscilação AP, com olhos abertos e fechados $(p<0,08)$. Ressalta-se que essas diferenças foram encontradas somente entre as idosas eutróficas e obesas, não sendo observadas em relação às sobrepesadas (Tabela 11).

Quanto à estratificação efetuada pela medida da CC, houve diferença significante apenas para as oscilações na direção AP, as quais foram observadas nas condições de base aberta e de BFOF. Essas diferenças foram observadas entre os tercis inferior e intermédio nas condições de base aberta, e entre os tercis inferior e superior, nas condições de olhos fechados. Ademais, é possível notar tendência para significância na oscilação $\mathrm{ML}$ das condições BAOA $(p<0,09)$ e BAOF $(p<0,06)$ (Tabela 12).

Por fim, para a classificação efetuada pelo \%G, foi encontrada diferença na oscilação AP, em todas as condições experimentais. Tratando da oscilação ML, também foi observada diferença na maioria das condições, exceto para BFOA. Cabe ressaltar que essas diferenças ocorreram somente entre os tercis inferior e superior (Tabela 13). 
Tabela 11. Estabilidade postural de mulheres idosas estratificadas de acordo com o IMC (eutróficas, sobrepesadas e obesas). Dados expressos em média \pm desvio padrão.

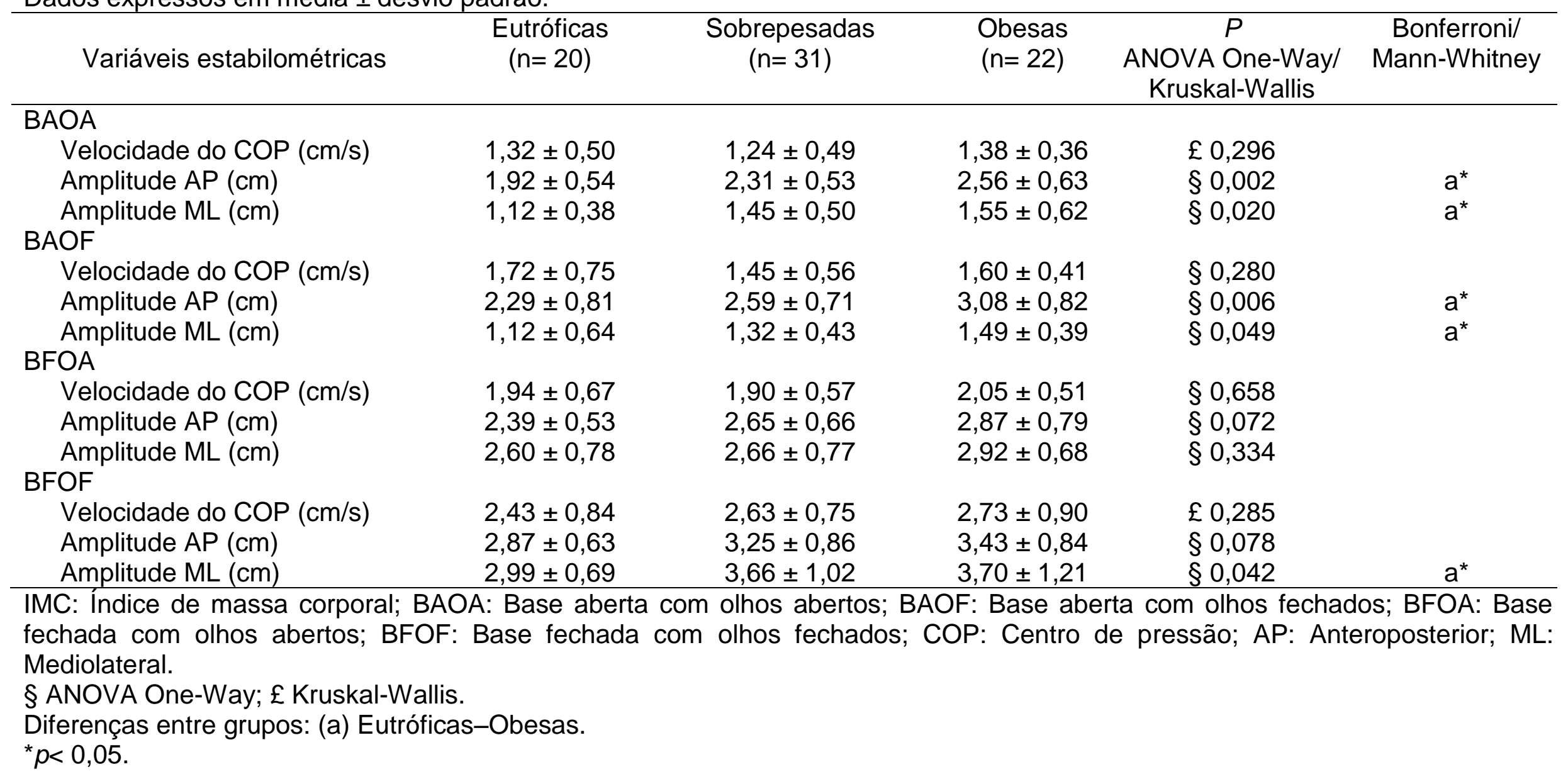


Tabela 12. Estabilidade postural de mulheres idosas estratificadas de acordo com os tercis da CC (tercil inferior, intermédio e superior). Dados expressos em média \pm desvio padrão.

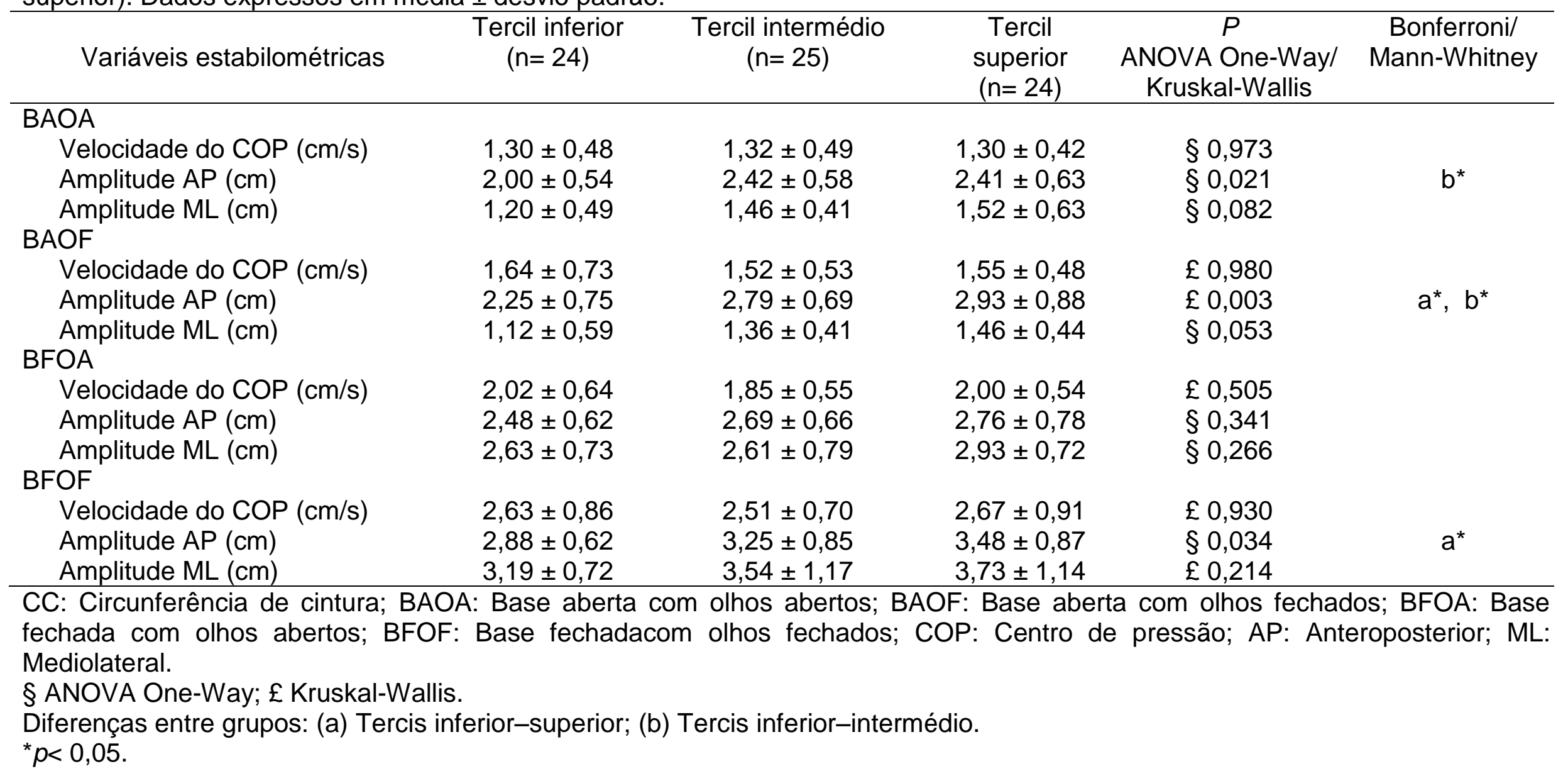


Tabela 13. Estabilidade postural de mulheres idosas estratificadas de acordo com os tercis do \%G (tercil inferior, intermédio e superior). Dados expressos em média \pm desvio padrão.

\begin{tabular}{|c|c|c|c|c|c|}
\hline Variáveis estabilométricas & $\begin{array}{l}\text { Tercil inferior } \\
(n=24)\end{array}$ & $\begin{array}{l}\text { Tercil intermédio } \\
(\mathrm{n}=25)\end{array}$ & $\begin{array}{c}\text { Tercil } \\
\text { superior } \\
(n=24)\end{array}$ & $\begin{array}{c}P \\
\text { ANOVA One-Way/ } \\
\text { Kruskal-Wallis }\end{array}$ & $\begin{array}{c}\text { Bonferroni/ } \\
\text { Mann-Whitney }\end{array}$ \\
\hline \multicolumn{6}{|l|}{ BAOA } \\
\hline Amplitude AP $(\mathrm{cm})$ & $1,99 \pm 0,58$ & $2,25 \pm 0,52$ & $2,60 \pm 0,58$ & $\S 0,001$ & $a^{*}$ \\
\hline Amplitude ML (cm) & $1,17 \pm 0,49$ & $1,47 \pm 0,55$ & $1,52 \pm 0,50$ & $£ 0,017$ & $a^{*}$ \\
\hline \multicolumn{6}{|l|}{ BAOF } \\
\hline Velocidade do COP $(\mathrm{cm} / \mathrm{s})$ & $1,64 \pm 0,70$ & $1,44 \pm 0,59$ & $1,63 \pm 0,43$ & $\S 0,414$ & \\
\hline Amplitude ML (cm) & $1,10 \pm 0,59$ & $1,37 \pm 0,45$ & $1,47 \pm 0,38$ & $\S 0,022$ & $a^{*}$ \\
\hline \multicolumn{6}{|l|}{ BFOA } \\
\hline Velocidade do COP $(\mathrm{cm} / \mathrm{s})$ & $1,94 \pm 0,64$ & $1,88 \pm 0,56$ & $2,05 \pm 0,55$ & $£ 0,452$ & \\
\hline Amplitude AP (cm) & $2,42 \pm 0,61$ & $2,58 \pm 0,60$ & $2,93 \pm 0,78$ & $\S 0,030$ & $a^{*}$ \\
\hline Amplitude ML (cm) & $2,53 \pm 0,73$ & $2,77 \pm 0,76$ & $2,87 \pm 0,74$ & $\S 0,292$ & \\
\hline \multicolumn{6}{|l|}{ BFOF } \\
\hline Velocidade do COP (cm/s) & $2,49 \pm 0,81$ & $2,56 \pm 0,72$ & $2,77 \pm 0,93$ & $£, 442$ & \\
\hline
\end{tabular}

\%G: Percentual de gordura corporal; BAOA: Base aberta com olhos abertos; BAOF: Base aberta com olhos fechados; BFOA: Base fechada com olhos abertos; BFOF: Base fechada com olhos fechados; COP: Centro de pressão; AP: Anteroposterior; ML: Mediolateral.

$\S$ ANOVA One-Way; £ Kruskal-Wallis.

Diferenças entre grupos: (a) Tercis inferior-superior.

${ }^{*} p<0,05 ;{ }^{* *} p<0,001$. 
Adicionalmente, a associação entre os índices de adiposidade corporal e as variáveis estabilométricas é demonstrada na Tabela 14. Reforçando as observações supracitadas, é possível observar que a velocidade de oscilação do COP, durante as diferentes condições experimentais, não apresentou correlação estatisticamente significante com os índices de adiposidade. A amplitude de deslocamento do COP nas direções AP e ML, por outro lado, demonstrou associação direta e significativa em algumas das condições testadas. Curiosamente, a CC foi o índice que melhor se correlacionou com as amplitudes de deslocamento - houve associação com a maioria delas, exceto com a amplitude ML da BFOA. Essas correlações foram classificadas como moderadas, para a amplitude AP nas condições com olhos fechados, e como fracas, para as demais. O IMC, por sua vez, se relacionou apenas, de maneira fraca, com a amplitude AP nas condições de base aberta. Quanto ao \%G, é possível observar associação fraca com a amplitude AP da maioria das condições experimentais, menos da BFOA. Em relação à amplitude $\mathrm{ML}$, observa-se correlação somente para BAOA, classificada como moderada.

Tabela 14. Correlação entre os índices de adiposidade corporal (IMC, CC e \%G) e a estabilidade postural de mulheres idosas $(n=73)$.

\begin{tabular}{|c|c|c|c|}
\hline Variáveis estabilométricas & IMC & CC & $\% G$ \\
\hline \multicolumn{4}{|l|}{$\mathrm{BAOA}$} \\
\hline Velocidade do COP (cm/s) & $£ 0,059$ & $£ 0,095$ & $£ 0,055$ \\
\hline Amplitude AP $(\mathrm{cm})$ & $\S 0,293^{*}$ & $\S 0,295^{*}$ & $\S 0,272^{*}$ \\
\hline Amplitude $\mathrm{ML}(\mathrm{cm})$ & $£ 0,230$ & $£ 0,292^{*}$ & $£ 0,320^{*}$ \\
\hline \multicolumn{4}{|l|}{ BAOF } \\
\hline Velocidade do COP (cm/s) & $\S-0,091$ & $\S-0,004$ & $\S-0,148$ \\
\hline Amplitude AP $(\mathrm{cm})$ & $\S 0,299^{*}$ & $\S 0,437^{* *}$ & $\S 0,274^{*}$ \\
\hline Amplitude ML (cm) & $\S 0,227$ & $\S 0,386^{*}$ & $\S 0,164$ \\
\hline \multicolumn{4}{|l|}{ BFOA } \\
\hline Velocidade do COP (cm/s) & $\S 0,030$ & $\S 0,107$ & $\S-0,010$ \\
\hline Amplitude AP $(\mathrm{cm})$ & $\S 0,178$ & $\S 0,254^{*}$ & $\S 0,211$ \\
\hline Amplitude ML (cm) & $\S 0,132$ & $\S 0,210$ & $\S 0,161$ \\
\hline \multicolumn{4}{|l|}{ BFOF } \\
\hline Velocidade do COP (cm/s) & $£ 0,090$ & $£ 0,103$ & $£ 0,128$ \\
\hline Amplitude AP $(\mathrm{cm})$ & $\S 0,207$ & $\S 0,361^{*}$ & $\S 0,268^{*}$ \\
\hline Amplitude ML (cm) & $£ 0,208$ & $£ 0,249^{*}$ & $£ 0,231$ \\
\hline \multicolumn{4}{|c|}{$\begin{array}{l}\text { IMC: Índice de massa corporal; CC: Circunferência de cintura; \%G: Percentual de } \\
\text { gordura corporal; BAOA: Base aberta com olhos abertos; BAOF: Base aberta com } \\
\text { olhos fechados; BFOA: Base fechada com olhos abertos; BFOF: Base fechada com } \\
\text { olhos fechados; COP: Centro de pressão; AP: Anteroposterior; ML: Mediolateral. } \\
\S \text { Coeficiente de correlação de Pearson; £ Coeficiente de correlação de Spearman. } \\
{ }^{\star} p<0,05 ;{ }^{* \star} p<0,001 .\end{array}$} \\
\hline
\end{tabular}




\subsection{ADIPOSIDADE CORPORAL E RISCO DE QUEDAS}

A prevalência de fatores risco para quedas entre as participantes, estratificadas de acordo com o IMC, a CC e o \%G, bem como a probabilidade das mesmas sofrerem uma queda nos próximos 12 meses, são apresentadas nas Tabelas 15, 16 e 17, respectivamente. É possível observar que a ocorrência de quedas no ano anterior e a diminuição da força muscular foram fatores de risco que se apresentaram significativamente diferentes entre os estratos dos índices de adiposidade corporal estudados. Para a classificação do IMC e da CC, houve diferença significativa, também, no comprometimento do tempo de reação. Tratando mais uma vez da estratificação pela CC, observa-se, ainda, diferença na diminuição da sensibilidade periférica. Para a classificação do \%G, por sua vez, foi encontrada diferença quanto ao uso de quatro medicamentos ou mais. Em relação à probabilidade de cair, nota-se diferença estatisticamente significante entre os estratos dos diferentes índices de adiposidade corporal. Notavelmente, maiores índices de adiposidade demonstraram maior prevalência dos fatores de risco, assim como maior probabilidade de queda.

As variáveis numéricas relacionadas ao risco de quedas são apresentadas nas Tabelas 18, 19 e 20, conforme a estratificação efetuada pelo IMC, CC e \%G, respectivamente. É notório que o número de fatores de risco para quedas, avaliado pelo QuickScreen, apresentou diferença significativa entre os grupos, em todas as classificações. As diferenças apontadas foram entre os estratos inferiores e superiores de adiposidade, bem como entre os inferiores e intermédios. Além disso, para a classificação da CC, é possível observar, também, diferença significativa nos valores da FES-I, entre os tercis inferior e superior; e tendência para significância nos valores do TUG $(p<0,07)$. Estes achados apontam para pior desempenho entre as participantes com maiores índices de adiposidade corporal. 
Tabela 15. Risco de quedas de mulheres idosas estratificadas de acordo com o IMC (eutróficas, sobrepesadas e obesas). Dados expressos em frequência absoluta e relativa.

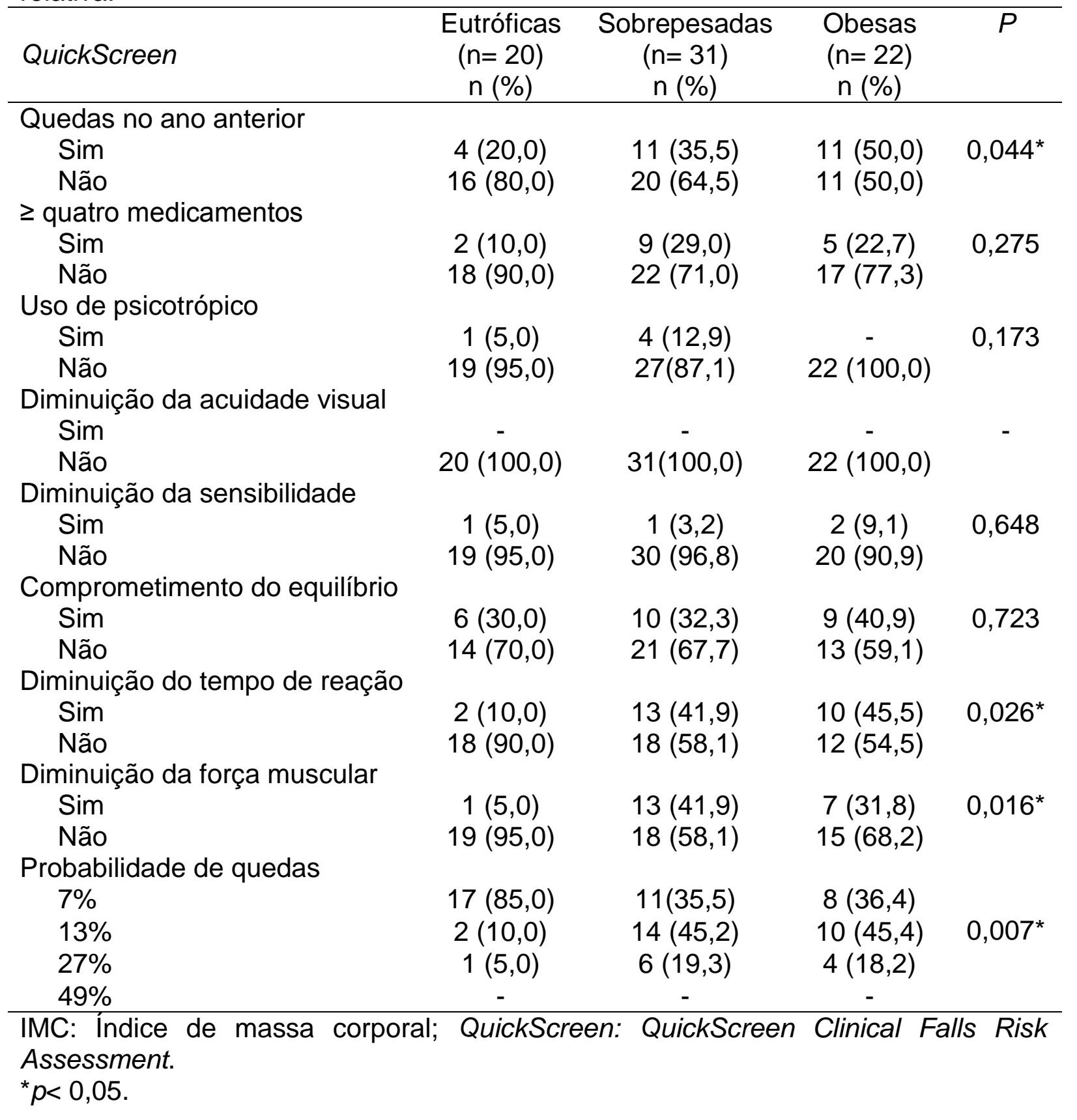


Tabela 16. Risco de quedas de mulheres idosas estratificadas de acordo com os tercis da CC (tercil inferior, intermédio e superior). Dados expressos em frequência absoluta e relativa.

\begin{tabular}{|c|c|c|c|c|}
\hline QuickScreen & $\begin{array}{c}\text { Tercil } \\
\text { inferior } \\
(\mathrm{n}=24) \\
\mathrm{n}(\%)\end{array}$ & $\begin{array}{c}\text { Tercil } \\
\text { intermédio } \\
(\mathrm{n}=25) \\
\mathrm{n}(\%)\end{array}$ & $\begin{array}{c}\text { Tercil } \\
\text { superior } \\
(\mathrm{n}=24) \\
\mathrm{n}(\%)\end{array}$ & $P$ \\
\hline \multicolumn{5}{|c|}{ Quedas no ano anterior } \\
\hline Sim & $5(20,8)$ & $8(32,0)$ & $13(54,2)$ & \multirow[t]{2}{*}{$0,017^{\star}$} \\
\hline Não & $19(79,2)$ & $17(68,0)$ & $11(45,8)$ & \\
\hline \multicolumn{5}{|c|}{$\geq$ quatro medicamentos } \\
\hline Sim & $5(20,8)$ & $4(16,0)$ & $7(29,2)$ & \multirow[t]{2}{*}{0,531} \\
\hline Não & $19(79,2)$ & $21(84,0)$ & $17(70,8)$ & \\
\hline \multicolumn{5}{|c|}{ Uso de psicotrópico } \\
\hline Sim & $2(8,3)$ & $2(8,0)$ & $1(4,2)$ & \multirow[t]{2}{*}{0,817} \\
\hline Não & $22(91,7)$ & $23(92,0)$ & $23(95,8)$ & \\
\hline \multicolumn{5}{|c|}{ Diminuição da acuidade visual } \\
\hline Sim & - & - & - & \multirow[t]{2}{*}{ - } \\
\hline Não & $24(100,0)$ & $25(100,0)$ & $24(100,0)$ & \\
\hline \multicolumn{5}{|c|}{ Diminuição da sensibilidade } \\
\hline Sim & - & - & $4(16,7)$ & \multirow[t]{2}{*}{$0,013^{*}$} \\
\hline Não & $24(100,0)$ & $25(100,0)$ & $20(83,3)$ & \\
\hline \multicolumn{5}{|c|}{ Comprometimento do equilíbrio } \\
\hline Sim & $5(20,8)$ & $9(36,0)$ & $11(45,8)$ & \multirow[t]{2}{*}{0,184} \\
\hline Não & $19(79,2)$ & $16(64,0)$ & $13(54,2)$ & \\
\hline \multicolumn{5}{|c|}{ Diminuição do tempo de reação } \\
\hline Sim & $2(8,3)$ & $11(44,0)$ & $12(50)$ & \multirow[t]{2}{*}{$0,004^{*}$} \\
\hline Não & $22(91,7)$ & $14(56,0)$ & $12(50)$ & \\
\hline \multicolumn{5}{|c|}{ Diminuição da força muscular } \\
\hline Sim & $1(4,2)$ & $10(40,0)$ & $10(41,7)$ & \multirow[t]{2}{*}{$0,005^{\star}$} \\
\hline Não & $23(95,8)$ & $15(60,0)$ & $14(58,3)$ & \\
\hline \multicolumn{5}{|c|}{ Probabilidade de quedas } \\
\hline $7 \%$ & $20(83,3)$ & $9(36,0)$ & $7(29,2)$ & \multirow[t]{4}{*}{$0,001^{*}$} \\
\hline $13 \%$ & $3(12,5)$ & $13(52,0)$ & $10(41,6)$ & \\
\hline $27 \%$ & $1(4,2)$ & $3(12,0)$ & $7(29,2)$ & \\
\hline $49 \%$ & - & - & - & \\
\hline $\begin{array}{l}\text { CC: circunfe } \\
\text { Assessment. } \\
{ }^{*} p<0,05 \text {. }\end{array}$ & & QuickS & Clinical $F_{c}$ & Is Risk \\
\hline
\end{tabular}


Tabela 17. Risco de quedas de mulheres idosas estratificadas de acordo com os tercis do \%G (tercil inferior, intermédio e superior). Dados expressos em frequência absoluta e relativa.

\begin{tabular}{|c|c|c|c|c|}
\hline QuickScreen & $\begin{array}{c}\text { Tercil } \\
\text { inferior } \\
(\mathrm{n}=24) \\
\mathrm{n}(\%) \\
\end{array}$ & $\begin{array}{c}\text { Tercil } \\
\text { intermédio } \\
(\mathrm{n}=25) \\
\mathrm{n}(\%)\end{array}$ & $\begin{array}{c}\text { Tercil } \\
\text { superior } \\
(\mathrm{n}=24) \\
\mathrm{n}(\%) \\
\end{array}$ & $P$ \\
\hline \multicolumn{5}{|c|}{ Quedas no ano anterior } \\
\hline Sim & $5(20,8)$ & $7(28,0)$ & $14(58,3)$ & \multirow[t]{2}{*}{$0,016^{*}$} \\
\hline Não & $19(79,2)$ & $18(72,0)$ & $10(41,7)$ & \\
\hline \multicolumn{5}{|c|}{$\geq$ quatro medicamentos } \\
\hline Sim & $2(8,3)$ & $10(40,0)$ & $4(16,7)$ & \multirow[t]{2}{*}{$0,021^{*}$} \\
\hline Não & $22(91,7)$ & $15(60,0)$ & $20(83,3)$ & \\
\hline \multicolumn{5}{|c|}{ Uso de psicotrópico } \\
\hline $\operatorname{Sim}$ & $1(4,2)$ & $4(16,0)$ & - & \multirow[t]{2}{*}{0,070} \\
\hline Não & $23(95,8)$ & $21(84,0)$ & $24(100,0)$ & \\
\hline \multicolumn{5}{|c|}{ Diminuição da acuidade visual } \\
\hline Sim & & - & & \multirow[t]{2}{*}{-} \\
\hline Não & $24(100,0)$ & $25(100,0)$ & $24(100,0)$ & \\
\hline \multicolumn{5}{|c|}{ Diminuição da sensibilidade } \\
\hline Sim & $1(4,2)$ & - & $3(12,5)$ & \multirow[t]{2}{*}{0,149} \\
\hline Não & $23(95,8)$ & $25(100)$ & $21(87,5)$ & \\
\hline \multicolumn{5}{|c|}{ Comprometimento do equilíbrio } \\
\hline Sim & $6(25,0)$ & $8(32,0)$ & $11(45,8)$ & \multirow[t]{2}{*}{0,301} \\
\hline Não & $18(75,0)$ & $17(68,0)$ & $13(54,2)$ & \\
\hline \multicolumn{5}{|c|}{ Diminuição do tempo de reação } \\
\hline Sim & $4(16,7)$ & $11(44,0)$ & $10(41,7)$ & \multirow[t]{2}{*}{0,085} \\
\hline Não & $20(83,3)$ & $14(56,0)$ & $14(58,3)$ & \\
\hline \multicolumn{5}{|c|}{ Diminuição da força muscular } \\
\hline Sim & $3(12,5)$ & $7(28,0)$ & $11(45,8)$ & \multirow[t]{2}{*}{$0,038^{*}$} \\
\hline Não & $21(87,5)$ & $18(72,0)$ & $13(54,2)$ & \\
\hline \multicolumn{5}{|c|}{ Probabilidade de quedas } \\
\hline $7 \%$ & $20(83,3)$ & $9(36,0)$ & $7(29,2)$ & \multirow[t]{4}{*}{$0,002^{*}$} \\
\hline $13 \%$ & $3(12,5)$ & $11(44,0)$ & $12(50,0)$ & \\
\hline $27 \%$ & $1(4,2)$ & $5(20,0)$ & $5(20,8)$ & \\
\hline $49 \%$ & - & - & - & \\
\hline
\end{tabular}


Tabela 18. Risco de quedas de mulheres idosas estratificadas de acordo com o IMC (eutróficas, sobrepesadas e obesas). Dados expressos em média \pm desvio padrão.

\begin{tabular}{|c|c|c|c|c|c|}
\hline & $\begin{array}{l}\text { Eutróficas } \\
(n=20)\end{array}$ & $\begin{array}{l}\text { Sobrepesadas } \\
\qquad(n=31)\end{array}$ & $\begin{array}{l}\text { Obesas } \\
(n=22)\end{array}$ & $\begin{array}{c}P \\
\text { ANOVA One-Way/ } \\
\text { Kruskal-Wallis }\end{array}$ & $\begin{array}{c}\text { Bonferroni/ } \\
\text { Mann-Whitney }\end{array}$ \\
\hline $\begin{array}{l}\text { QuickScreen - Fatores de risco para quedas } \\
\text { TUG (s) } \\
\text { FFS-I }\end{array}$ & $\begin{array}{l}0,85 \pm 0,988 \\
6,53 \pm 0,84\end{array}$ & $\begin{array}{l}1,97 \pm 1,426 \\
6,80 \pm 1,06\end{array}$ & $\begin{array}{c}2,00 \pm 1,447 \\
7,10 \pm 1,03 \\
2909+757\end{array}$ & $\begin{array}{l}£ 0,005 \\
£ 0,141 \\
\delta 055 ?\end{array}$ & $a^{*}, b^{*}$ \\
\hline
\end{tabular}

IMC: Índice de massa corporal; QuickScreen: QuickScreen Clinical Falls Risk Assessment; TUG: Timed Up and Go; FES-I: Escala de Eficácia de Quedas - Internacional.

$\S$ ANOVA One-Way; £ Kruskal-Wallis.

Diferenças entre grupos: (a) Eutróficas-Obesas; (b) Eutróficas-Sobrepesadas.

${ }^{*} p<0,05$.

Tabela 19. Risco de quedas de mulheres idosas estratificadas de acordo com os tercis da CC (tercil inferior, intermédio e superior). Dados expressos em média \pm desvio padrão.

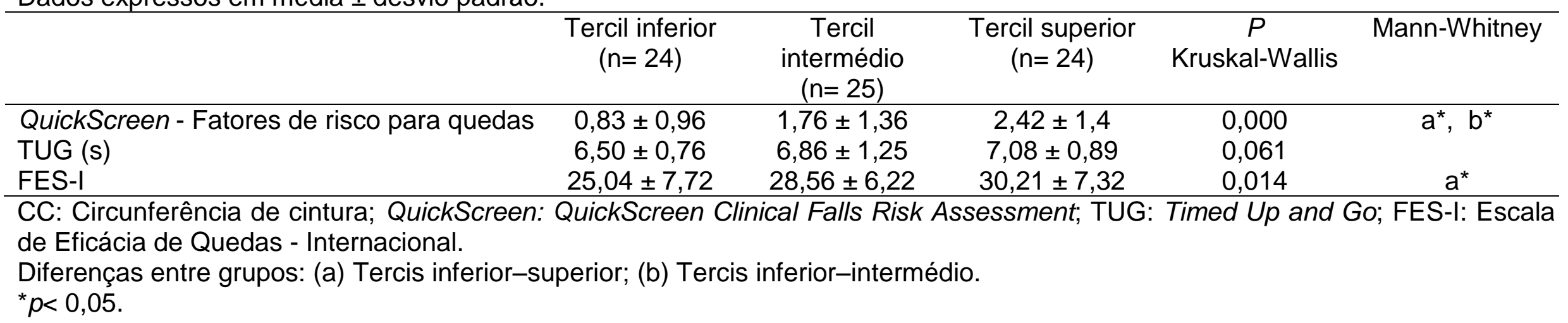


Tabela 20. Risco de quedas de mulheres idosas estratificadas de acordo com os tercis do \%G (tercil inferior, intermédio e superior). Dados expressos em média \pm desvio padrão.

\begin{tabular}{lccccc}
\hline & $\begin{array}{c}\text { Tercil inferior } \\
(\mathrm{n}=24)\end{array}$ & $\begin{array}{c}\text { Tercil } \\
\text { intermédio } \\
(\mathrm{n}=25)\end{array}$ & $\begin{array}{c}\text { Tercil } \\
\text { superior } \\
(\mathrm{n}=24)\end{array}$ & $\begin{array}{c}P \\
\text { Kruskal-Wallis }\end{array}$ & $\begin{array}{c}\text { Mann-Whitney } \\
\text { QuickScreen - Fatores de risco para quedas }\end{array}$ \\
TUG (s) & $0,92 \pm 1,018$ & $1,88 \pm 1,48$ & $2,21 \pm 1,38$ & 0,002 & $\mathrm{a}^{*}, \mathrm{~b}^{*}$ \\
FES-I & $6,50 \pm 0,81$ & $6,83 \pm 1,04$ & $7,12 \pm 1,10$ & 0,106 & 0,123 \\
\hline
\end{tabular}

\%G: percentual de gordura corporal; QuickScreen: QuickScreen Clinical Falls Risk Assessment; TUG: Timed Up and Go; FES-I: Escala de Eficácia de Quedas - Internacional.

Diferenças entre grupos: (a) Tercis inferior-superior; (b) Tercis inferior-intermédio.

${ }^{*} p<0,05$. 
De modo complementar, a associação entre os índices de adiposidade corporal e as variáveis relacionadas ao risco de quedas é demonstrada na Tabela 21. Corroborando as observações supracitadas, a CC foi o índice que melhor se correlacionou com as variáveis de risco de quedas - houve associação significativa, direta e moderada com o comprometimento do tempo de reação, a diminuição da força muscular, o número de fatores de risco para quedas, a probabilidade de cair e o desempenho no teste TUG. Observa-se, ainda, padrão de associação similar, porém classificada como fraca, para ocorrência de quedas no ano anterior, diminuição da sensibilidade e FES-I. Para os demais índices (i.e. IMC e \%G), é possível observar correlação significativa, direta e moderada com o número de fatores de risco para quedas e com a probabilidade de cair, e de maneira fraca com o comprometimento do tempo de reação, a diminuição da força muscular e o desempenho no teste TUG. Ademais, a ocorrência de quedas no ano anterior se associou de forma fraca com o IMC e de forma moderada com o \%G, ambas significativas e diretas.

Tabela 21. Correlação entre os índices de adiposidade corporal (IMC, CC e \%G) e o risco de quedas de mulheres idosas $(n=73)$.

\begin{tabular}{|c|c|c|c|}
\hline & IMC & $\mathrm{CC}$ & $\% G$ \\
\hline \multicolumn{4}{|l|}{ QuickScreen } \\
\hline Quedas no ano anterior & $£ 0,280^{*}$ & $£ 0,271^{*}$ & $£ 0,335^{*}$ \\
\hline$\geq$ quatro medicamentos & $£ 0,119$ & $£ 0,140$ & $£ 0,065$ \\
\hline Uso de psicotrópico & $£-0,134$ & $£-0,071$ & \\
\hline \multicolumn{4}{|l|}{ Diminuição da acuidade visual } \\
\hline Diminuição da sensibilidade & $£ 0,129$ & $£ 0,290^{*}$ & $£ 0,107$ \\
\hline Comprometimento do equilíbrio & & & \\
\hline Diminuição do tempo de reação & $£ 0,267^{*}$ & $£ 0,377^{*}$ & $£ 0,255^{*}$ \\
\hline Diminuição da força muscular & $£ 0,248^{*}$ & $£ 0,365^{\star}$ & $£ 0,294^{*}$ \\
\hline Fatores de risco para quedas & $\S 0,326^{*}$ & $\S 0,470^{* *}$ & $\S 0,348^{*}$ \\
\hline Probabilidade de quedas & $£ 0,369^{*}$ & $£ 0,501^{* *}$ & $£ 0,378^{*}$ \\
\hline TUG & $\S 0,244^{*}$ & & $\S 0,242^{*}$ \\
\hline FES-I & $\S 0,082$ & $\S 0,272^{*}$ & $\S 0,108$ \\
\hline \multicolumn{4}{|c|}{$\begin{array}{l}\text { IMC: Índice de massa corporal; CC: Circunferência de cintura; \%G: Percentual de } \\
\text { gordura corporal; QuickScreen: QuickScreen Clinical Falls Risk Assessment; TUG } \\
\text { Timed Up and Go; FES-I: Escala de Eficácia de Quedas - Internacional. } \\
\text { § Coeficiente de correlação de Pearson; £ Coeficiente de correlação de Spearman. } \\
{ }^{*} p<0,05 ;{ }^{* *} p<0,001 \text {. }\end{array}$} \\
\hline
\end{tabular}


Por fim, a Tabela 22 apresenta o Odds Ratio dos estratos superiores dos índices de adiposidade corporal (IMC, CC e \%G) para os desfechos de ocorrência de quedas no ano anterior e risco de quedas aumentado (QuickScreen $\geq 27 \%$ ), adotando como referência os estratos inferiores de adiposidade. É notório que o excesso de adiposidade corporal está relacionado a uma maior razão de possibilidades para a ocorrência de quedas no ano anterior, bem como para o risco de quedas aumentado. Dentre os índices analisados, o \% apresentou a maior razão de possibilidades para a ocorrência de quedas no ano anterior, seguido da CC e do IMC. Para o risco de quedas aumentado, apenas a CC apresentou razão de possibilidades aumentada de forma significativa.

Tabela 22. Odds Ratio (Intervalo de Confiança $=95 \%$ ) dos estratos superiores dos índices de adiposidade corporal (IMC, CC e \%G) para os desfechos de ocorrência de quedas no ano anterior e risco de quedas aumentado (QuickScreen $\geq 27 \%$ ), adotando como referência os estratos inferiores de adiposidade.

\begin{tabular}{lcc}
\hline & Quedas no ano anterior & Risco de quedas aumentado \\
\hline IMC - Obesas & $4,00(1,01-15,87)^{\star}$ & $4,22(0,43-41,45)$ \\
CC - Tercil superior & $4,49(1,26-16,01)^{\star}$ & $9,47(1,06-84,38)^{\star}$ \\
$\%$ \% - Tercil superior & $5,32(1,48-19,06)^{\star}$ & $6,05(0,65-56,37)$ \\
\hline IMC: İndice de massa corporal; CC: Circunferência de cintura; \%G: Percentual de \\
gordura corporal; QuickScreen: QuickScreen Clinical Falls Risk Assessment. \\
${ }^{*} p<0,05$.
\end{tabular}




\section{DISCUSSÃO}

A maior ocorrência de quedas em idosos com excesso de adiposidade corporal tem ganhado evidência em estudos recentes (Fjeldstad et al., 2008; Himes e Reynolds, 2012; Mitchell et al., 2014). No entanto, os mecanismos associados a esta condição ainda não estão claros. No presente estudo, comparou-se a força muscular, a distribuição de pressão plantar, a estabilidade postural e o risco de quedas de mulheres idosas estratificadas de acordo com diferentes índices de adiposidade corporal (IMC, CC e \%G). Verificou-se, ainda, a correlação destes índices com as variáveis supracitadas. Os principais achados foram: a) idosas com maior adiposidade demonstraram menor força muscular relativa; b) houve comprometimento da distribuição de pressão plantar em idosas com excesso de adiposidade, caracterizado, sobretudo, por maior força máxima na maioria das regiões do pé, maior área de contato e maior pico de pressão no mediopé, e valores mais elevados do índice de arco dinâmico; c) idosas com maiores índices de adiposidade corporal exibiram maior amplitude de deslocamento do COP nas direções $\mathrm{AP}$ e $\mathrm{ML}$; e d) o risco de quedas se associou positivamente com a adiposidade corporal. Para melhor compreensão do leitor, a discussão dos achados deste estudo segue estruturada em tópicos.

\subsection{ADIPOSIDADE CORPORAL E FORÇA MUSCULAR}

Ao comparar a força muscular de mulheres idosas estratificadas de acordo com diferentes índices de adiposidade corporal, observou-se que os valores absolutos se mostraram semelhantes entre os grupos. Quando a força muscular foi relativizada para a massa corporal, no entanto, idosas com excesso de adiposidade exibiram uma força reduzida. Estes resultados são especialmente importantes, visto que o comprometimento da força muscular relativa está associado a limitações funcionais em indivíduos obesos (Capodaglio et al., 2010).

Contrariando os achados do presente estudo, revisão de literatura conduzida por Maffiuletti et al. (2013) apontam que pessoas obesas apresentam maior força muscular absoluta - o que ocorre devido às adaptações musculoesqueléticas decorrentes de uma maior sobrecarga. Essa revisão, porém, deve ser interpretada 
com cautela, já que a maioria dos estudos incluídos em sua análise foram conduzidos em sujeitos jovens e adultos. Quando tratamos especificamente de idosos, é importante considerar que o processo de envelhecimento pode comprometer o mecanismo de adaptação à sobrecarga (Kalyani et al., 2014). Realmente, boa parte dos estudos que investigaram o impacto da obesidade sobre a força muscular em idosos verificou que o excesso de adiposidade não estava relacionado a uma maior força absoluta (Dey et al., 2009; Stenholm et al., 2011; Paolillo et al., 2012; Hardy et al., 2013; Cooper et al., 2014; Vilaça et al., 2014; Charlton et al., 2015; Shen et al., 2015). Quanto à força muscular relativa, parece haver um consenso em relação ao impacto negativo exercido pela obesidade (Stenholm et al., 2011; Paolillo et al., 2012; Maffiuletti et al., 2013; Shen et al., 2015).

Cabe esclarecer que o comprometimento da força muscular observado em pessoas obesas é multifatorial. Ele pode estar vinculado a um estilo de vida sedentário, maus hábitos alimentares, infiltração de gordura muscular, baixos níveis de hormônios anabólicos, resistência à insulina, e aumento da atividade inflamatória (Stenholm et al., 2008). Todavia, esses mecanismos ainda não foram completamente explorados (Kalyani et al., 2014).

Em nosso estudo, a força muscular foi avaliada por intermédio de diferentes medidas (i.e. FPM, e PT dos extensores do joelho a $60 \% / \mathrm{s}^{-1}$, a $180^{\circ} / \mathrm{s}^{-1}$ e isométrico). A FPM é um indicador geral de força muscular amplamente utilizado em pesquisas como esta (Dey et al., 2009; Stenholm et al., 2011; Hardy et al., 2013; Cooper et al., 2014; Vilaça et al., 2014; Charlton et al., 2015; Shen et al., 2015). O PT dos extensores do joelho, por sua vez, está intimamente associado ao risco de quedas (Takazawa et al., 2003; Sieri e Beretta, 2004; Perry et al., 2007; Antero-Jacquemin et al., 2012; Crozara et al., 2013) e também já foi investigado em estudos anteriores (Dey et al., 2009; Koster et al., 2011; Paolillo et al., 2012). Por meio da medida isométrica, é possível obter valores de força máxima. Esses valores, entretanto, podem não ser preditivos de desempenho dinâmico. Sendo assim, avaliamos também o PT a $60^{\circ} / \mathrm{s}^{-1}$ e a $180^{\circ} / \mathrm{s}^{-1}$, indicativos de força e potência muscular, respectivamente (Brown e Weir, 2001). É evidente que, independente da velocidade de mensuração, idosas com excesso de adiposidade corporal exibiram menor força muscular relativa.

Para finalizar, é importante ressaltar que, por se tratar de um estudo transversal, relações de causa e efeito não podem ser estabelecidas. Estudos 
prévios, no entanto, trazem importantes contribuições nesse sentido. Stenholm et al. (2011), por exemplo, demonstram que a exposição prolongada à obesidade está associada a menor FPM relativa na idade avançada. Cooper et al. (2014), por outro lado, evidenciam que aumentos mais expressivos do IMC, observados a partir dos 15 anos de idade, não foram associados com a FPM absoluta no início da velhice. Salienta-se que esses resultados corroboram os nossos achados.

\subsection{ADIPOSIDADE CORPORAL E DISTRIBUIÇÃO DE PRESSÃO PLANTAR}

O presente estudo analisou a influência do excesso de adiposidade corporal sobre a distribuição de pressão plantar em mulheres idosas. Como o esperado, maiores índices de adiposidade foram associados a valores mais elevados de força máxima na maioria das regiões do pé, exceto hálux e demais dedos. Quando a força máxima é relativizada para a massa corporal, no entanto, esse padrão de associação persiste apenas no mediopé. Digno de nota, essas forças foram distribuídas em uma maior área de contato do pé com o solo, especialmente do mediopé. A maior área de contato, todavia, não foi suficiente para compensar os valores mais elevados de força máxima, de modo que o pico de pressão se mostrou significativamente maior no mediopé das idosas classificadas nos estratos superiores dos índices de adiposidade estudados.

Esses achados são consistentes com estudos prévios, que identificaram maior pico de pressão plantar durante a marcha de indivíduos obesos (Hills et al., 2001; Birtane e Tuna, 2004; Monteiro et al., 2010; Butterworth et al., 2015; Mickle e Steele, 2015). Esses estudos, porém, devem ser analisados com cautela, já que a maioria foi conduzida em uma amostra de adultos, e a idade é um fator que exerce influência direta sobre a pressão plantar (Hessert et al., 2005; Bosch et al., 2009). Nesse sentido, Mickle e Steele (2015) foram pioneiros em examinar os efeitos do sobrepeso e da obesidade sobre a distribuição de pressão plantar de pessoas com 60 anos ou mais. Corroborando os nossos resultados, foi obervado maior pico de pressão no mediopé dos idosos com excesso de adiposidade corporal. Foram encontrados, ainda, valores mais elevados no metatarso I, diferentemente do nosso estudo, em que optamos por analisar o antepé de forma integral, visando maior confiabilidade dos dados (Deschamps et al., 2009). 
Adicionalmente, maiores índices de adiposidade foram associados a valores mais elevados do índice de arco dinâmico, o que também foi observado por Faria et al. (2010) e Butterworth et al. (2015). Um índice de arco dinâmico igual ou superior a 0,26 , como o verificado entre as idosas classificadas nos estratos superiores de adiposidade, é indicativo de pé plano (Cavanagh e Rodgers, 1987). De fato, pesquisas anteriores evidenciam a relação entre a obesidade e a ocorrência desse tipo de pé em idosos (Otsuka et al., 2003; Aurichio et al., 2011; Azarfam et al., 2014).

Sendo assim, os nossos achados suportam a hipótese de que a obesidade aumenta as tensões aplicadas ao pé, não só em virtude da massa corporal aumentada, como também por meio de alterações estruturais (i.e. achatamento do pé) (Butterworth et al., 2015). Acredita-se que, em condições de sobrecarga, as forças verticais transmitidas pela tíbia contribuem para o colapso do arco longitudinal medial, resultando em maior área de contato do mediopé com o solo (Faria et al., 2010). Ademais, nós podemos especular que a diminuição da força muscular relativa, observada nas idosas com excesso de adiposidade corporal, também contribui para as alterações estruturais do pé. Evidências demonstram que os músculos intrínsecos e extrínsecos do pé auxiliam no suporte do arco longitudinal medial (Thordarson et al., 1995; Wong, 2007), e que indivíduos com o pé plano apresentam comprometimento de alguns desses músculos (Angin et al., 2014). Corroborando esse pressuposto, Mickle e Steele (2015) verificaram diminuição da força dos músculos flexor do hálux e flexor dos dedos em idosos obesos. Além disso, mulheres com obesidade sarcopênica apresentaram pico de pressão mais elevado, quando comparadas com aquelas que possuíam apenas obesidade (Monteiro et al., 2010).

É interessante notar, ainda, que as idosas classificadas nos estratos superiores dos índices de adiposidade apresentaram valores significativamente menores de força máxima quando relativizada para a massa corporal, especialmente no retropé e nos dedos. Esses achados podem ser reflexos do maior índice de arco dinâmico observado entre elas. Realmente, indivíduos com pés planos parecem distribuir maior pressão no mediopé e, consequentemente, menor pressão nas demais regiões (Chuckpaiwong et al., 2008; Queen et al., 2009; Han, J. T. et al., 2011; Bertani, 2014).

De acordo com a revisão de literatura, este estudo foi o primeiro a avaliar a influência de diferentes índices de adiposidade corporal sobre a distribuição de 
pressão plantar. Curiosamente, quando as idosas foram estratificadas de acordo com a CC, observou-se que aquelas classificadas no tercil superior apresentaram maior área de contato no antepé, diferentemente da classificação efetuada pelo IMC e pelo \%G, em que essa diferença foi visualizada apenas no mediopé. A CC é uma medida indicativa de adiposidade abdominal (Pouliot et al., 1994), e o acúmulo de gordura nessa região faz com que o centro de gravidade se posicione mais anteriormente em relação à articulação do tornozelo (Corbeil et al., 2001), gerando maior impacto no antepé (Hills et al., 2001; Teh et al., 2006). Também é válido observar que apenas para essa estratificação, foi encontrada diferença significativa na força máxima e no pico de pressão dos dedos, onde idosas do tercil superior apresentaram valores menores que as do tercil intermédio.

Em nota, parâmetros baropodométricos são afetados pela velocidade da marcha com que a avaliação da distribuição de pressão plantar é executada. De um modo geral, valores aumentados de força e de pressão plantar são observados em maiores velocidades (Burnfield et al., 2004; Taylor et al., 2004). O controle da velocidade, no entanto, pode interferir no padrão natural das passadas (Rosenbaum e Becker, 1997). Dessa forma, optamos pela execução do teste em velocidade autoselecionada, registrando a velocidade marcha com que cada idosa realizava a tarefa. Cabe expor que as voluntárias com excesso de adiposidade corporal apresentaram menor velocidade da marcha. Portanto, os valores aumentados da força máxima e do pico de pressão não foram em função da velocidade.

Por se tratar de um estudo transversal, quaisquer relações de causa e efeito devem ser interpretadas com cautela. Como o tempo de exposição à obesidade não foi controlado, nós não podemos determinar se as modificações funcionais e estruturais do pé são agudas ou desenvolvidas ao longo de um período prolongado de tempo. Também não se sabe se essas alterações podem ser revertidas após redução da massa corporal. Song et al. (2015) adicionam evidências nesse sentido, ao verificar que mesmo reduções moderadas do peso foram capazes de minimizar a pressão plantar em algumas regiões do pé (i.e. porção lateral do mediopé e metatarso IV). Não está claro, porém, o porquê dessas modificações terem ocorrido apenas nessas regiões específicas - talvez haja uma contribuição de alterações estruturais já instaladas, como o colapso do arco longitudinal medial, por exemplo. 


\subsection{ADIPOSIDADE CORPORAL E ESTABILIDADE POSTURAL}

O presente estudo comparou a estabilidade postural de mulheres idosas estratificadas de acordo com diferentes índices de adiposidade corporal. Observouse que idosas com excesso de adiposidade apresentaram maior amplitude de deslocamento do COP nas direções AP e ML, o que pode ser interpretado como comprometimento do equilíbrio. Esses achados são consistentes com estudos prévios, que também identificaram pior estabilidade em idosos obesos (Mainenti et al., 2011; Dutil et al., 2013; Melzer e Oddsson, 2015; Siqueira e Geraldes, 2015).

Duas hipóteses tentam explicar a influência negativa do excesso de adiposidade sobre o mecanismo de controle postural. A primeira diz respeito à dificuldade em detectar oscilações posturais. Trabalho conduzido por Kavounoudias et al. (1998) demonstra importante contribuição dos mecanorreceptores plantares para a manutenção do equilíbrio. Indivíduos obesos, no entanto, apresentam diminuição da sensibilidade desses receptores, devido a uma maior pressão exercida sobre a superfície plantar (Hue et al., 2007). De fato, foi observado no presente estudo que idosas com excesso de adiposidade exibiram maior pico de pressão no mediopé; e, de acordo com a Lei de Weber, um estímulo só pode percebido quando a sua magnitude física ultrapassa a fração constante da sua intensidade inicial (Lanzara, 1994). Sendo assim, pessoas obesas apresentam menor capacidade em detectar mudanças na posição do COP, o que explicaria, em parte, a sua maior amplitude de deslocamento (Wu e Madigan, 2014).

A segunda hipótese está relacionada à sobrecarga mecânica exercida pelas dimensões corporais mais pronunciadas. $O$ excesso de massa corporal faz com que o centro de gravidade fique posicionado mais anteriormente em relação às articulações do tornozelo, o que causa um torque gravitacional maior. Para manter a estabilidade postural, este torque gravitacional deve ser contrabalanceado por torques musculares mais pronunciados (Corbeil et al., 2001; Simoneau e Corbeil, 2005; Simoneau e Teasdale, 2015). O excesso de adiposidade, entretanto, foi relacionado a um comprometimento do pico de torque relativo, colaborando para menor eficiência das estratégias de ajustes posturais.

Vale ressaltar que, mesmo havendo diferenças na amplitude de deslocamento do COP, a velocidade de oscilação se mostrou semelhante entre os grupos, característica que também foi observada por Melzer e Oddsson (2015). Esses 
resultados permitem inferir que as idosas obesas não foram capazes de gerar respostas motoras rápidas o suficiente para compensar a sobrecarga mecânica exercida pelas dimensões corporais mais pronunciadas. Dutil et al. (2013), por outro lado, verificaram que idosas obesas apresentavam maior velocidade de oscilação em todas as condições testadas. Esse aumento da velocidade minimizou 0 deslocamento excessivo do COP na condição de olhos abertos, de modo a não ser observada diferença significativa entre os grupos. Adicionalmente, em mulheres de meia idade, a obesidade foi relacionada a uma maior velocidade de oscilação somente em condições mais desafiadoras, como com os olhos fechados (Kováčiková et al., 2014) e em superfícies instáveis (Hita-Contreras et al., 2013).

Diferentemente de indivíduos jovens e adultos, em que o excesso de peso está claramente atrelado à maior velocidade do COP (Teasdale et al., 2013), em idosos, é possível notar certa divergência. Levando em consideração que a velocidade do COP está diretamente associada à variabilidade dos comandos motores para o controle do equilíbrio (Simoneau e Teasdale, 2015), e que o processo de envelhecimento por si só já compromete tais comandos motores (Horak, 2006), acredita-se que em mulheres idosas, o sistema de controle postural já esteja comprometido de tal forma que não seja possível aumentar a frequência das repostas motoras frente a uma maior sobrecarga mecânica. Isso explicaria o fato de não termos encontrado diferenças significativas na velocidade de oscilação do COP.

Em nosso estudo, a obesidade foi classificada de acordo com diferentes índices de adiposidade corporal (i.e. IMC, CC e \%G). Apesar do IMC ser amplamente utilizado em investigações como esta (Carneiro et al., 2012; Dutil et al., 2013; Hita-Contreras et al., 2013; Kováčiková et al., 2014; Melzer e Oddsson, 2015; Siqueira e Geraldes, 2015), a sua acurácia diagnóstica na predição do excesso de adiposidade corporal é limitada, especialmente em indivíduos idosos (Romero-Corral et al., 2008). Em nota, este índice não é capaz de distinguir massa gorda e massa magra, o que ganha importante repercussão nesse contexto, já que a força muscular também está associada ao déficit no equilíbrio (Horlings et al., 2008). Realmente, quando comparamos a estabilidade postural de idosas estratificadas pelo \%G, observamos que aquelas classificadas no estrato superior apresentam maior amplitude de deslocamento do COP em todas as condições testadas; ao passo que, de acordo com a classificação do IMC, as diferenças se concentram nas condições de base aberta. Digno de nota, foi identificado apenas um estudo que utilizou o \%G 
para fazer essas análises - o mesmo confirma que idosas com \%G elevado exibem maior amplitude de deslocamento AP na condição de olhos fechados (Mainenti et al., 2011).

Além de avaliar o impacto da obesidade, é importante verificar a influência de diferentes padrões de distribuição de adiposidade corporal sobre o controle postural. Nesse sentido, Hita-Contreras et al. (2013) observaram que o padrão andróide afetava negativamente a maioria das variáveis estabilométricas analisadas. Corroborando esse achado, nós observamos que a CC foi o índice que melhor se correlacionou com a amplitude de deslocamento do COP, o que também foi encontrado por Siqueira e Geraldes (2015). Essa melhor associação provavelmente ocorreu porque o acúmulo de gordura na região abdominal está diretamente atrelado à projeção anterior do COP (Corbeil et al., 2001). Quando comparamos a estabilidade postural de idosas estratificadas pela CC, entretanto, percebemos que a amplitude de descolamento do COP se apresenta significativamente diferente apenas na direção $A P$, embora haja tendência à significância na direção $M L$.

É valido esclarecer que a estabilidade postural foi avaliada em quatro condições distintas: BAOA, BAOF, BFOA e BFOF. Como a estabilidade postural diz respeito à capacidade de manter o COP nos limites da base de sustentação, ao efetuar a avaliação nas condições de base fechada, estamos impondo um desafio à manutenção do equilíbrio (Horak, 2006). O mesmo acontece quando restringimos a visão, já que, para haver um controle postural adequado, o indivíduo deve adquirir informações contínuas sobre seu posicionamento e sua trajetória no espaço (Peterka, 2002). Notavelmente, a utilização de diferentes condições experimentais é frequente na literatura (Mainenti et al., 2011; Carneiro et al., 2012; Dutil et al., 2013; Hita-Contreras et al., 2013; Kováčiková et al., 2014; Melzer e Oddsson, 2015; Siqueira e Geraldes, 2015).

Em tempo, é importante observar que as idosas classificadas nos estratos superiores dos índices de adiposidade estudados exibiram maior amplitude de deslocamento do COP somente quando comparadas com aquelas classificadas nos estratos inferiores, não sendo notada diferença significativa em relação aos estratos intermédios. Apesar de não haver significância, é possível visualizar uma tendência linear de comprometimento do equilíbrio à medida que se aumenta a adiposidade. De fato, pesquisas anteriores evidenciam uma forte correlação entre a instabilidade postural e a massa corporal (Hue et al., 2007; Teasdale et al., 2007). 
Por fim, cabe salientar que a maior amplitude de deslocamento do COP, observada nas idosas com excesso de adiposidade corporal, apresenta importante significado clínico. Estudos demonstram que o aumento do deslocamento na direção ML está relacionado a um maior risco de quedas (Maki et al., 1994; Lord et al., 1999; Melzer et al., 2004; Piirtola e Era, 2006), e que instabilidade AP aumenta as chances de lesões graves após a ocorrência das mesmas (Kurz et al., 2013). Sendo assim, a obesidade representa um importante fator de risco para quedas em mulheres idosas.

\subsection{ADIPOSIDADE CORPORAL E RISCO DE QUEDAS}

O nosso estudo foi pioneiro em analisar a relação entre o excesso de adiposidade corporal e o risco de quedas em mulheres idosas utilizando instrumentos de fácil implementação na prática clínica. Ao avaliar o risco de quedas por meio do QuickScreen, observou-se que o excesso de adiposidade corporal estava associado a um risco de quedas aumentado, sendo que os principais fatores que colaboraram para a identificação desse risco aumentado foram a ocorrência de quedas no ano anterior, a diminuição do tempo de reação e o comprometimento da força muscular.

Dados epidemiológicos demonstram, realmente, uma maior ocorrência de quedas em idosos obesos (Fjeldstad et al., 2008; Himes e Reynolds, 2012; Mitchell et al., 2014). Fjeldstad et al. (2008), por exemplo, observaram que a prevalência de quedas entre os obesos foi de $27 \%$, ao passo que entre aqueles com peso normal foi de apenas 15\%. Em nosso estudo, esses valores se mostraram mais elevados aproximadamente $20 \%$ das idosas classificadas nos estratos inferiores de adiposidade corporal caíram no ano anterior, enquanto que a prevalência entre as idosas classificadas no estrato superior se encontra acima dos 50\%. De maneira complementar, nós calculamos o OR para a ocorrência de quedas anteriores e confirmamos que o excesso de adiposidade estava associado a um risco aumentado para esse desfecho. Corroborando esse resultado, Mitchell et al. (2014) identificaram que a obesidade estava relacionada a um risco $31 \%$ maior de sofrer uma queda e a um risco 32\% maior de sofrer múltiplas quedas. Himes e Reynolds (2012), por sua vez, apontaram que, comparado com os idosos de peso normal, o OR para o risco 
de quedas foi de 1,12 (IC 95\% 1,01-1,24) para obesidade grau I, 1,26 (IC 95\% 1,051,51) para obesidade grau II, e 1,50 (IC 95\% 1,21-1,86) para obesidade grau III.

Além da maior ocorrência de quedas no ano anterior, outro fator determinante para o resultado do QuickScreen foi a diminuição do tempo de reação, a qual foi avaliada por meio do teste de step alternado. Esse teste exige força, equilíbrio e velocidade, e é capaz de predizer o risco de quedas em pessoas idosas (Tiedemann et al., 2010). Conforme discutido anteriormente, a obesidade está associada a uma instabilidade postural e a uma diminuição da força muscular relativa, inclusive quando mensurada numa velocidade mais acentuada. Sendo assim, parece natural que o excesso de adiposidade esteja relacionado a um baixo desempenho nesse teste.

O terceiro fator que colaborou para o resultado do QuickScreen foi o comprometimento da força muscular, o qual foi testado mediante a tarefa de passar da posição sentada para em pé cinco vezes consecutivas. $O$ baixo desempenho exibido pelas idosas classificadas nos estratos superiores de adiposidade reforça os resultados discutidos previamente, que apontam uma relação entre a obesidade e a diminuição da força muscular relativa. Evidentemente, a redução da força muscular relativa está associada a limitações funcionais (Capodaglio et al., 2010), que por sua vez são indicativas de futuras quedas (Tiedemann et al., 2008).

Cabe expor, agora, que a adiposidade corporal não se associou ao comprometimento do equilíbrio quando avaliado pelo QuickScreen, o que contraria os achados apresentados no tópico anterior. Uma possível explicação para isso é que nesse instrumento, essa habilidade é mensurada por meio do teste semitandem, o qual foi previamente descrito como uma tarefa difícil de ser completada por boa parte dos idosos, independentemente do nível de adiposidade (Lord et al., 1999).

Outro aspecto interessante é que a diminuição da sensibilidade periférica foi associada a valores aumentados da CC, mas não do IMC e do \%G. Vale esclarecer que a CC tem sido apontada como o melhor índice preditivo de síndrome metabólica (Gadelha et al., 2016), e isso, por si só, já poderia justificar um comprometimento da sensibilidade. Ademais, o aumento da pressão plantar, observado entre as idosas com excesso de adiposidade corporal, também acarreta numa diminuição da sensibilidade (Hue et al., 2007). O método empregado para a avaliação da sensibilidade no QuickScreen, entretanto, consiste em aplicar estímulos sobre o 
maléolo lateral da perna dominante (Tiedemann et al., 2010), o que pode não refletir a sensibilidade da superfície plantar.

Para finalizar as análises acerca desse instrumento de avaliação, nós calculamos o OR para o risco de quedas aumentado (QuickScreen $\geq 27 \%$ ) e identificamos que apenas o excesso de adiposidade abdominal estava associado a um risco elevado para esse desfecho. Esse achado se agrega a evidências prévias que apontam a CC como o melhor índice preditivo de incapacidade funcional em mulheres idosas (Angleman et al., 2006; Lisko et al., 2014; Dong et al., 2015).

Outro instrumento comumente recomendado em diretrizes de prática clínica para a avaliação do risco de quedas é o teste TUG (Kenny et al., 2011; Moyer, 2012; Nice, 2013). Modelos de regressão logística conduzidos em estudos prospectivos demonstram que mesmo um aumento discreto no tempo de execução desse teste já é capaz de predizer um risco de quedas aumentado. Mais especificamente, diferenças de um segundo representam um aumento de $2 \%$ a $9 \%$ na probabilidade de um idoso cair (Lin et al., 2004; Shimada et al., 2009; Kojima et al., 2015). Apesar de não ter sido observada diferença significativa entre os estratos de adiposidade corporal, o desempenho no teste TUG se correlacionou com todos os índices de adiposidade estudados. Resultados semelhantes foram encontrados em pesquisas anteriores, conduzidas com o objetivo de verificar a influência da obesidade sobre a funcionalidade de mulheres idosas (Valentine et al., 2009; Shin et al., 2014). Esses achados reforçam, então, o impacto negativo do excesso de adiposidade corporal sobre o risco de quedas nessa população.

Por fim, nós identificamos que as idosas classificadas no estrato superior da medida de CC exibiram um medo de cair mais acentuado do que aquelas classificadas no estrato inferior. Esse dado merece atenção especial, visto que o medo de cair acarreta numa restrição das atividades de vida diária em $40 \%$ dos indivíduos (Zijlstra et al., 2007), além de representar um importante fator de risco para quedas (Friedman et al., 2002). Foi encontrado um único estudo que analisou esta associação em indivíduos idosos, o qual reforça os nossos dados (Jeon, 2013).

\subsection{APLICAÇÕES PRÁTICAS E PERSPECTIVAS}

Os profissionais da saúde devem se preocupar com a ocorrência de obesidade em indivíduos idosos. Sem o controle adequado, o processo de 
envelhecimento resulta em acúmulo de tecido adiposo, que gera repercussões negativas à saúde (Han, T. et al., 2011; Cetin e Nasr, 2014). Além de consequências metabólicas, já bem descritas na literatura (Gadelha et al., 2016), os resultados do presente estudo apontam que o excesso de adiposidade corporal está associado a um risco de quedas aumentado em mulheres idosas. As quedas representam a principal causa de morte acidental nessa população (Tinetti, 2003); e quando não são fatais, acarretam em importante restrição nas atividades de vida diária (Zijlstra et al., 2007). Sendo assim, a prevenção e o tratamento da obesidade poderiam, dentre outros aspectos benéficos, reduzir o risco de quedas e, consequentemente, melhorar a qualidade de vida da população estudada.

Levando em consideração que a obesidade decorre de um balanço energético positivo, as estratégias de intervenção devem enfatizar a reeducação alimentar e a promoção de níveis adequados de atividade física (OMS,1999). Adicionalmente, os nossos achados evidenciam que o maior risco de quedas observado em idosas obesas pode estar associado a um comprometimento da força muscular relativa, a valores elevados de pressão no mediopé e a uma instabilidade postural. Recomenda-se, portanto, a adição de condutas específicas para o fortalecimento muscular, a correção da pisada e a melhora do equilíbrio. Essas práticas devem ser orientadas por uma equipe multidisciplinar, incluindo médicos, fisioterapeutas, educadores físicos, nutricionistas e psicólogos.

Para finalizar, é válido enaltecer que a presença de obesidade deve ser considerada em avaliações do risco de quedas, o que não acontece atualmente (Kenny et al., 2011; Moyer, 2012; Nice, 2013). Conforme já mencionado, medidas simples, como o IMC e a CC, apresentam associação significativa com o risco de quedas em mulheres idosas. Esses índices podem, então, ser facilmente aplicados na prática clínica como ferramenta de identificação desse fator de risco.

\subsection{PONTOS FORTES E LIMITAÇÕES}

O nosso estudo foi pioneiro em avaliar a influência da adiposidade corporal sobre a força muscular, a distribuição de pressão plantar, a estabilidade postural e o risco de quedas em mulheres idosas, utilizando diferentes índices de adiposidade. Foram empregadas, por nós, medidas de fácil implementação na prática clínica, 
como o IMC, que é um índice amplamente utilizado para o diagnóstico da obesidade (Romero-Corral et al., 2008), e a CC, que é um valor representativo de adiposidade abdominal (Pouliot et al., 1994). Além disso, nós efetuamos a mensuração do \%G pelo DEXA, considerado por muitos como padrão ouro de avaliação da gordura corporal (Cornier et al., 2011).

As limitações também são reconhecidas. Em primeiro lugar, a avaliação da força muscular foi conduzida sem levar em consideração músculos importantes para a manutenção do arco plantar (Thordarson et al., 1995) e para a execução de estratégias de ajustes posturais (Simoneau e Corbeil, 2005). É válido esclarecer, no entanto, que a FPM é um indicativo geral de força muscular de baixo custo e fácil aplicação (Ikemoto et al., 2007), enquanto e que o PT dos extensores do joelho está intimamente associado à ocorrência de quedas em idosos e tem sido considerado padrão ouro na prática clínica e em pesquisa (Takazawa et al., 2003; Sieri e Beretta, 2004; Perry et al., 2007; Antero-Jacquemin et al., 2012; Crozara et al., 2013).

Adicionalmente, nós não podemos determinar se os valores mais elevados do índice de arco dinâmico, observado entre as idosas com excesso de adiposidade corporal, estão realmente associados a uma alteração estrutural do arco longitudinal medial do pé, ou se decorre apenas de uma maior deposição de gordura na superfície plantar. Para isso, seriam necessárias avaliações radiográficas, para verificar a conformação óssea do pé (Wearing et al., 2012), ou ultrassonográficas, para mensurar a espessura do tecido subcutâneo (Riddiford-Harland et al., 2011). O importante é que, independentemente da causa, um maior índice de arco dinâmico acarreta em maior pressão no mediopé, que, por sua vez, pode comprometer a detecção de oscilações posturais e predispor as quedas (Wu e Madigan, 2014). Ademais, a análise baropodométrica foi conduzida em uma plataforma de pressão, que é o instrumento mais recomendado em investigações como esta (Orlin e Mcpoil, 2000). Evidentemente, nós também adotamos um método padrão-ouro para mensurar as oscilações posturais (i.e. plataforma de força) (Le Clair e Riach, 1996).

Outra limitação do estudo é que a ocorrência de quedas foi avaliada por meio de autorrelato, o que pode constituir um viés de memória. Todavia, nós tivemos o cuidado de excluir as voluntárias com déficit cognitivo das nossas análises. Além disso, o instrumento que considera a ocorrência de quedas anteriores para quantificar o risco de quedas (i.e. QuickScreen), é uma ferramenta acurada para rastrear múltiplas quedas em idosos comunitários (Tiedemann et al., 2010). Vale 
salientar, ainda, que o nosso estudo foi o primeiro a analisar a relação entre o excesso de adiposidade corporal e o risco de quedas em mulheres idosas utilizando instrumentos que podem ser facilmente empregados na prática clínica.

Cabe, agora, ressaltar que a nossa amostra foi constituída por mulheres idosas relativamente saudáveis e independentes funcionais; sendo assim, os resultados não podem ser estendidos a outras populações. Ademais, a natureza transversal do estudo não permite estabelecer quaisquer relações de causa e efeito. Sugere-se, então, o desenvolvimento de estudos prospectivos para confirmar o impacto negativo da obesidade sobre a força muscular, a distribuição de pressão plantar, a estabilidade postural e, consequentemente, o risco de quedas em mulheres idosas. Pesquisas futuras devem considerar, ainda, variáveis confundidoras em suas análises, como idade, tempo de menopausa, terapia de reposição hormonal e nível de atividade física. 


\section{CONCLUSÃO}

Com base nos resultados apresentados, é possível concluir que o excesso de adiposidade corporal está associado a um risco de quedas aumentado em mulheres idosas. Este risco aumentado pode ser parcialmente explicado por uma diminuição da força muscular relativa, por valores elevados de pressão no mediopé e por uma pior estabilidade postural. Salienta-se que os achados do presente estudo se agregam a evidências prévias que apontam a obesidade como um importante fator de risco para quedas em mulheres idosas. 


\section{REFERÊNCIAS}

AMBROSE, A. F.; PAUL, G.; HAUSDORFF, J. M. Risk factors for falls among older adults: a review of the literature. Maturitas, v. 75, n. 1, p. 51-61, 2013. ISSN 03785122.

ANGIN, S. et al. Ultrasound evaluation of foot muscles and plantar fascia in pes planus. Gait \& posture, v. 40, n. 1, p. 48-52, 2014. ISSN 0966-6362.

ANGLEMAN, S.; HARRIS, T.; MELZER, D. The role of waist circumference in predicting disability in periretirement age adults. International journal of obesity, $\mathrm{v}$. 30, n. 2, p. 364-373, 2006. ISSN 0307-0565.

ANTERO-JACQUEMIN, J. D. S. et al. Comparação da função muscular isocinética dos membros inferiores entre idosos caidores e não caidores. Fisioterapia e Pesquisa, v. 19, n. 1, p. 39-44, 2012. ISSN 2316-9117.

AURICHIO, T. R.; REBELATTO, J. R.; DE CASTRO, A. P. The relationship between the body mass index (BMI) and foot posture in elderly people. Archives of gerontology and geriatrics, v. 52, n. 2, p. e89-e92, 2011. ISSN 0167-4943.

AZARFAM, A. A. Y. et al. The relationship between body mass index and footprint parameters in older people. The Foot, v. 24, n. 4, p. 186-189, 2014. ISSN 09582592.

BEAUFRERE, B.; MORIO, B. Fat and protein redistribution with aging: metabolic considerations. European journal of clinical nutrition, v. 54, p. S48-53, 2000. ISSN 0954-3007.

BERTANI, M. C. Differences of foot arch index and plantar pressure in elderly people during standing: considering gender, age and foot dominance. 2014.

BERTOLUCCI, P. H. et al. O mini-exame do estado mental em uma populaçäo geral: impacto da escolaridade. Arq. Neuropsiquiatr, v. 52, n. 1, p. 1-7, 1994. ISSN 0004-282X.

BIRTANE, M.; TUNA, H. The evaluation of plantar pressure distribution in obese and non-obese adults. Clinical Biomechanics, v. 19, n. 10, p. 1055-1059, 2004. ISSN 0268-0033.

$\mathrm{BOSCH}, \mathrm{K}$. et al. From "first" to "last" steps in life-pressure patterns of three generations. Clinical Biomechanics, v. 24, n. 8, p. 676-681, 2009. ISSN 02680033.

BRASIL. Ministério do Planejamento, Orçamento e Gestão. . Orçamento federal ao alcance de todos., v. Brasília: Secretaria de Orçamento Federal, 2011.

. Vigitel Brasil 2014: Vigilância de Fatores de Risco e Proteção para Doenças Crônicas por Inquérito Telefônico. Ministério da Saúde, 2015. 
BRENTON-RULE, A. R. Foot and ankle characteristics associated with falls and falls risk in adults with rheumatoid arthritis. 2015. Auckland University of Technology

BROWN, L. E.; WEIR, J. P. ASEP PROCEDURES RECOMMENDATION I: ACCURATE ASSESSMENT OF MUSCULAR STRENGTH AND POWER. Professionalization of Exercise Physiology, v. 4, n. 11, 2001. ISSN 1099-5862.

BURNFIELD, J. M. et al. The influence of walking speed and footwear on plantar pressures in older adults. Clinical Biomechanics, v. 19, n. 1, p. 78-84, 2004. ISSN 0268-0033.

BUS, S. A.; DE LANGE, A. A comparison of the 1-step, 2-step, and 3-step protocols for obtaining barefoot plantar pressure data in the diabetic neuropathic foot. Clinical Biomechanics, v. 20, n. 9, p. 892-899, 2005. ISSN 0268-0033.

BUTTERWORTH, P. A. et al. Foot posture, range of motion and plantar pressure characteristics in obese and non-obese individuals. Gait \& posture, v. 41, n. 2, p. 465-469, 2015. ISSN 0966-6362.

CAMARGOS, F. F. et al. Adaptação transcultural e avaliação das propriedades psicométricas da Falls Efficacy Scale-International em idosos brasileiros (FES-IBRASIL). Rev Bras Fisioter, v. 14, n. 3, p. 237-43, 2010.

CAPODAGLIO, P. et al. Functional limitations and occupational issues in obesity: a review. International Journal of Occupational Safety and Ergonomics, v. 16, n. 4, p. 507-523, 2010. ISSN 1080-3548.

CARNEIRO, J. A. O. et al. Obese elderly women exhibit low postural stability: a novel three-dimensional evaluation system. Clinics, v. 67, n. 5, p. 475-481, 2012. ISSN 1807-5932.

CARVALHO, J. A. M. D.; GARCIA, R. A. O envelhecimento da populaçäo brasileira: um enfoque demográfico. Cad. saúde pública, v. 19, n. 3, p. 725-733, 2003. ISSN 0102-311X.

CAVANAGH, P. R.; RODGERS, M. M. The arch index: a useful measure from footprints. Journal of biomechanics, v. 20 , n. 5 , p. 547-551, 1987. ISSN 00219290.

CETIN, D. C.; NASR, G. Obesity in the elderly: more complicated than you think. Cleveland clinic Journal of medicine, v. 81, n. 1, p. 51-61, 2014. ISSN 0891-1150.

CHAIWANICHSIRI, D.; JANCHAI, S.; TANTISIRIWAT, N. Foot disorders and falls in older persons. Gerontology, v. 55, n. 3, p. 296-302, 2008. ISSN 0304-324X.

CHARLTON, K. et al. Lean Body Mass Associated with Upper Body Strength in Healthy Older Adults While Higher Body Fat Limits Lower Extremity Performance and Endurance. Nutrients, v. 7, n. 9, p. 7126-7142, 2015. 
CHUANG, J.-F. et al. Obese patients who fall have less injury severity but a longer hospital stay than normal-weight patients. World journal of emergency surgery, $\mathrm{n}$. 1, p. 3, 2016. ISSN 1749-7922.

CHUCKPAIWONG, B. et al. The effect of foot type on in-shoe plantar pressure during walking and running. Gait \& posture, v. 28, n. 3, p. 405-411, 2008. ISSN 0966-6362.

COMPSTON, J. E. et al. Obesity, health-care utilization, and health-related quality of life after fracture in postmenopausal women: Global Longitudinal Study of Osteoporosis in Women (GLOW). Calcified tissue international, v. 94, n. 2, p. 223231, 2014. ISSN 0171-967X.

COOPER, R. et al. Body mass index from age 15 years onwards and muscle mass, strength, and quality in early old age: Findings from the MRC National Survey of Health and Development. The Journals of Gerontology Series A: Biological Sciences and Medical Sciences, p. glu039, 2014. ISSN 1079-5006.

CORBEIL, P. et al. Increased risk for falling associated with obesity: mathematical modeling of postural control. Neural Systems and Rehabilitation Engineering, IEEE Transactions on, v. 9, n. 2, p. 126-136, 2001. ISSN 1534-4320.

CORNIER, M.-A. et al. Assessing adiposity a scientific statement from the American Heart Association. Circulation, v. 124, n. 18, p. 1996-2019, 2011. ISSN 0009-7322.

CROZARA, L. F. et al. Motor readiness and joint torque production in lower limbs of older women fallers and non-fallers. Journal of Electromyography and Kinesiology, v. 23, n. 5, p. 1131-1138, 2013. ISSN 1050-6411.

DAVIS, J. et al. International comparison of cost of falls in older adults living in the community: a systematic review. Osteoporosis international, v. 21, n. 8, p. 12951306, 2010. ISSN 0937-941X.

DEANDREA, S. et al. Risk factors for falls in community-dwelling older people: a systematic review and meta-analysis. Epidemiology, v. 21, n. 5, p. 658-668, 2010. ISSN 1044-3983.

DESCHAMPS, K. et al. Inter-and intra-observer reliability of masking in plantar pressure measurement analysis. Gait \& posture, v. 30, n. 3, p. 379-382, 2009. ISSN 0966-6362.

DEY, D. K. et al. Changes in body composition and its relation to muscle strength in 75-year-old men and women: a 5-year prospective follow-up study of the NORA cohort in Göteborg, Sweden. Nutrition, v. 25, n. 6, p. 613-619, 2009. ISSN 08999007.

DOBRIANSKY, P. J.; SUZMAN, R. M.; HODES, R. J. Why population aging matters: A global perspective. National Institute on Aging, National Institutes of Health, US Department of Health and Human Services, US Department of State, 2007. 
DONG, H.-J. et al. Obese very old women have low relative handgrip strength, poor physical function, and difficulties in daily living. The journal of nutrition, health \& aging, v. 19, n. 1, p. 20-25, 2015. ISSN 1279-7707.

DUNLOP, D. D. et al. Incidence of functional limitation in older adults: the impact of gender, race, and chronic conditions. Archives of physical medicine and rehabilitation, v. 83, n. 7, p. 964-971, 2002. ISSN 0003-9993.

DUTIL, M. et al. The impact of obesity on balance control in community-dwelling older women. Age, v. 35, n. 3, p. 883-890, 2013. ISSN 0161-9152.

ELIA, M.; RITZ, P.; STUBBS, R. Total energy expenditure in the elderly. European journal of clinical nutrition, v. 54, p. S92-103, 2000. ISSN 0954-3007.

FAKHOURI, T. H. I. et al. Prevalence of obesity among older adults in the United States, 2007-2010. Citeseer, 2012.

FARIA, A. et al. The relationship of body mass index, age and triceps-surae musculotendinous stiffness with the foot arch structure of postmenopausal women.

Clinical Biomechanics, v. 25, n. 6, p. 588-593, 2010. ISSN 0268-0033.

FERRARI, C.; CRISTINA, S. F.; MOÇA, T. V. F. Falls in Elderly with Plantar Changes. British Journal of Medicine \& Medical Research, v. 4, n. 34, 2014. ISSN 2231-0614.

FESS, E.E. Grip strength. In: CASANOVA, J.S. Clinical Assessment Recommendations. 2. ed. Chicago: American Society of Hand Therapists, 1992.

FINLAYSON, M. L.; PETERSON, E. W. Falls, aging, and disability. Physical medicine and rehabilitation clinics of North America, v. 21, n. 2, p. 357-373, 2010. ISSN 1047-9651.

FJELDSTAD, C. et al. The influence of obesity on falls and quality of life. Dynamic Medicine, v. 7, n. 1, p. 4, 2008. ISSN 1476-5918.

FLEGAL, K. M. et al. Overweight and obesity in the United States: prevalence and trends, 1960-1994. International journal of obesity and related metabolic disorders: journal of the International Association for the Study of Obesity, v. 22, n. 1, p. 39-47, 1998.

FLEGAL, K. M. et al. Prevalence and trends in obesity among US adults, 19992000. Jama, v. 288, n. 14, p. 1723-1727, 2002. ISSN 0098-7484.

FOGELHOLM, M. et al. Predictors of Weight Change in Middle-aged and Old Men. Obesity research, v. 8, n. 5, p. 367-373, 2000. ISSN 1550-8528.

FRIEDMAN, S. M. et al. Falls and fear of falling: which comes first? A longitudinal prediction model suggests strategies for primary and secondary prevention. Journal of the American Geriatrics Society, v. 50, n. 8, p. 1329-1335, 2002. ISSN 15325415. 
FULLER, G. F. Falls in the elderly. American family physician, v. 61, n. 7, p. 215968, 2173-4, 2000. ISSN 0002-838X.

GADELHA, A. B. et al. COMPARISON OF ADIPOSITY INDICES AND CUT-OFF VALUES IN THE PREDICTION OF METABOLIC SYNDROME IN POSTMENOPAUSAL WOMEN. Diabetes \& Metabolic Syndrome: Clinical Research \& Reviews, 2016. ISSN 1871-4021.

GANZ, D. A. et al. Will my patient fall? Jama, v. 297, n. 1, p. 77-86, 2007. ISSN 0098-7484.

GOLDACRE, M. J.; ROBERTS, S. E.; YEATES, D. Mortality after admission to hospital with fractured neck of femur: database study. Bmj, v. 325, n. 7369, p. 868869, 2002. ISSN 0959-8138.

GRAF, C. The Lawton instrumental activities of daily living (IADL) scale. The Gerontologist, v. 9, n. 3, p. 179-186, 2009.

GRAVANTE, G. et al. Comparison of ground reaction forces between obese and control young adults during quiet standing on a baropodometric platform. Clinical Biomechanics, v. 18, n. 8, p. 780-782, 2003. ISSN 0268-0033.

GRINKER, J. A. et al. Body habitus changes among adult males from the normative aging study: relations to aging, smoking history and alcohol intake. Obesity research, v. 3, n. 5, p. 435-446, 1995. ISSN 1550-8528.

HAN, J. T. et al. Differences in plantar foot pressure and COP between flat and normal feet during walking. Journal of Physical Therapy Science, v. 23, n. 4, p. 683-685, 2011. ISSN 0915-5287.

HAN, T.; TAJAR, A.; LEAN, M. Obesity and weight management in the elderly. British medical bulletin, v. 97, n. 1, p. 169-196, 2011. ISSN 0007-1420.

HARDY, R. et al. Body mass index, muscle strength and physical performance in older adults from eight cohort studies: the HALCyon programme. PLoS One, v. 8, n. 2, p. e56483, 2013. ISSN 1932-6203.

HEDLEY, A. A. et al. Prevalence of overweight and obesity among US children, adolescents, and adults, 1999-2002. Jama, v. 291, n. 23, p. 2847-2850, 2004. ISSN 0098-7484.

HESSERT, M. J. et al. Foot pressure distribution during walking in young and old adults. BMC geriatrics, v. 5, n. 1, p. 1, 2005. ISSN 1471-2318.

HILLS, A. et al. Plantar pressure differences between obese and non-obese adults: a biomechanical analysis. International journal of obesity and related metabolic disorders: journal of the International Association for the Study of Obesity, v. 25, n. 11, p. 1674-1679, 2001. 
HIMES, C. L.; REYNOLDS, S. L. Effect of obesity on falls, injury, and disability. Journal of the American Geriatrics Society, v. 60, n. 1, p. 124-129, 2012. ISSN $1532-5415$.

HITA-CONTRERAS, F. et al. Relationship of body mass index and body fat distribution with postural balance and risk of falls in Spanish postmenopausal women. Menopause, v. 20, n. 2, p. 202-208, 2013. ISSN 1072-3714.

HORAK, F. B. Postural orientation and equilibrium: what do we need to know about neural control of balance to prevent falls? Age and ageing, v. 35, n. suppl 2, p. ii7ii11, 2006. ISSN 0002-0729.

HORLINGS, C. G. et al. A weak balance: the contribution of muscle weakness to postural instability and falls. Nature Clinical Practice Neurology, v. 4, n. 9, p. 504515, 2008. ISSN 1745-834X.

HORNBROOK, M. C. et al. Preventing falls among community-dwelling older persons: results from a randomized trial. The Gerontologist, v. 34, n. 1, p. 16-23, 1994. ISSN 0016-9013.

HUE, O. et al. Body weight is a strong predictor of postural stability. Gait \& posture, v. 26 , n. 1 , p. $32-38,2007$. ISSN 0966-6362.

IBGE. Censo Populacional 2010: Rio de Janeiro 2010.

Projeção da População por Sexo e Idade para o Brasil, Grandes Regiões e Unidades da Federação 2013: Rio de Janeiro 2013.

IKEMOTO, Y. et al. Force-time parameters during explosive isometric grip correlate with muscle power. Sport Sciences for Health, v. 2, n. 2, p. 64-70, 2007. ISSN 1824-7490.

INOUYE, S. K.; BROWN, C. J.; TINETTI, M. E. Medicare nonpayment, hospital falls, and unintended consequences. New England Journal of Medicine, v. 360, n. 23, p. 2390-2393, 2009. ISSN 0028-4793.

JEON, B.-J. The effects of obesity on fall efficacy in elderly people. Journal of Physical Therapy Science, v. 25, n. 11, p. 1485-1489, 2013. ISSN 0915-5287.

KALYANI, R. R.; CORRIERE, M.; FERRUCCI, L. Age-related and disease-related muscle loss: the effect of diabetes, obesity, and other diseases. The Lancet Diabetes \& Endocrinology, v. 2, n. 10, p. 819-829, 2014. ISSN 2213-8587.

KANNEL, W. B.; GORDON, T.; CASTELLI, W. P. Obesity, lipids, and glucose intolerance. The Framingham Study. The American journal of clinical nutrition, v. 32, n. 6, p. 1238-1245, 1979. ISSN 0002-9165.

KAVOUNOUDIAS, A.; ROLL, R.; ROLL, J.-P. The plantar sole is a 'dynamometric map'for human balance control. Neuroreport, v. 9, n. 14, p. 3247-3252, 1998. ISSN 0959-4965. 
KENNY, R. et al. Summary of the updated American Geriatrics Society/British Geriatrics Society clinical practice guideline for prevention of falls in older persons. Journal of the American Geriatrics Society, v. 59, n. 1, p. 148-157, 2011. ISSN 0002-8614.

$\mathrm{KIM}, \mathrm{T}$. N. et al. Impact of Visceral Fat on Skeletal Muscle Mass and Vice Versa in a Prospective Cohort Study: The Korean Sarcopenic Obesity Study (KSOS). PLoS One, v. 9, n. 12, p. e115407, 2014. ISSN 1932-6203.

KOJIMA, G. et al. Does the timed up and go test predict future falls among British community-dwelling older people? Prospective cohort study nested within a randomised controlled trial. BMC geriatrics, v. 15, n. 1, p. 38, 2015. ISSN 1471 2318.

KOSTER, A. et al. Does the amount of fat mass predict age-related loss of lean mass, muscle strength, and muscle quality in older adults? The Journals of Gerontology Series A: Biological Sciences and Medical Sciences, v. 66, n. 8, p. 888-895, 2011. ISSN 1079-5006.

KOVÁČIKOVÁ, Z. et al. Assessment of postural stability in overweight and obese middle-aged women. Acta Gymnica, v. 44, n. 3, p. 149-153, 2014. ISSN 23364920.

KOWAL, P. et al. Data resource profile: the World Health Organization Study on global AGEing and adult health (SAGE). International journal of epidemiology, v. 41 , n. 6, p. 1639-1649, 2012. ISSN 0300-5771.

KURZ, I.; ODDSSON, L.; MELZER, I. Characteristics of balance control in older persons who fall with injury-A prospective study. Journal of Electromyography and Kinesiology, v. 23, n. 4, p. 814-819, 2013. ISSN 1050-6411.

KUSKOWSKA-WOLK, A.; RÖSSNER, S. Body mass distribution of a representative adult population in Sweden. Diabetes research and clinical practice, v. 10, p. S37S41, 1990. ISSN 0168-8227.

LAMB, S. E. et al. Development of a common outcome data set for fall injury prevention trials: the Prevention of Falls Network Europe consensus. Journal of the American Geriatrics Society, v. 53, n. 9, p. 1618-1622, 2005. ISSN 1532-5415.

LANZARA, R. G. Weber's law modeled by the mathematical description of a beam balance. Mathematical biosciences, v. 122, n. 1, p. 89-94, 1994. ISSN 0025-5564.

LE CLAIR, K.; RIACH, C. Postural stability measures: what to measure and for how long. Clinical Biomechanics, v. 11, n. 3, p. 176-178, 1996. ISSN 0268-0033.

LEBRÃO, M. L. O envelhecimento no Brasil: aspectos da transição demográfica e epidemiológica. Saúde Coletiva, v. 4, n. 17, p. 135-40, 2007.

LIN, M. R. et al. Psychometric comparisons of the timed up and go, one-leg stand, functional reach, and Tinetti balance measures in community-dwelling older people. 
Journal of the American Geriatrics Society, v. 52, n. 8, p. 1343-1348, 2004. ISSN 1532-5415.

LISKO, I. et al. Association of body mass index and waist circumference with physical functioning: the vitality $90+$ study. The Journals of Gerontology Series A: Biological Sciences and Medical Sciences, p. glu202, 2014. ISSN 1079-5006.

LORD, S. R. et al. Lateral stability, sensorimotor function and falls in older people. Journal of the American Geriatrics Society, v. 47, n. 9, p. 1077-1081, 1999. ISSN 1532-5415.

MAFFIULETTI, N. A. et al. The impact of obesity on in vivo human skeletal muscle function. Current Obesity Reports, v. 2, n. 3, p. 251-260, 2013. ISSN 2162-4968.

MAINENTI, M. R. M. et al. Adiposity and postural balance control: Correlations between bioelectrical impedance and stabilometric signals in elderly Brazilian women. Clinics, v. 66, n. 9, p. 1513-1518, 2011. ISSN 1807-5932.

MAKI, B. E.; HOLLIDAY, P. J.; TOPPER, A. K. A prospective study of postural balance and risk of falling in an ambulatory and independent elderly population. Journal of gerontology, v. 49, n. 2, p. M72-M84, 1994. ISSN 0022-1422.

MANSON, J. E. et al. Body weight and mortality among women. New England Journal of Medicine, v. 333, n. 11, p. 677-685, 1995. ISSN 0028-4793.

MATHIOWETZ, V. et al. Reliability and validity of grip and pinch strength evaluations. The Journal of Hand Surgery, v. 9, n. 2, p. 222-226, 1984.

MATSUDO, S. et al. Questinário internacional de atividade f1sica (IPAQ): estudo de validade e reprodutibilidade no Brasil. Rev. bras. ativ. fís. saúde, v. 6, n. 2, p. 0518, 2001. ISSN 1413-3482.

MELZER, I.; BENJUYA, N.; KAPLANSKI, J. Postural stability in the elderly: a comparison between fallers and non-fallers. Age and ageing, v. 33, n. 6, p. 602-607, 2004. ISSN 0002-0729.

MELZER, I.; ODDSSON, L. I. Altered characteristics of balance control in obese older adults. Obesity research \& clinical practice, 2015. ISSN 1871-403X.

MENZ, H. B. Biomechanics of the ageing foot and ankle: a mini-review. Gerontology, v. 61, n. 4, p. 381-388, 2015. ISSN 1423-0003.

MENZ, H. B.; MORRIS, M. E.; LORD, S. R. Foot and ankle risk factors for falls in older people: a prospective study. The Journals of Gerontology Series A: Biological Sciences and Medical Sciences, v. 61, n. 8, p. 866-870, 2006. ISSN 1079-5006.

MICKLE, K. J. et al. Foot pain, plantar pressures, and falls in older people: a prospective study. Journal of the American Geriatrics Society, v. 58, n. 10, p. 1936-1940, 2010. ISSN 1532-5415. 
MICKLE, K. J.; STEELE, J. R. Obese older adults suffer foot pain and foot-related functional limitation. Gait \& posture, v. 42, n. 4, p. 442-447, 2015. ISSN 0966-6362.

MITCHELL, R. J. et al. Associations between obesity and overweight and fall risk, health status and quality of life in older people. Australian and New Zealand journal of public health, v. 38, n. 1, p. 13-18, 2014. ISSN 1753-6405.

MOKDAD, A. $\mathrm{H}$. et al. The continuing epidemics of obesity and diabetes in the United States. Jama, v. 286, n. 10, p. 1195-1200, 2001. ISSN 0098-7484.

MONTEIRO, M. et al. Influence of obesity and sarcopenic obesity on plantar pressure of postmenopausal women. Clinical Biomechanics, v. 25, n. 5, p. 461467, 2010. ISSN 0268-0033.

MORELAND, J. D. et al. Muscle weakness and falls in older adults: a systematic review and meta-analysis. Journal of the American Geriatrics Society, v. 52, n. 7, p. 1121-1129, 2004. ISSN 1532-5415.

MOYER, V. A. Prevention of falls in community-dwelling older adults: US Preventive Services Task Force recommendation statement. Annals of Internal Medicine, v. 157, n. 3, p. 197-204, 2012. ISSN 0003-4819.

MUNDIAL, B. Envelhecendo em um Brasil mais velho. Washington, DC: Banco Mundial, 2011.

NEVITT, M. C.; CUMMINGS, S. R.; HUDES, E. S. Risk factors for injurious falls: a prospective study. Journal of gerontology, v. 46, n. 5, p. M164-M170, 1991. ISSN 0022-1422.

NEWMAN, A. B. et al. Sarcopenia: alternative definitions and associations with lower extremity function. Journal of the American Geriatrics Society, v. 51, n. 11, p. 1602-1609, 2003. ISSN 1532-5415.

NICE, C. F. C. P. A. Falls: Assessment and Prevention of Falls in Older People. 2013.

O'LOUGHLIN, J. L. et al. Incidence of and risk factors for falls and injurious falls among the community-dwelling elderly. American journal of epidemiology, v. 137, n. 3, p. 342-354, 1993. ISSN 0002-9262.

OMS. The world health report 2002: reducing risks, promoting healthy life. World Health Organization, 2002.

. Good health adds life to years. Global brief for World Health Day, 2012.

ONU. World Population Prospects: the 2010 revision. New York: Unites Nations, 2011.

ORGANIZATION, W. H. Obesity: preventing and managing the global epidemic: report of a WHO consultation. WHO technical report series, v. 894, p. 253, 1999. 
ORLIN, M. N.; MCPOIL, T. G. Plantar pressure assessment. Physical therapy, v. 80 , n. 4, p. 399-409, 2000. ISSN 0031-9023.

OTSUKA, R. et al. [Association of flatfoot with pain, fatigue and obesity in Japanese over sixties]. [Nihon koshu eisei zasshi] Japanese journal of public health, v. 50, n. 10, p. 988-998, 2003. ISSN 0546-1766.

OWENS, P. L. et al. Emergency department visits for injurious falls among the elderly, 2006. 2009.

PAOLILLO, F. R. et al. Effects of excess body mass on strength and fatigability of quadriceps in postmenopausal women. Menopause, v. 19, n. 5, p. 556-561, 2012. ISSN 1072-3714.

PERRY, M. C. et al. Strength, power output and symmetry of leg muscles: effect of age and history of falling. European journal of applied physiology, v. 100, n. 5, p. 553-561, 2007. ISSN 1439-6319.

PETERKA, R. Sensorimotor integration in human postural control. Journal of neurophysiology, v. 88, n. 3, p. 1097-1118, 2002. ISSN 0022-3077.

PIIRTOLA, M.; ERA, P. Force platform measurements as predictors of falls among older people-a review. Gerontology, v. 52, n. 1, p. 1-16, 2006. ISSN 1423-0003.

PODSIADLO, D.; RICHARDSON, S. The timed" Up \& Go": a test of basic functional mobility for frail elderly persons. Journal of the American Geriatrics Society, v. 39, n. 2, p. 142-148, 1991. ISSN 0002-8614.

POULIOT, M.-C. et al. Waist circumference and abdominal sagittal diameter: best simple anthropometric indexes of abdominal visceral adipose tissue accumulation and related cardiovascular risk in men and women. The American journal of cardiology, v. 73, n. 7, p. 460-468, 1994. ISSN 0002-9149.

QUEEN, R. M. et al. Differences in plantar loading between flat and normal feet during different athletic tasks. Gait \& posture, v. 29, n. 4, p. 582-586, 2009. ISSN 0966-6362.

REAVEN, G. M. Role of insulin resistance in human disease. Diabetes, v. 37, n. 12, p. 1595-1607, 1988. ISSN 0012-1797.

RIDDIFORD-HARLAND, D.; STEELE, J. R.; BAUR, L. Are the feet of obese children fat or flat\&quest; Revisiting the debate. International journal of obesity, v. 35, n. 1 , p. 115-120, 2011. ISSN 0307-0565.

RISSANEN, A.; HELIÖVAARA, M.; AROMAA, A. Overweight and anthropometric changes in adulthood: a prospective study of 17,000 Finns. International journal of obesity, v. 12, n. 5, p. 391-401, 1987. ISSN 0307-0565. 
ROMERO-CORRAL, A. et al. Accuracy of body mass index in diagnosing obesity in the adult general population. International journal of obesity, v. 32, n. 6 , p. 959966, 2008. ISSN 0307-0565.

ROSENBAUM, D.; BECKER, H. P. Plantar pressure distribution measurements. Technical background and clinical applications. Foot and Ankle Surgery, v. 3, n. 1, p. 1-14, 1997. ISSN 1460-9584.

ROSENBERG, I. H. Epidemiologic and methodologic problems in determining nutritional status of older persons. American Journal of Clinical Nutrition, v. 50, n. 5, p. 1121-1235, 1989.

ROUBENOFF, R.; CASTANEDA, C. Sarcopenia-understanding the dynamics of aging muscle. Jama, v. 286, n. 10, p. 1230-1231, 2001. ISSN 0098-7484.

RUBENSTEIN, L. Z. Falls in older people: epidemiology, risk factors and strategies for prevention. Age and ageing, v. 35, n. suppl 2, p. ii37-ii41, 2006. ISSN 00020729.

RUBENSTEIN, L. Z.; JOSEPHSON, K. R. The epidemiology of falls and syncope. Clinics in geriatric medicine, v. 18, n. 2, p. 141-158, 2002. ISSN 0749-0690.

SCHRAMM, J. M. D. A. et al. Transição epidemiológica e o estudo de carga de doença no Brasil. Ciência \& Saúde Coletiva, v. 9, n. 4, p. 897-908, 2004.

SHELKEY, M.; WALLACE, M. Katz index of independence in activities of daily living (ADL). The Gerontologist, v. 10, n. 1, p. 20-30, 1998.

SHEN, S. et al. Body Mass Index Is Associated with Physical Performance in Suburb-Dwelling Older Chinese: A Cross-Sectional Study. PLoS One, v. 10, n. 3, p. e0119914, 2015. ISSN 1932-6203.

SHIMADA, $\mathrm{H}$. et al. Which neuromuscular or cognitive test is the optimal screening tool to predict falls in frail community-dwelling older people? Gerontology, v. 55, n. 5, p. 532-538, 2009. ISSN 1423-0003.

SHIN, H. et al. Physical performance in relation to body composition and bone mineral density in healthy, overweight, and obese postmenopausal women. Journal of geriatric physical therapy, v. 37, n. 1, p. 7-16, 2014. ISSN 1539-8412.

SIERI, T.; BERETTA, G. Fall risk assessment in very old males and females living in nursing homes. Disability and rehabilitation, v. 26, n. 12, p. 718-723, 2004. ISSN 0963-8288.

SIMONEAU, M.; CORBEIL, P. The effect of time to peak ankle torque on balance stability boundary: experimental validation of a biomechanical model. Experimental brain research, v. 165, n. 2, p. 217-228, 2005. ISSN 0014-4819. 
SIMONEAU, M.; TEASDALE, N. Balance control impairment in obese individuals is caused by larger balance motor commands variability. Gait \& posture, v. 41, n. 1, p. 203-208, 2015. ISSN 0966-6362.

SIQUEIRA, F. D. M. S.; GERALDES, A. A. R. Influência do estado nutricional, distribuição da gordura corporal e força muscular na estabilometria de idosas. Rev. nutr, v. 28, n. 6, p. 581-596, 2015. ISSN 1415-5273.

SONG, J. et al. Effects of weight loss on foot structure and function in obese adults: a pilot randomized controlled trial. Gait \& posture, v. 41, n. 1, p. 86-92, 2015. ISSN 0966-6362.

STENHOLM, S. et al. Sarcopenic obesity-definition, etiology and consequences. Current opinion in clinical nutrition and metabolic care, v. 11, n. 6, p. 693, 2008.

STENHOLM, S. et al. Association between obesity history and hand grip strength in older adults-exploring the roles of inflammation and insulin resistance as mediating factors. The Journals of Gerontology Series A: Biological Sciences and Medical Sciences, v. 66, n. 3, p. 341-348, 2011. ISSN 1079-5006.

TAKAZAWA, K. et al. Lower-extremity muscle forces measured by a hand-held dynamometer and the risk of falls among day-care users in Japan: using multinomial logistic regression analysis. Disability and rehabilitation, v. 25, n. 8, p. 399-404, 2003. ISSN 0963-8288.

TAYLOR, A. J.; MENZ, H. B.; KEENAN, A.-M. The influence of walking speed on plantar pressure measurements using the two-step gait initiation protocol. The Foot, v. 14, n. 1, p. 49-55, 2004. ISSN 0958-2592.

TEASDALE, N. et al. Reducing weight increases postural stability in obese and morbid obese men. International journal of obesity, v. 31, n. 1, p. 153-160, 2007. ISSN 0307-0565.

TEASDALE, N. et al. Obesity alters balance and movement control. Current Obesity Reports, v. 2, n. 3, p. 235-240, 2013. ISSN 2162-4968.

TEH, E. et al. Static and frequency domain analysis of plantar pressure distribution in obese and non-obese subjects. Journal of Bodywork and Movement Therapies, v. 10, n. 2, p. 127-133, 2006. ISSN 1360-8592.

THORDARSON, D. B. et al. Dynamic Support of the Human Longitudinal Arch: A Biomechanical Evaluation. Clinical orthopaedics and related research, v. 316, p. 165-172, 1995.

TIEDEMANN, A.; LORD, S. R.; SHERRINGTON, C. The development and validation of a brief performance-based fall risk assessment tool for use in primary care. The Journals of Gerontology Series A: Biological Sciences and Medical Sciences, p. glq067, 2010. ISSN 1079-5006. 
TIEDEMANN, A. et al. The comparative ability of eight functional mobility tests for predicting falls in community-dwelling older people. Age and ageing, v. 37, n. 4, p. 430-435, 2008. ISSN 0002-0729.

TINETTI, M. E. Preventing falls in elderly persons. New England Journal of Medicine, v. 348, n. 1, p. 42-49, 2003. ISSN 0028-4793.

TROMP, A. et al. Predictors for falls and fractures in the Longitudinal Aging Study Amsterdam. Journal of bone and mineral research, v. 13, n. 12, p. 1932-1939, 1998. ISSN 1523-4681.

VALENTINE, R. J. et al. Sex impacts the relation between body composition and physical function in older adults. Menopause (New York, NY), v. 16, n. 3, p. 518, 2009.

VAN DER LEEDEN, M. et al. Reproducibility of plantar pressure measurements in patients with chronic arthritis: a comparison of one-step, two-step, and three-step protocols and an estimate of the number of measurements required. Foot \& ankle international, v. 25, n. 10, p. 739-744, 2004. ISSN 1071-1007.

VILAÇA, K. H. C. et al. Body composition, physical performance and muscle quality of active elderly women. Archives of gerontology and geriatrics, v. 59, n. 1, p. 4448, 2014. ISSN 0167-4943.

VILLAREAL, D. T. et al. Obesity in older adults: technical review and position statement of the American Society for Nutrition and NAASO, The Obesity Society. Obesity research, v. 13, n. 11, p. 1849-1863, 2005. ISSN 1550-8528.

WEARING, S. C. et al. Footprint-based estimates of arch structure are confounded by body composition in adults. Journal of Orthopaedic Research, v. 30, n. 8, p. 1351-1354, 2012. ISSN 1554-527X.

WONG, Y. S. Influence of the abductor hallucis muscle on the medial arch of the foot: a kinematic and anatomical cadaver study. Foot \& ankle international, v. 28, n. 5, p. 617-620, 2007. ISSN 1071-1007.

WU, X.; MADIGAN, M. L. Impaired plantar sensitivity among the obese is associated with increased postural sway. Neuroscience letters, v. 583, p. 49-54, 2014. ISSN 0304-3940.

ZIJLSTRA, G. et al. Prevalence and correlates of fear of falling, and associated avoidance of activity in the general population of community-living older people. Age and ageing, v. 36, n. 3, p. 304-309, 2007. ISSN 0002-0729. 


\section{LISTA DE ANEXOS}

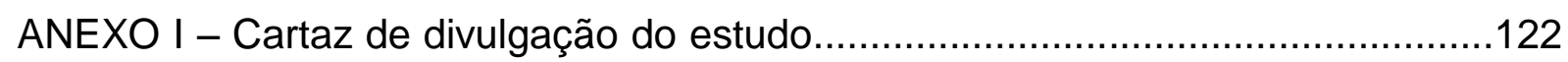

ANEXO II - Parecer do Comitê de Ética em Pesquisa (CEP) ...............................123

ANEXO III - Termo de Consentimento Livre e Esclarecido (TCLE) .......................124

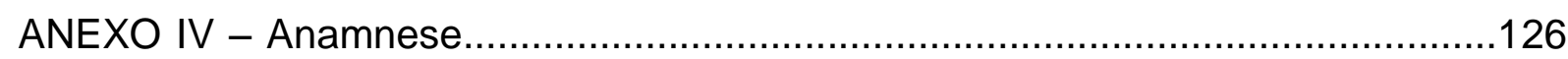

ANEXO V - Mini-Exame do Estado Mental (MEEM) ….....................................130

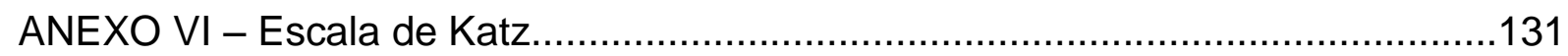

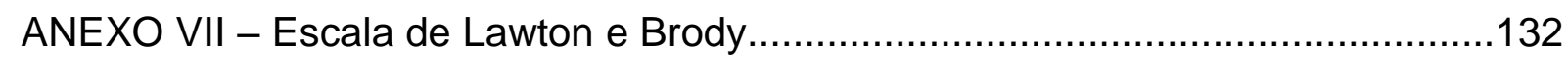

ANEXO VIII - Questionário Internacional de Atividade Física (IPAQ).....................133

ANEXO IX - Quickscreen Clinical Falls Risk Assessment ...................................135

ANEXO X - Escala de Eficácia de Quedas - Internacional (FES-I)......................136

ANEXO XI - Produção científica/ resumo publicado em anais de congresso..........138

ANEXO XII - Produção científica/ resumo publicado em anais de congresso........139

ANEXO XIII - Produção científica/ resumo publicado em anais de congresso.......140

ANEXO XIV - Produção científica/ resumo publicado em anais de congresso........141

ANEXO XV - Produção científica/ resumo publicado em anais de congresso.........142 


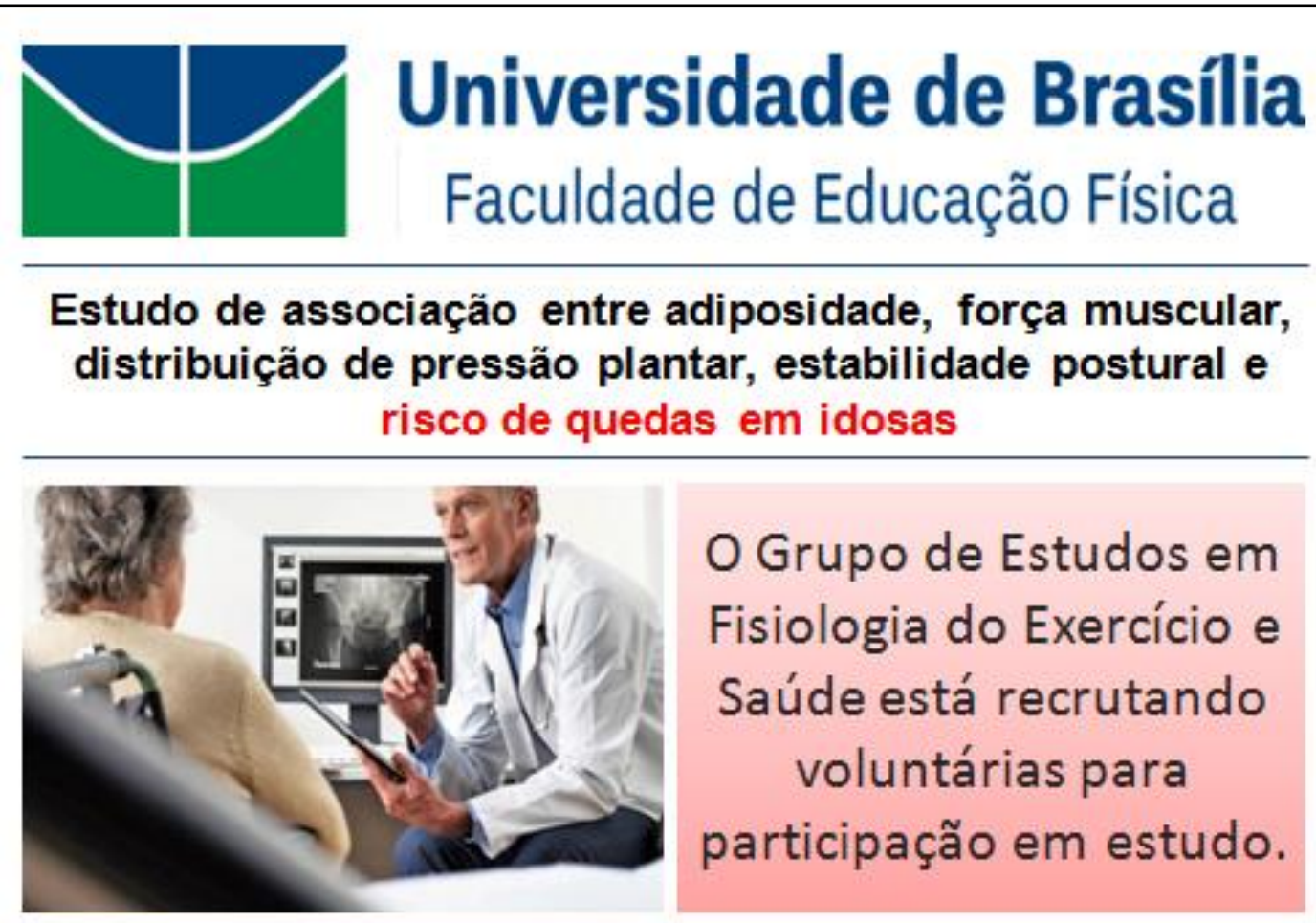

Se você é mulher e possui mais de 60 anos, PARTICIPE!

Benefícios: As voluntárias serão beneficiadas com exames de alta qualidade inteiramente gratuitos.
Densitometria óssea Composição corporal Força muscular Distribuição de pressão plantar Equilíbrio postural Risco de quedas

Supervisão: Prof. Dr. Ricardo Moreno Lima
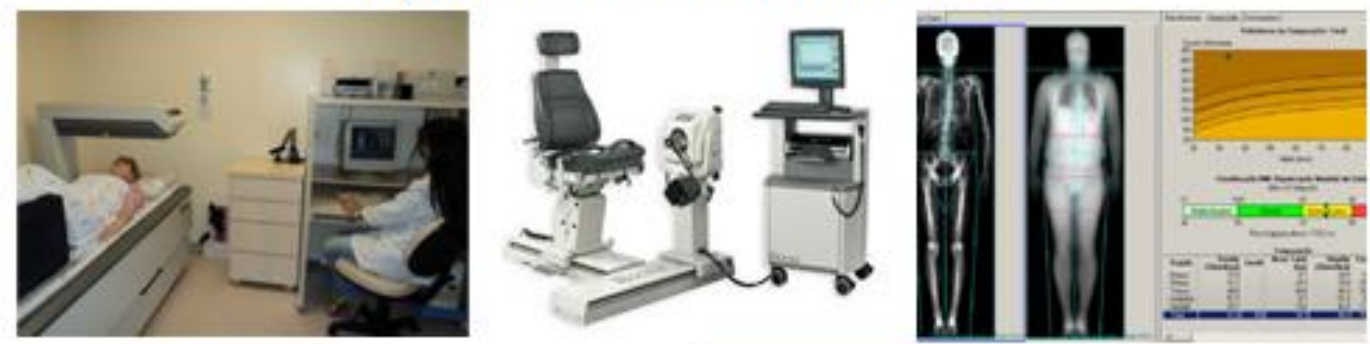

Informações adicionais:

Silvia: (61) 82055934

silvia_grn@hotmail.com 
ANEXO II

PARECER DO COMITÊ DE ÉTICA EM PESQUISA (CEP)

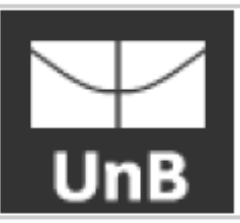

\section{FACULDADE DE CIÊNCIAS DA SAÚDE DA UNIVERSIDADE DE BRASÍLIA - CEP/FS-UNB}

\section{PARECER CONSUBSTANCIADO DO CEP}

DADOS DO PROJETO DE PESQUISA

Título da Pesquisa: ESTUDO DE ASSOCIAÇÃO ENTRE ADIPOSIDADE, FORÇA MUSCULAR, ESTABILIDADE POSTURAL, DISTRIBUIÇÃO DE PRESSÃO PLANTAR E RISCO DE QUEDAS EM IDOSAS

Pesquisador: Silvia Gonçalves Ricci Neri

Área Temática:

Versão: 4

CAAE: 44939215.1 .0000 .0030

Instituição Proponente: Faculdade de Educação Física - UnB

Patrocinador Principal: Financiamento Próprio

DADOS DO PARECER

Número do Parecer: 1.223.636

Situação do Parecer:

Aprovado

Necessita Apreciação da CONEP:

Não

BRASILIA, 11 de Setembro de 2015

Assinado por:

Marie Togashi

(Coordenador)

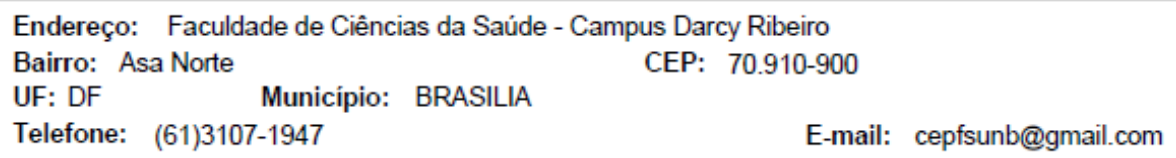




\section{ANEXO III \\ TERMO DE CONSENTIMENTO LIVRE E ESCLARECIDO (TCLE)}

Convidamos a Senhora a participar do projeto de pesquisa "Estudo de associação entre adiposidade, força muscular, distribuição de pressão plantar, estabilidade postural e risco de quedas em idosas", sob a responsabilidade da pesquisadora Silvia Gonçalves Ricci Neri.

O objetivo desta pesquisa é verificar a associação entre índices de adiposidade corporal, força muscular, estabilidade postural, distribuição de pressão plantar e risco de quedas em mulheres idosas.

A senhora receberá todos os esclarecimentos necessários antes e no decorrer da pesquisa e Ihe asseguramos que seu nome não aparecerá, sendo mantido o mais rigoroso sigilo pela omissão total de quaisquer informações que permitam identificá-la.

A sua participação se dará por meio de duas visitas a Faculdade de Educação Física da Universidade de Brasília (FEF-UnB) para a realização dos procedimentos. Na primeira visita será aplicada uma anamnese e efetuada a avaliação da função cognitiva, da funcionalidade e do nível de atividade física. Será realizado, ainda, a antropometria e a avaliação da força muscular. Numa segunda visita, será efetuada a avaliação da composição corporal, da distribuição de pressão plantar, da estabilidade postural e do risco de quedas. As visitas serão previamente agendas e terão duração de aproximadamente duas horas cada uma.

Os procedimentos são relativamente simples e bem aceitos por indivíduos de todas as idades. Eles vêm sendo implementados regularmente na FEF-UnB e aproximadamente 200 mulheres pós-menopausadas já foram submetidas a este protocolo. Nenhuma ocorrência foi registrada desde o início da sua implementação. Tratando especificamente da avaliação da força muscular, é possível que haja algum desconforto. Isso ocorre devido à necessidade de realizar a extensão do joelho com o maior vigor possível. Este desconforto está relacionado com uma sensação de cansaço local, sem sobrecarga geral dos sistemas fisiológicos. Cabe adicionar que todo esforço será feito para minimizar eventuais desconfortos e você poderá fazer pausas ou mesmo suspender a realização da avaliação sem nenhum prejuízo.

Se a Senhora aceitar participar, estará contribuindo para o avanço da ciência. Além disso, você será beneficiada com a avaliação da composição corporal, da força muscular, da estabilidade postural, da distribuição de pressão plantar e do risco de sofrerem quedas. Tais avaliações serão realizadas com instrumentos considerados padrão-ouro. Os resultados dos testes e exames serão entregues de forma individualizada, possibilitando a explicação dos resultados e esclarecimento de eventuais dúvidas. Dessa forma, você terá posse de informações que poderão favorecer a sua saúde.

A Senhora pode se recusar a responder qualquer questão ou participar de qualquer procedimento que lhe traga constrangimento, podendo desistir de participar da pesquisa em 
qualquer momento sem nenhum prejuízo para a Senhora. Sua participação é voluntária, isto é, não há pagamento por sua colaboração.

Todas as despesas que você tiver relacionadas diretamente ao projeto de pesquisa (passagem para o local da pesquisa, alimentação no local da pesquisa ou exames para realização da pesquisa) serão cobertas pelo pesquisador responsável.

Caso haja algum dano direto ou indireto decorrente de sua participação na pesquisa, você poderá ser indenizado, obedecendo-se as disposições legais vigentes no Brasil.

Os resultados da pesquisa serão divulgados na FEF-UnB podendo ser publicados posteriormente. Os dados e materiais serão utilizados somente para esta pesquisa e ficarão sob a guarda do pesquisador por um período de cinco anos, após isso serão destruídos.

Se a Senhora tiver qualquer dúvida em relação à pesquisa, por favor, telefone para: Silvia Gonçalves Ricci Neri, na FEF-UnB, no telefone (61)3107-2512/ (61)8205-5934, de 8 às 18 horas.

Este projeto foi Aprovado pelo Comitê de Ética em Pesquisa da Faculdade de Ciências da Saúde (CEP/FS) da Universidade de Brasília. O CEP é composto por profissionais de diferentes áreas cuja função é defender os interesses dos participantes da pesquisa em sua integridade e dignidade e contribuir no desenvolvimento da pesquisa dentro de padrões éticos. As dúvidas com relação à assinatura do TCLE ou os direitos do participante da pesquisa podem ser obtidos através do telefone: (61) 3107-1947 ou do e-mail cepfs@unb.br ou cepfsunb@gmail.com, horário de atendimento de $10: 00$ hs às $12: 00$ hs e de $13: 30$ hs às $15: 30 h s$, de segunda a sexta-feira. Este documento foi elaborado em duas vias, uma ficará com o pesquisador responsável e a outra com a Senhora.

Nome / assinatura

Silvia Gonçalves Ricci Neri

Pesquisador Responsável

Brasília, de de 


\section{ANEXO IV}

\section{ANAMNESE}

ID:

Prezada voluntária,

Muito obrigado pela participação em nossa pesquisa! Solicitamos o preenchimento do questionário abaixo para conhecimento dos seus hábitos de vida e estado de saúde. Por favor, preencha com bastante atenção, estes dados são fundamentais para o êxito do nosso trabalho.

Informações gerais

Nome:

Data de nascimento: l 1

Idade: anos
Nível de escolaridade:
( ) 10 grau
( ) $2^{\circ}$ grau

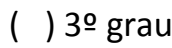
( ) Completo ( ) Incompleto

Endereço:

Telefone(s) para contato:

\section{Hábitos de saúde}

Consome bebida alcoólica? （） Sim （） Não Com que frequência?

É fumante? ( ) Sim ( ) Não Fuma quantos cigarros por dia?

Já fumou? ( ) Sim （）Não Por quanto tempo?

Parou há quanto tempo?

Tempo de menopausa:

Faz terapia de reposição hormonal? （） Sim （） Não Há quanto tempo? 


$\begin{aligned} \text { Já fez terapia de reposição hormonal? （） Sim （） Não } \quad \text { Há quanto tempo? } & \text { Por quanto tempo? }\end{aligned}$

Pratica atividade física regularmente? ( ) Sim ( ) Não

\section{Modalidade 1:}

Pratica há quanto tempo?

Frequência (vezes por semana): $\quad \begin{array}{lllllllllll}\text { ( ) } 1 & \text { ( ) } 2 & \text { ( ) } 3 & \text { ( )4 } & \text { ( )5 } & \text { ( )6 } & \text { ( ) } 7\end{array}$

Duração (minutos por sessão): minutos

\section{Modalidade 2:}

Pratica há quanto tempo?

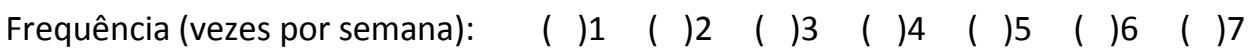

Duração (minutos por sessão): minutos

\section{Modalidade 3:}

Pratica há quanto tempo?

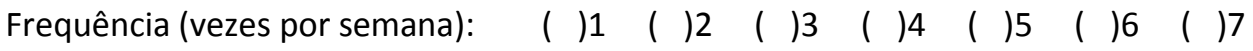

Duração (minutos por sessão): minutos

\section{Informações médicas}

\section{Assinale no quadro abaixo as doenças você apresenta:}

$\begin{array}{llc}\text { Hipertensão Arterial } & \begin{array}{c}\text { Doença neurológica } \\ \text { Diabetes Mellitus }\end{array} \\ \text { Doença Cardiovascular } & \text { Vestibulopatia }\end{array}$

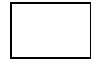

Osteoporose

Apresenta alguma outra doença? ( ) Sim ( ) Não 
Você já teve/ tem:

Câncer

Prótese
Problema nas vistas

Usa óculos

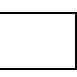

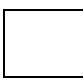

Marcapasso/desfibrilador implantado

Informações adicionais:

Você já fez alguma cirurgia? （） Sim （） Não

De quê?

Há quanto tempo?

Você sente alguma dor? ( ) Sim ( ) Não

Em qual parte do corpo?

Há quanto tempo?

Em que momento?

( ) Em repouso ( ) Em movimento ( ) Em repouso e em movimento

Com que frequência?

Quais remédios você toma? Em quais horários? 
Observações:

Data: 1

Avaliador:

MUITO OBRIGADO! 


\section{ANEXO V}

\section{MINI-EXAME DO ESTADO MENTAL (MEEM)}

Nome:

ID:

Data: I Avaliador:

\begin{tabular}{|l|l|l|}
\hline Orientação temporal (5 pontos) & $\begin{array}{l}\text { Qual é o ANO, SEMESTRE, MÊS, DIA DO MÊS e DIA DA } \\
\text { SEMANA em que estamos? }\end{array}$ & \\
\hline Orientação espacial (5 pontos) & $\begin{array}{l}\text { Qual é o ESTADO, CIDADE, BAIRRO, RUA e LOCAL em } \\
\text { que estamos? }\end{array}$ & \\
\hline Registro (3 pontos) & Repetir: CANECA, TIJOLO, TAPETE. & \\
\hline Atenção e cálculo (5 pontos) & $\begin{array}{l}\text { Subtrair: 100-7 = 93-7 = 86-7 = 79-7 = 72-7 = 65 } \\
\text { Ou, soletrar a palavra MUNDO de trás para frente. }\end{array}$ & \\
\hline Memória de evocação (3 pontos) & Quais os três objetos perguntados anteriormente? & \\
\hline Nomear dois objetos (2 pontos) & Relógio e caneta. & \\
\hline Repetir (1 ponto) & "Nem aqui, nem ali, nem lá." & Escore: \\
\hline Comando de estágios (3 pontos) & $\begin{array}{l}\text { Apanhe esta folha de papel com a mão direita, dobre-a } \\
\text { ao meio, e coloque-a no chão. }\end{array}$ & \\
\hline Ler e executar (1 ponto) & FECHE OS OLHOS. & (1 ponto) \\
\hline Escrever uma frase (1 pscrever uma frase que tenha sentido. & \\
\hline Copiar diagrama (1 ponto) & Copiar dois pentágonos com interseção. \\
\hline
\end{tabular}




\section{ANEXO VI}

\section{ESCALA DE KATZ}

Nome:

ID:

Data: / / Avaliador:

\section{1- BANHO}

( ) I Independente (necessita de ajuda apenas para lavar uma parte do corpo, p.ex.costas ou extremidades)

()$^{0}$ Dependente (necessita de ajuda para lavar mais que uma parte do corpo; necessita de ajuda para entrar e sair da banheira; não se lava sozinho)

\section{2- VESTIR}

( ) Independente (escolhe a roupa adequada, veste-a e aperta-a; exclui atar os sapatos)

( $)^{0}$ Dependente (precisa de ajuda para se vestir;não é capaz de se vestir)

\section{3- UTILIZAÇÃO DO SANITÁRIO}

( ) $)^{1}$ Independente (não necessita de ajuda para entrar e sair do wc; usa a sanita, limpa-se e veste-se adequadamente; pode usar urinol pela noite

()$^{0}$ Dependente (usa urinol ou arrastadeira ou necessita de ajuda para aceder e utilizar a sanita)

\section{4- TRANSFERÊNCIA (cama / cadeira)}

( ) I Independente (não necessita de ajuda para sentar-se ou levantar-se de uma cadeira nem para entrar ou sair da cama; pode usar ajudas técnicas, p.ex. bengala

$\left(\right.$ ) ${ }^{0}$ Dependente (necessita de alguma ajuda para se deitar ou levantar da cama/ cadeira; está acamado)

\section{5- CONTINÊNCIA (vesical / fecal)}

( ) I Independente (controlo completo da miç̧ão e defecação)

()$^{0}$ Dependente (incontinência total ou parcial vesical e/ou fecal; utilização de enemas, algália, urinol ou arrastadeira)

\section{6- ALIMENTAÇÃO}

( ) I' Independente ( leva a comida do prato à boca sem ajuda; exclui cortar a carne)

( ) ${ }^{0}$ Dependente (necessita de ajuda para comer; não come em absoluto ou necessita de nutrição entérica / parentérica)

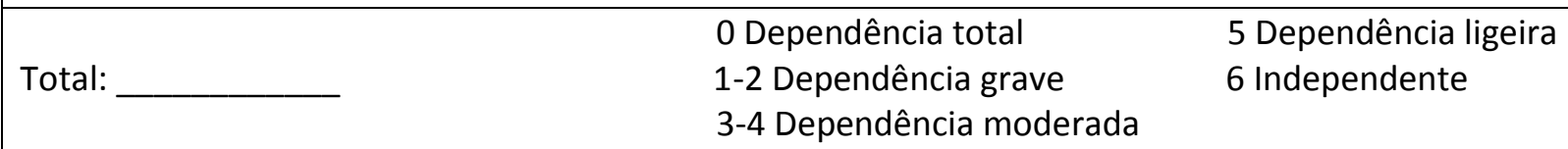




\section{ANEXO VII}

\section{ESCALA DE LAWTON E BRODY}

Nome:

ID:

Data:

Avaliador:

\section{1- Utilização do telefone}

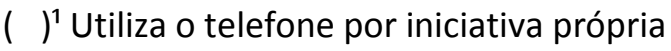

( ) ' É capaz de marcar bem alguns números familiares

( ) $)^{1}$ É capaz de pedir para telefonar, mas não é capaz de marcar

()$^{0}$ Não é capaz de usar o telefone

\section{3- Preparação das refeições}

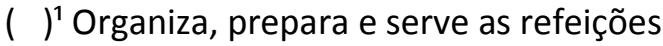
sozinho e adequadamente

$\left(\right.$ ) ${ }^{0}$ Prepara adequadamente as refeições se os alimentos são fornecidos.

( ) ${ }^{0}$ Prepara, aquece e serve as refeições, mas não segue uma dieta adequada

()$^{0}$ Necessita que the preparem e sirvam as refeições

\section{5- Lavagem da roupa}

( ) $)^{1}$ Lava sozinho toda a sua roupa

( ) Lava sozinho pequenas peças de roupa

()$^{0}$ A lavagem da roupa tem de ser feita por terceiros

\section{2- Fazer compras}

( ) $)^{1}$ Realiza todas as compras necessárias independentemente

()$^{0}$ Realiza independentemente pequenas compras

()$^{0}$ Necessita de ir acompanhado para fazer qualquer compra

()$^{0}$ É totalmente incapaz de comprar

\section{4- Tarefas domésticas}

( ) Mantém a casa sozinho ou com ajuda ocasional (trabalhos pesados)

( ) Realiza tarefas ligeiras, como lavar pratos ou fazer a cama

( ) $)^{1}$ Realiza tarefas ligeiras, mas não pode manter um nível adequado de limpeza

()$^{0}$ Necessita de ajuda em todas as tarefas domésticas

()$^{0}$ Não participa em nenhuma tarefa doméstica

\section{6- Utilização de meios de transporte}

( ) $)^{1}$ Viaja sozinho em transporte público ou conduz o seu próprio carro

( ) $)^{1}$ É capaz de apanhar um táxi, mas não usa outro transporte

( $)^{1}$ Viaja em transportes públicos quando vai acompanhado

( ) $)^{0}$ Só utiliza o táxi ou o automóvel com ajuda de terceiros

()$^{0}$ Não viaja

\section{7- Manejo da medicação}

( ) ' É capaz de tomar a medicação à hora e dose corretas

()$^{0}$ Toma a medicação se a dose é preparada previamente ()$^{0}$ Não é capaz de administrar a sua medicação

\section{8- Responsabilidade de assuntos financeiros}

( ) Encarrega-se de assuntos financeiros sozinho

( ) $)^{1}$ Realiza as compras diárias, mas necessita de ajuda em grandes compras e no banco

()$^{0}$ Incapaz de manusear o dinheiro

Total: 


\section{ANEXO VIII \\ QUESTIONÁRIO INTERNACIONAL DE ATIVIDADE FÍSICA (IPAQ) - VERSÃO CURTA}

Nome:

ID:

Data:

Avaliador:

Nós estamos interessados em saber que tipos de atividade física as pessoas fazem como parte do seu dia a dia. As perguntas estão relacionadas ao tempo que você gasta fazendo atividade física na ÚLTIMA semana. As perguntas incluem as atividades que você faz no trabalho, para ir de um lugar a outro, por lazer, por esporte, por exercício ou como parte das suas atividades em casa ou no jardim. Suas respostas são MUITO importantes. Por favor, responda cada questão mesmo que considere que não seja ativo. Obrigado pela sua participação!

Para responder as questões lembre que:

D Atividades físicas VIGOROSAS são aquelas que precisam de um grande esforço físico e que fazem respirar MUITO mais forte que o normal

$>$ Atividades físicas MODERADAS são aquelas que precisam de algum esforço físico e que fazem respirar UM POUCO mais forte que o normal

Para responder as perguntas pense somente nas atividades que você realiza por pelo menos $\mathbf{1 0}$ minutos contínuos de cada vez.

1a. Em quantos dias da última semana você CAMINHOU por pelo menos 10 minutos contínuos em casa ou no trabalho, como forma de transporte para ir de um lugar para outro, por lazer, por prazer ou como forma de exercício?
dias por SEMANA
( ) Nenhum

1b. Nos dias em que você caminhou por pelo menos 10 minutos contínuos quanto tempo no total você gastou caminhando por dia?

Horas: Minutos:

2a. Em quantos dias da última semana, você realizou atividades MODERADAS por pelo menos 10 minutos contínuos, como por exemplo, pedalar leve na bicicleta, nadar, dançar, fazer ginástica aeróbica leve, jogar vôlei recreativo, carregar pesos leves, fazer serviços domésticos na casa, no quintal ou no jardim como varrer, aspirar, cuidar do jardim, ou qualquer atividade que fez aumentar moderadamente sua respiração ou batimentos do coração (POR FAVOR, NÃO INCLUA CAMINHADA). 
dias por SEMANA ( ) Nenhum

2b. Nos dias em que você fez essas atividades moderadas por pelo menos 10 minutos contínuos, quanto tempo no total você gastou fazendo essas atividades por dia?

Horas: Minutos:

3a. Em quantos dias da última semana, você realizou atividades VIGOROSAS por pelo menos 10 minutos contínuos, como por exemplo, correr, fazer ginástica aeróbica, jogar futebol, pedalar rápido na bicicleta, jogar basquete, fazer serviços domésticos pesados em casa, no quintal ou cavoucar no jardim, carregar pesos elevados ou qualquer atividade que fez aumentar MUITO sua respiração ou batimentos do coração.

$$
\text { dias por SEMANA （） Nenhum }
$$

3b. Nos dias em que você fez essas atividades vigorosas por pelo menos 10 minutos contínuos quanto tempo no total você gastou fazendo essas atividades por dia?

Horas: Minutos:

Estas últimas questões são sobre o tempo que você permanece sentado todo dia, no trabalho, na escola ou faculdade, em casa e durante seu tempo livre. Isto inclui o tempo sentado estudando, sentado enquanto descansa, fazendo lição de casa visitando um amigo, lendo, sentado ou deitado assistindo TV. Não inclua o tempo gasto sentando durante o transporte em ônibus, trem, metrô ou carro.

4a. Quanto tempo no total você gasta sentado durante um dia de semana?

Horas: Minutos:

4b. Quanto tempo no total você gasta sentado durante em um dia de final de semana?

Horas: Minutos: 


\section{ANEXO IX \\ QUICKSCREEN CLINICAL FALLS RISK ASSESSMENT}

Nome:

ID:

Data: / Avaliador:

\begin{tabular}{|c|c|c|}
\hline AVALIAÇÃO & $\begin{array}{c}\text { PRESENÇA DE FATOR DE } \\
\text { RISCO } \\
\text { (por favor, circule) }\end{array}$ & AÇÃO \\
\hline
\end{tabular}

Quedas anteriores

Uma ou mais quedas no último ano

$\operatorname{Sim} /$ Não

Medicamentos

\begin{tabular}{|l|c|c|}
\hline Quatro ou mais (excluir vitaminas) & Sim / Não & \\
\hline Algum psicotrópico & Sim / Não & \\
\hline
\end{tabular}

Visão

Teste de acuidade visual - incapaz de ler tudo até a 5a linha

Sim / Não

Sensação periférica

Teste de sensibilidade tátil - incapaz de sentir dois de três estímulos aplicados

Sim / Não

Força / Tempo de reação / Equilíbrio

Teste de semi-tandem - incapaz de permanecer por $10 \mathrm{~s}$

Teste de step alternado - incapaz de completar em $10 \mathrm{~s}$

Teste de passar da posição sentada para em pé - incapaz de completar em $12 \mathrm{~s}$

\begin{tabular}{|c|c|c|}
\hline Sim / Não & \\
\hline Sim / Não & \\
\hline Sim / Não & \\
\hline
\end{tabular}

\begin{tabular}{|l|c|c|c|c|}
\hline Número de fatores de risco & $0-1$ & $2-3$ & $4-5$ & $6+$ \\
\hline Probabilidade de cair & $7 \%$ & $13 \%$ & $27 \%$ & $49 \%$ \\
\hline
\end{tabular}

Este paciente tem \% de probabilidade de cair nos próximos 12 meses. 


\section{ANEXO X}

\section{ESCALA DE EFICÁCIA DE QUEDAS - INTERNACIONAL (FES-I)}

Nome:

ID:

Data: /

Avaliador:

Agora nós gostaríamos de fazer algumas perguntas sobre qual é sua preocupação a respeito da possibilidade de cair. Por favor, responda imaginando como você normalmente faz a atividade. Se você atualmente não faz a atividade (por ex. alguém vai às compras para você), responda de maneira a mostrar como você se sentiria em relação a quedas se você tivesse que fazer essa atividade. Para cada uma das seguintes atividades, por favor, marque o quadradinho que mais se aproxima de sua opinião sobre o quão preocupado você fica com a possibilidade de cair, se você fizesse esta atividade.

\begin{tabular}{|c|c|c|c|c|}
\hline & $\begin{array}{l}\text { Nem um pouco } \\
\text { preocupado }\end{array}$ & $\begin{array}{l}\text { Um pouco } \\
\text { preocupado }\end{array}$ & $\begin{array}{l}\text { Muito } \\
\text { preocupado }\end{array}$ & $\begin{array}{c}\text { Extremamente } \\
\text { preocupado }\end{array}$ \\
\hline $\begin{array}{c}\text { Limpando a casa (ex: passar } \\
\text { pano, aspirar ou tirar a } \\
\text { poeira) }\end{array}$ & 1 & 2 & 3 & 4 \\
\hline Vestindo ou tirando a roupa & 1 & 2 & 3 & 4 \\
\hline Preparando refeições simples & 1 & 2 & 3 & 4 \\
\hline Tomando banho & 1 & 2 & 3 & 4 \\
\hline Indo às compras & 1 & 2 & 3 & 4 \\
\hline $\begin{array}{c}\text { Sentando ou levantando de } \\
\text { uma cadeira }\end{array}$ & 1 & 2 & 3 & 4 \\
\hline Subindo ou descendo escadas & 1 & 2 & 3 & 4 \\
\hline Caminhando pela vizinhança & 1 & 2 & 3 & 4 \\
\hline
\end{tabular}




\begin{tabular}{|c|c|c|c|c|}
\hline & $\begin{array}{l}\text { Nem um pouco } \\
\text { preocupado }\end{array}$ & $\begin{array}{l}\text { Um pouco } \\
\text { preocupado }\end{array}$ & $\begin{array}{l}\text { Muito } \\
\text { preocupado }\end{array}$ & $\begin{array}{l}\text { Extremamente } \\
\text { preocupado }\end{array}$ \\
\hline $\begin{array}{l}\text { Pegando algo acima de sua } \\
\text { cabeça ou do chão }\end{array}$ & 1 & 2 & 3 & 4 \\
\hline $\begin{array}{c}\text { Indo atender o telefone antes } \\
\text { que pare de tocar }\end{array}$ & 1 & 2 & 3 & 4 \\
\hline $\begin{array}{c}\text { Andando sobre superfície } \\
\text { escorregadia (ex: chão } \\
\text { molhado) }\end{array}$ & 1 & 2 & 3 & 4 \\
\hline $\begin{array}{l}\text { Visitando um amigo ou } \\
\text { parente }\end{array}$ & 1 & 2 & 3 & 4 \\
\hline $\begin{array}{l}\text { Andando em lugares cheios } \\
\text { de gente }\end{array}$ & 1 & 2 & 3 & 4 \\
\hline $\begin{array}{c}\text { Caminhando sobre superfície } \\
\text { irregular (com pedras, } \\
\text { esburacada) }\end{array}$ & 1 & 2 & 3 & 4 \\
\hline $\begin{array}{l}\text { Subindo ou descendo uma } \\
\text { ladeira }\end{array}$ & 1 & 2 & 3 & 4 \\
\hline $\begin{array}{l}\text { Indo a uma atividade social } \\
\text { (ex: ato religioso, reunião de } \\
\text { família ou encontro no clube) }\end{array}$ & 1 & 2 & 3 & 4 \\
\hline
\end{tabular}




\title{
ANEXO XI \\ PRODUÇÃO CIENTÍFICA/ RESUMO PUBLICADO EM ANAIS DE CONGRESSO
}

\author{
GADELHA, A.B.; NERI, S.G.R.; SAFONS, M.P.; MOREIRA, S.R.; LIMA, R.M. Adiposity Indexes \\ Comparisons And Cut-off Values In The Prediction Of Disability In Older Women. In: American \\ College of Sports Medicine Annual Meeting, 2016, Boston. Official Journal of the American College of \\ Sports Medicine, v. 48, n. 5, 2016.
}

Purpose: To compare adiposity indexes and propose its cut-off values in the prediction of disability in older women. Methods: 87 volunteers ( $67.27 \pm 6.45$ years) took part in this cross-sectional study, who underwent functional tests, body composition assessment using DXA, and had 5 anthropometric indexes measured (Waist Circumference - WC, Waist-to-Height Ratio - WHtR, Body Mass Index BMI, Body Adiposity Index - BAI, and Conicity Index - C index). Senior fitness test battery was performed to evaluate functionality, consisting of 30-s chair stand, 8-foot up-and-go, and 6-minute walk. Disability was determined as at least two from three performance scores below reference values. Pearson's correlation was conducted to identify relationship between variables. Cut-off values to predict disability were obtained from Receiver's Operating Characteristic (ROC) curves considering its sensibility and specificity. Area under the ROC curve and confidence intervals were used to compare the predictive ability of each adiposity index. Moreover, odds ratio for each adiposity index were calculated for disability outcome. Results: Disability prevalence was $36.8 \%$. Senior fitness test battery scores showed stronger associations with WC $(r=-0.345 ; p<0.01)$, WHtR $(r=-0.417 ; p<0.01)$, and BAI $(r=0.296 ; p<0.01)$. The cut-off values for each adiposity index were $89.5 \mathrm{~cm}, 39.2 \%, 26.93 \mathrm{~kg} / \mathrm{m} 2$, $34.6 \%, 0.51 \mathrm{~cm}$, and 1.23 , for WC, DXA-derived body fat percentage, BMI, BAl, WHtR, and C index, respectively. Significant greater risks for disability outcome were found for volunteers who had WHtR (7.75; Cl: 1.0 - 63.2; $p=0.05)$ or WC $(3.16 ; 1.3-7.8 ; p<0.01)$ measurements above cut-off values. None of the remaining adiposity measurements predicted disability risks. Conclusions: Adiposity indexes considering abdominal fat ( $\mathrm{WC}$ and $\mathrm{WHtR}$ ) had stronger relationship with functional performance and its cut-off values exhibited predicative skill for disability in older women, in spite of gold standard body composition evaluation using DXA. Easy and low cost implementation of these measurements suggests potential practical applications. 


\section{ANEXO XII \\ PRODUÇÃO CIENTÍFICA/ RESUMO PUBLICADO EM ANAIS DE CONGRESSO}

GADELHA, A.B.; NERI, S.G.R.; MOREIRA, S.R.; DUTRA, M.T.; SAFONS, M.P.; LIMA, R.M. Comparação entre índices da adiposidade corporal e identificação de pontos de corte para predição de síndrome metabólica em mulheres idosas. In: 38 Simpósio Internacional de Ciências do Esporte - CELAFISCS, 2015, São Paulo. Anais 38오 Simpósio Internacional de Ciências do Esporte - CELAFISCS, p. 65, 2015.

Introdução: Com o avançar da idade, observa-se um aumento ponderal, particularmente de massa gorda. Em mulheres pós-menopausadas, esta alteração na composição corporal está associada a diversos fatores de risco cardiometabólico. O agrupamento destes fatores de risco tem sido reportado como síndrome metabólica (SM). Objetivo: Comparar os principais índices da adiposidade corporal e identificar pontos de corte na predição de SM em mulheres idosas. Método: Uma amostra representativa de mulheres idosas residentes no Distrito Federal ( $n=149 ; 67,17 \pm 6,12$ anos) foi submetida à avaliação da composição corporal por meio do DEXA e outros 5 índices antropométricos: circunferência de cintura (CC), relação cintura estatura (RCE), índice de massa corporal (IMC), índice de adiposidade corporal (IAC) e índice de conicidade (IC). A pressão arterial foi medida por método oscilométrico e análise sanguínea foi conduzida para perfil glicêmico e perfil lipídico. A classificação da SM adotada obedeceu aos critérios do NCEP-ATP III. Pontos de corte específicos para cada índice de adiposidade corporal foram identificados a partir de sua especificidade e sensibilidade, utilizando curvas ROC. Após a aplicação dos pontos de corte, o odds ratio foi calculado para o desfecho de SM. O nível de significância adotado foi de $p<0,05$. Resultados: A prevalência de $S M$ identificada foi equivalente a $29,5 \%$, sendo que o grupo classificado com este desfecho apresentou condição cardiometabólica inferior em comparação ao grupo de referência, com exceção de colesterol total e LDL. Ademais, todos os índices antropométricos estudados foram significativamente maiores nos portadores da SM. A Tabela 1 apresenta os pontos de corte e o odds ratio de cada índice estudado para o desfecho de SM. Destaca-se que o odds ratio para identificar a SM foi maior para a RCE (odds ratio $=10,2$; intervalo de confiança $=2,9-35,9$ ) quando comparado aos demais índices. Na comparação entre as curvas ROC, tanto a CC quanto a RCE apresentaram-se maiores que o percentual de gordura medido pelo DEXA, o IAC , o IC e o IMC $(p<0,05)$. Conclusão: Os índices da adiposidade que consideraram a gordura abdominal, com ênfase para a RCE, apresentaram maior poder discriminatório e relacionamento mais consistente com o desfecho de SM em mulheres idosas. Pontos de corte para estes índices foram propostos e poderão ser úteis na pratica clinica de atendimento ao idoso. Agência de Fomento: FAP-DF; CNPq; CAPES.

Tabela 1. Pontos de corte (sensibilidade e especificidade) e Odds Ratio para o desfecho de sindrome metabólica em mulheres idosas residentes no Distrito Federal, Brasil.

\begin{tabular}{lcc}
\hline & \multicolumn{2}{c}{ Sindrome Metabólica } \\
\hline Indices & Ponto de corte & Odds Ratio $(\mathrm{IC}=95 \%)$ \\
Circunferência de Cintura (cm) & $88,0(88,6 ; 70,5)$ & $5,5(1,9-15,7)^{\star *}$ \\
Massa Gorda (\%) & $43,7(63,6 ; 63,8)$ & $3,1(1,5-6,4)^{\star \star}$ \\
İndice de Massa Corporal $\left(\mathrm{kg} / \mathrm{m}^{2}\right)$ & $26,9(72,7 ; 67,6)$ & $5,6(2,6-12,1)^{\star \star}$ \\
İndice da Adiposidade Corporal $(\%)$ & $36,3(52,3 ; 75,2)$ & $3,3(1,6-7,0)^{\star *}$ \\
Relação Cintura-Estatura (cm/cm) & $0,6(84,1 ; 67,6)$ & $10,2(2,9-35,9)^{\star *}$ \\
İndice de Conicidade (UA) & $1,2(84,1 ; 61,9)$ & $4,4(1,5-12,5)^{\star \star}$ \\
\hline
\end{tabular}

$\mathrm{IC}=$ Intervalo de confiança; UA= Unidade Arbitrária; ${ }^{*}=p<0,05$ 


\title{
ANEXO XIII \\ PRODUÇÃO CIENTÍFICA/ RESUMO PUBLICADO EM ANAIS DE CONGRESSO
}

\author{
NERI, S.G.R.; GADELHA, A.B.; GAUCHE, R.; PAIVA, F.L.; CORREIA, A.L.M. ; LIMA, R.M. Efeitos \\ do treinamento resistido baseado na percepção subjetiva de esforço sobre o pico de torque

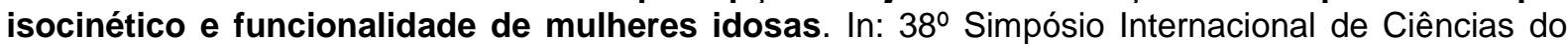

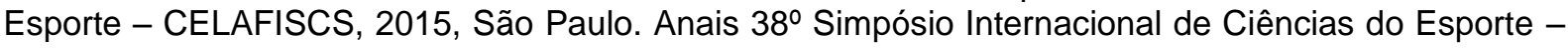 \\ CELAFISCS, p. 144, 2015.
}

Introdução: $O$ envelhecimento está associado à perda progressiva de força muscular e consequente limitação funcional. Nesse contexto, o treinamento resistido (TR) pode ser uma ferramenta importante na manutenção da força e da funcionalidade de mulheres idosas. Objetivo: Verificar os efeitos de 12 semanas de TR, com intensidade baseada na percepção subjetiva de esforço, sobre o pico de torque isocinético (PT) dos extensores do joelho dominante e funcionalidade de mulheres idosas. Método: Participaram deste estudo 35 idosas, alocadas em grupo controle (GC; 66,92 $\pm 4,50$ anos; IMC: $25,04 \pm 2,97 \mathrm{~kg} / \mathrm{m} 2$ ) ou experimental (GE; $65,00 \pm 4,15$ anos; IMC: $28,37 \pm 4,97 \mathrm{~kg} / \mathrm{m} 2$ ). O GE foi submetido a 12 semanas de TR (3x/sem), 3 séries de 12 repetições para cada exercício (supino, remada, abdução de ombros, leg press, cadeira flexora, extensora e abdutora, e flexão plantar), com intervalo de recuperação de $1^{\prime}$. A progressão de carga foi conduzida com a escala de percepção subjetiva de esforço OMNI-RES, iniciando com 6 pontos e incrementando 1 ponto a cada 4 semanas, com concomitante redução de repetições (12, 10 e 8, respectivamente). Foram avaliados o PT dos extensores do joelho dominante (60 e $180 \%$ s-1) e a funcionalidade (Sentar e levantar em 30s, Timed Up and Go e Caminhada de 6'). A diferença das médias foi comparada por ANCOVA com post-hoc de Bonferroni. Resultados: Os efeitos das 12 semanas do protocolo de intervenção sobre a força muscular e funcionalidade estão apresentados na Tabela 1. Pode-se observar que houve interação significativa para o PT isocinético a 60 e a 180\%/s-1 ( $p=0,001)$, com aumento significativo para o GE $(p<0,001)$. Ademais, o GE também apresentou melhora no Teste de Caminhada de 6' ( $p$ $<0,001)$. Conclusão: Um programa de TR de 12 semanas, com intensidade baseada na percepção subjetiva de esforço, promove alterações positivas no PT isocinético a 60 e a $180 \% \mathrm{~s}-1$ e na funcionalidade de mulheres idosas. Agência de Fomento: CNPq, CAPES.

Tabela 1. Diferenças no pico de torque isocinético (60 e 180\%s-1) e na funcionalidade (T30, TUG e TC6) após 12 semanas de treinamento resistido baseado na percepção subjetiva de esforço. Dados expressos em diferença das médias \pm erro padrão.

\begin{tabular}{lccccccc}
\hline Variável & \multicolumn{3}{c}{ Grupo controle $(\mathrm{n}=13)$} & \multicolumn{2}{c}{ Grupo experimental $(\mathrm{n}=22)$} & Interação $(p)$ \\
\hline PT $60 \%$ s-1 $(\mathrm{Nm})$ & $-3,655$ & \pm & 2,801 & 12,023 & $\pm 2,151^{* \dagger}$ & 0,001 \\
PT $180^{\circ} / \mathrm{s}-1(\mathrm{Nm})$ & $-1,553$ & \pm & 2,203 & 10,313 & $\pm 1,675 * \dagger$ & 0,001 \\
T30 & $-0,182$ & \pm & 0,985 & 1,107 & \pm & 0,683 & 0,364 \\
TUG $(\mathrm{s})$ & $-0,545$ & \pm & 0,245 & $-0,614$ & \pm & 0,178 & 0,836 \\
TC6 $(\mathrm{m})$ & $-22,516$ & \pm & 11,434 & 44,656 & \pm & $8,933^{*} \dagger$ & 0,001
\end{tabular}

PT: Pico de torque; T30: Teste de sentar e levantar em 30 s; TUG: Timed Up and Go; TC6: Teste da caminhada de 6 min. *Diferença significativa quando comparado à linha de base $(p<0,001)$. $\uparrow$ Diferença significativa quando comparado ao valor pós do grupo controle $(p<0,001)$. 


\title{
ANEXO XIV \\ PRODUÇÃO CIENTÍFICA/ RESUMO PUBLICADO EM ANAIS DE CONGRESSO
}

\author{
LIMA, R.M.; GAUCHE, R.; GADELHA, A.B.; PAIVA, F.L.; NERI, S.G.R.; VIANNA, L.C. Blood \\ pressure reactivity to mental stress is attenuated following resistance exercises in treated \\ older hypertensive women. In: International Society for Autonomic Neuroscience 2015 Meeting, \\ 2015, Stresa. Autonomic Neuroscience: Basic and Clinical, v.192. p.111, 2015.
}

Introduction: Hypertensive patients show increased blood pressure (BP) response to mental stress, which is partially attributed to elevated sympathetic reactivity. Besides its positive effects on muscle function, resistance exercises (RE) may also benefit cardiovascular health. BP response to mental stress, which is of relevant prognostic value, is acutely attenuated after aerobic exercise, however, the effects of RE has yet to be investigated. The aim of the present study was to investigate the effects of $\mathrm{RE}$ on autonomic control and BP reactivity to mental stress in treated older hypertensive women.

Methods: Ten hypertensive women $(71.1 \pm 5.5 \mathrm{yr})$ were randomly assigned to two RE sessions differing only on its arrangement (traditional and circuit). Mental stress was induced through a computerized 3-min Stroop word-color test before and one hour after each training session. BP was measured during mental stress and in 15 min intervals over one hour after exercise. Heart rate variability (HRV) was monitored as a measure of autonomic control. Results: Post-exercise BP was unchanged in comparison to resting values. Mental stress provoked significant increases ( $\mathrm{P}$ b 0.01) in $\mathrm{BP}$ both before and after each RE session. However, BP reactivity to mental stress was significantly attenuated after both RE sessions when compared to pre-exercise (14 \pm 2.2 vs $10 \pm 1.5 \mathrm{mmHg}$ for traditional, $14 \pm 2.8$ vs $8.6 \pm 1.9 \mathrm{mmHg}$ for circuit; $\mathrm{P}$ b 0.01 ). No differences were observed for HRV. Conclusions: Both traditional and circuit RE training attenuated BP reactivity to mental stress test in older hypertensive women, with no different effects between sessions. These results are unrelated to changes in HRV. 


\section{ANEXO XV \\ PRODUÇÃO CIENTÍFICA/ RESUMO PUBLICADO EM ANAIS DE CONGRESSO}

CORREIA, A.L.M.; GAUCHE, R.; GADELHA, A.B.; PAIVA, F.L.; NERI, S.G.R.; LIMA, R.M. Postexercise blood pressure following different resistance training methods in treated older hypertensive women. In: American Heart Association's 2015 Scientific Sessions, 2015, Orlando. Circulation, v. 132, 2015.

Introduction: The purpose of this study was to examine post-exercise blood pressure following different resistance training methods in treated older hypertensive women. Methods: The sample consisted of 14 female volunteers with controlled hypertension (age $69.86 \pm 5.67$ years, weight 59.31 $\pm 9.77 \mathrm{~kg}$, height $1.52 \pm 0.06 \mathrm{~m}, \mathrm{BMI} 25.76 \pm 4.44 \mathrm{~kg} / \mathrm{m} 2$ ) who attended six Laboratory visits. The first four visits aimed at collecting anthropometric data, familiarization and determining the training load. In the fifth and sixth visits, volunteers performed a traditional resistance exercise method (TRE) and a circuit resistance exercise method (CRE), in a randomized order. The sessions were separated by at least 48 hours, involved the following exercises: leg press, seated row, knee extension, bench press, knee flexion, lateral raise with dumbbells and seated calf raises. In TRE, the exercises were performed in three sets of 12 repetitions with an interval of 60 seconds between sets and exercises. In the CRE, the exercises were performed in circuit, with 3 rounds of 12 repetitions with 30 seconds rest between exercises and 60 seconds between rounds. The intensity was adjusted corresponding to the level 4 of the scale of perceived exertion to resistance exercise. Systolic blood pressure (SBP) and diastolic blood pressure (DBP) were measured at rest, 15, 30, 45 and 60 minutes after the exercise sessions. Mean blood pressure (MBP) was calculated. Data normality was verified with the Shapiro-Wilk test. ANOVA for repeated measures (time $X$ method) was used for data analysis. Significance was set at $p$ $<0.05$. Results: Although mean SBP values were reduced following exercise, no significant effects of time, methods or time X method interaction were noted in SBP, DBP and MBP. Conclusions: Both resistance training methods, on intensity corresponding to the level 4 of perceived exertion scale, were not able to significantly alter the blood pressure of treated older hypertensive women.

\begin{tabular}{|c|c|c|c|c|c|}
\hline & Rest & Is min & 30 nsin & 45 min & 60 nsin \\
\hline \multicolumn{6}{|c|}{ SPB [nishHg] } \\
\hline TRE & $120.55 \pm 7.12$ & $115.00 \pm 10.02$ & $116.21 \pm 10 . \%$ & $118.43 \pm 5.72$ & $121.36 \pm 10.05$ \\
\hline CRE & $119.56 \pm 7.75$ & $116.86 \pm 11.14$ & $116.14 \pm 7.42$ & $|15.00 \pm 9.6|$ & $113.71 \pm 9.62$ \\
\hline \multicolumn{6}{|c|}{ DBP (Inก) } \\
\hline TRE & $69.46 \pm 5.00$ & $70.14 \pm 6.56$ & $70.36 \pm 6.43$ & $69.86 \pm 6.16$ & $71.29 \pm 5.61$ \\
\hline CRE & $69.63 \pm 5.36$ & $70.00 \pm 8.35$ & $69.29 \pm 8.33$ & $69.36 \pm 6.99$ & $69.93 \pm 5.37$ \\
\hline \multicolumn{6}{|c|}{$\operatorname{MBP}\left(\mathrm{nm}^{\prime} \mathrm{H}_{3}\right)$} \\
\hline TRE & $86.49 \pm 4.78$ & $85.10 \pm 6.98$ & $R S .64 \pm 6.26$ & $86.10 \pm 5.40$ & $R 7.98 \pm 6.06$ \\
\hline CRE & $86.15 \pm 5.13$ & $85.62 \pm 8.71$ & $84.93 \pm 7.68$ & $84.57 \pm 7.10$ & $R S .83 \pm 6.06$ \\
\hline
\end{tabular}

